LBL-37383

UC- 1600

\title{
EFFICIENCY IMPROVEMENTS IN U.S. OFFICE EQUIPMENT: EXPECTED POLICY IMPACTS AND UNCERTAINTIES
}

\author{
Jonathan G. Koomey, Michael Cramer, MaryAnn Piette, and Joseph H. Eto
}

\author{
Energy Analysis Program \\ Energy and Environment Division \\ Ernest Orlando Lawrence Berkeley National Laboratory \\ University of California \\ Berkeley, CA 94720
}

December 1995

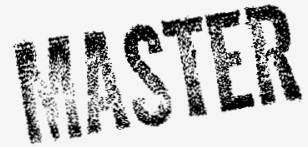

This work was supported by the Assistant Secretary for Energy Efficiency and Renewable Energy, Office of Building Technologies of the U.S. Department of Energy under Contract No. DE-AC03-76SF00098. 


\section{DISCLAIMER}

This report was prepared as an account of work sponsored by an agency of the United States Government. Neither the United States Government nor any agency thereof, nor any of their employees, make any warranty, express or implied, or assumes any legal liabiiity or responsibility for the accuracy, completeness, or usefulness of any information, apparatus, product, or process disclosed, or represents that its use would not infringe privately owned rights. Reference herein to any specific commercial product, process, or service by trade name, trademark, manufacturer, or otherwise does not necessarily constitute or imply its endorsement, recommendation, or favoring by the United States Government or any agency thereof. The views and opinions of authors expressed herein do not necessarily state or reflect those of the United States Government or any agency thereof. 


\section{DISCLAIMER}

Portions of this document may be illegible in electronic image products. Images are produced from the best available original document. 


\section{EXECUTIVE SUMMARY}

This report describes a detailed end-use forecast of office equipment energy use for the US commercial sector. We explore the likely impacts of the US Environmental Protection Agency's ENERGY STAR office equipment program and the potential impacts of advanced technologies. The ENERGY STAR program encourages manufacturers to voluntarily incorporate power saving features into personal computers, monitors, printers, copiers, and fax machines in exchange for allowing manufacturers to use the EPA ENERGY STAR logo in their advertising campaigns. The Advanced technology case assumes that the most energy efficient current technologies are implemented regardless of cost.

The main findings from our analysis are as follows:

- Office equipment currently uses about $7 \%$ of all commercial sector electricity, with that fraction projected to grow to $7.6 \%$ by 2010 . Total Electricity used by office equipment is projected to grow from 58 TWh in 1990 to $78 \mathrm{TWh}$ in 2010 in the absence of ENERGY STAR or any other government policies.

- While total energy use for office equipment has grown rapidly in recent years, this growth is likely to slow in the next decade (even in the Business-as-usual case) because the US commercial sector market is becoming saturated (especially for PC CPUs and monitors) and because mainframe and minicomputer energy use per unit is declining quickly.

- The likely energy and dollar savings in the commercial sector from the ENERGY STAR program are significant on a national scale. Total electricity savings will range from 10 to $23 \mathrm{TWh} /$ year in 2010 , and will most likely be about $17 \mathrm{TWh} /$ year by 2010 . The most likely level of savings represents the annual output of three $1000 \mathrm{MW}$ power plants, and results in net benefits to society exceeding $\$ 1$ billion per year after the year 2000.

- The cost of achieving ENERGY STAR efficiency levels is estimated by the manufacturers to be negligible, while the cumulative direct cost of funding the ENERGY STAR Program is on the order of a few million dollars. This policy therefore saves US society large amounts of money with minimal expenditure of public funds.

- In the worst case, the ENERGY STAR programs should result in commercial sector energy savings of about $10 \mathrm{TWh}$ /year in 2010. Even in this case, energy and dollar savings will substantially exceed expected costs to society.

The Advanced case demonstrates that significant additional savings may be achieved from advanced technologies if these technologies can be reduced in cost from current levels. This case results in savings beyond the ENERGY STAR MostLikely case of about $29 \mathrm{TWh} /$ year by 2010 . These savings are worth an additional $\$ 2.3$ billion per year in 2010 . 


\section{TABLE OF CONTENTS}

EXECUTIVE SUMMARY $\ldots \ldots \ldots \ldots \ldots \ldots \ldots \ldots \ldots \ldots \ldots \ldots \ldots \ldots \ldots \ldots$

INTRODUCTION $\ldots \ldots \ldots \ldots \ldots \ldots \ldots \ldots \ldots \ldots \ldots \ldots \ldots \ldots \ldots \ldots \ldots \ldots \ldots \ldots \ldots \ldots \ldots$

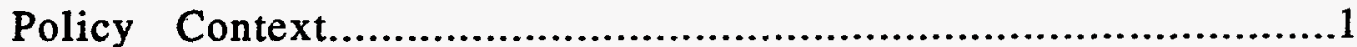

Purposes of This Study .....................................................2

Organization of the Report.................................................... 3

METHODOL OGY Y................................................. 3

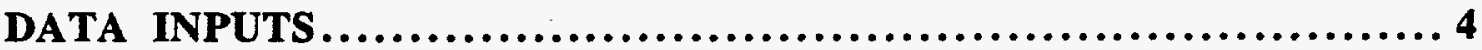

Equipment Power Levels ..................................................4

Equipment Lifetimes..........................................................8

Base Year Device and Occupant Densities .....................................8

Forecasted Equipment Densities ..............................................

Equipment Stock Forecast ....................................................11

Equipment Usage .........................................................13

Unit Energy Consumption...............................................13

Business-As-Usual Energy Use Intensities......................................16

Floorspace Projections ...................................................17

Equipment Stock........................................................ 17

Sales of Energy Star Equipment ........................................ 17

RESULTS $\ldots \ldots \ldots \ldots \ldots \ldots \ldots \ldots \ldots \ldots \ldots \ldots \ldots \ldots \ldots \ldots \ldots \ldots \ldots \ldots \ldots \ldots \ldots \ldots$

Effect of Energy Star Most-Likely and Advanced Scenario Assumptions ........20

Uncertainties in the Savings Calculations........................................24

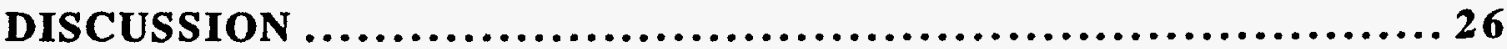

Cost effectiveness of Energy Star Program..........................................26

The US Market for PCs, Monitors, Fax Machines and Laser Printers.............27

Mainframes and Minicomputers................................................27

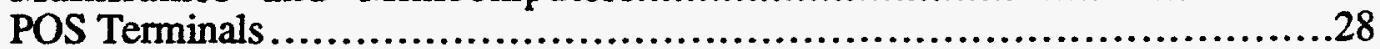

Advanced Technology........................................................28

Comparison with Annual Energy Outlook 1995 Office Equipment Forecast......28

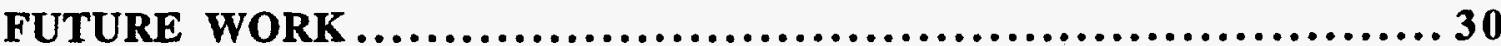

Mainframe and Minicomputers...............................................30

POS Terminals ................................................................ 30

Secondary HVAC Impacts........................................................30

Office Equipment Densities and Stocks .....................................30

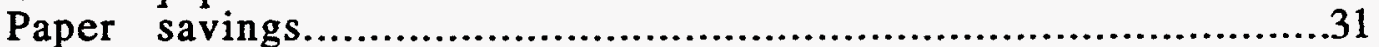

Multifunction Devices ....................................................31

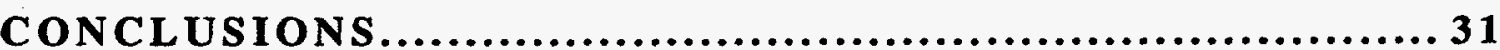

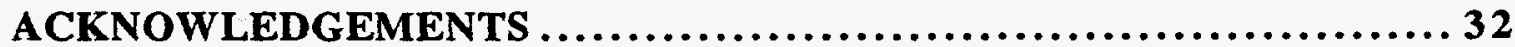

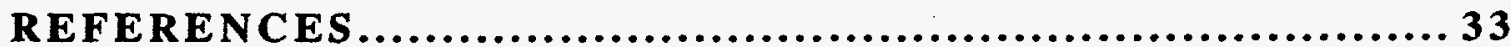

APPENDIX A: DEVELOPMENT OF THE OFFICE EQUIPMENT

ENERGY-USE MODEL....................................... 37

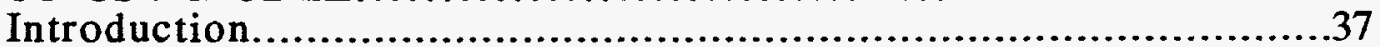

Model Theory and Data Flow ....................................................... 37

Model Explanation and Inputs.............................................40

APPENDIX B: COMMEND INPUT DATA FILE $\ldots \ldots \ldots \ldots \ldots \ldots \ldots \ldots \ldots 61$

APPENDIX C: BRIEFING CHARTS AND TABLES................62 


\section{LIST OF TABLES}

Table 1: Energy Star PC, Monitor, Printer, Copier, and Fax Machine

Characteristics .2

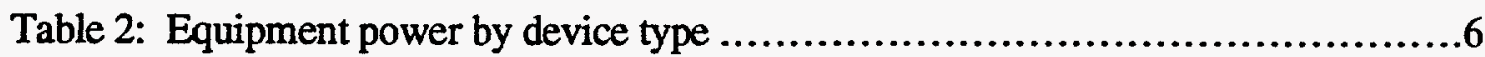

Table 2: Equipment power by device type (continued) ..............................7

Table 3: Average lifetimes for office equipment ....................................8

Table 4: Equipment Stocks (millions of units).............................................12

Table 5: PC CPU stocks by sector (millions)................................................13

Table 6: Estimated sales of Energy Star-compliant equipment (\% of sales).................17

Table 7: Percent of Energy Star Compliant Equipment Sold Assumed to be Enabled (By Policy Case) ...................................................................

Table 8: Comparison of Office Equipment Energy Use Forecasts ......................29

\section{LIST OF FIGURES}

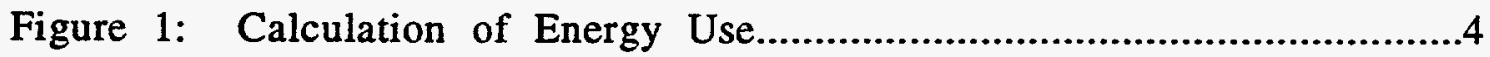

Figure 2: Calculation of Equipment Densities .....................................5

Figure 3a: Equipment Densities in Offices Using ITI Growth Rates Extrapolated

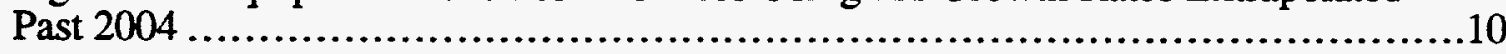

Figure 3b: Equipment Densities in Offices in This Study .............................10

Figure 4: Usage by device type (\% of year) ........................................

Figure 5: Unit Energy Consumption by Machine Type ............................15

Figure 6a: Normalized Trends in Floorspace, EUI, and Annual Energy Use ...........19

Figure 6b: Normalized Trends in Floorspace, EUI, and Annual Energy Use Without Mainframes or Minicomputers .................................................19

Figure 7: Comparison of Annual Electricity Use by Equipment Type in BusinessAs-Usual, Energy Star, and Advanced Scenarios ......................................21

Figure 8: Percentage of Total Savings by Equipment Type in 2010 ...................22

Figure 9: Savings by Equipment Type From the Energy Star Program as a Percentage of Baseline Electricity Use

Figure 10: Projected Annual Electricity Use for US Office Equipment, Sensitivity Analysis 


\section{INTRODUCTION}

This report describes a detailed end-use forecast of office equipment energy use for the US commercial sector. It builds upon earlier work for the state of New York (Piette et al. 1995) and revises that work to reflect conditions for the US as a whole. The forecasting methodology is used first to establish a baseline scenario and then to assess the projected effects of, and uncertainties surrounding, the US Environmental Protection Agency's (EPA's) ENERGY STAR office equipment program. It also investigates the potential impacts of an "Advanced Technology" scenario, where energy saving innovations are assumed to be pursued without regard to cost.

\section{Policy Context}

Office equipment became an important source of load growth for electric utilities in the 1980 s, as personal computers and associated peripherals became widespread. For both utilities and governments concerned with long-term energy planning, reliable estimates of future changes in energy used by office equipment are essential.

Several programs and policies designed to reduce energy use by office equipment have recently been adopted in the U.S. and Europe. Probably the most significant activity in the U.S. is the U.S. EPA'S ENERGY STAR office equipment program. This program, announced during the summer of 1993, has ushered a new generation of power-managed office technologies into the marketplace. Over 2000 models of computers, monitors, and printers are now listed as ENERGY STAR qualified products. The EPA recently expanded the program to include copiers and fax machines. To qualify as an ENERGY STAR PC or monitor, the equipment must be able to reduce power consumption to $30 \mathrm{~W}$ or less during idle periods (Table 1). Printer, copier, fax, and combination printer/fax machine power requirements are a function of output speed.

Not all ENERGY STAR units are equal in their energy efficiency. Efforts to assess, specify, and procure more efficient equipment are hampered by the lack of standard methods for measuring and reporting the energy use of each device. Currently the EPA allows manufacturers to conduct their own measurements, so the data in the EPA ENERGY STAR product list has not been verified by independent tests. To address this void, the Energy Policy Act of 1992 calls for a voluntary national testing and information program for office equipment. The Department of Energy has worked with representatives from the Council on Office Product Energy Efficiency (COPEE) to develop such standards. However, industry commitment to this process is uncertain.

A major reason for the rapid adoption of ENERGY STAR equipment in the markplace was the signing of executive order (E.O. 12845) by President Clinton. Under this order, the world's largest purchaser of office equipment, the U.S. government, is required to purchase ENERGY STAR PCs, monitors, and printers. This market-pull strategy has had a significant effect on the market penetration of ENERGY STAR equipment.

Similar activities to promote energy-efficient office technologies are underway in several European countries and Japan (Dandridge 1994, Smith et al. 1994). Two notable activities in Europe demonstrate the broad interest in reducing the energy use of office equipment. First, the Swedish Board for Industrial and Technical Development (NUTEK) has supported the development of power-managed monitors and is continuing to encourage power management in several additional devices. It is also sponsoring market surveys to 
Table 1: Energy Star PC, Monitor, Printer, Copier, and Fax Machine Characteristics

\begin{tabular}{|c|c|c|c|}
\hline $\begin{array}{l}\text { Equipment } \\
\text { Category }\end{array}$ & $\begin{array}{l}\text { Default Time } \\
\text { to Low- } \\
\text { Power State }\end{array}$ & $\begin{array}{l}\text { Max. Power } \\
\text { in Low- } \\
\text { Power State }\end{array}$ & $\begin{array}{c}\text { Date } \\
\text { in Force }\end{array}$ \\
\hline $\begin{array}{l}P C \text { (without monitor) (1) } \\
\text { Monitors (I) }\end{array}$ & $\begin{array}{l}\mathrm{na} \\
\mathrm{na}\end{array}$ & $\begin{array}{l}30 \mathrm{~W} \\
30 \mathrm{~W}\end{array}$ & $\begin{array}{l}\text { mid } 1993 \\
\text { mid } 1993\end{array}$ \\
\hline $\begin{array}{r}\text { Printers and Printer/Fax Combos: } \\
1-7 \text { pages per minute } \\
8-14 \text { pages per minute } \\
\text { Color and/or }>14 \text { pages per minute }\end{array}$ & $\begin{array}{l}15 \mathrm{~min} . \\
30 \mathrm{~min} . \\
60 \mathrm{~min} .\end{array}$ & $\begin{array}{l}15 \mathrm{~W} \\
30 \mathrm{~W} \\
45 \mathrm{~W}\end{array}$ & $\begin{array}{l}1 \text { Oct } 95 \\
1 \text { Oct } 95 \\
1 \text { Oct } 95\end{array}$ \\
\hline $\begin{array}{l}\text { Fax Machines: } \\
\text { 1-7 pages per minute } \\
\text { 8-14 pages per minute } \\
\text { >14 pages per minute }\end{array}$ & $\begin{array}{l}5 \mathrm{~min} . \\
5 \mathrm{~min} . \\
15 \mathrm{~min} .\end{array}$ & $\begin{array}{l}15 \mathrm{~W} \\
30 \mathrm{~W} \\
45 \mathrm{~W}\end{array}$ & $\begin{array}{l}1 \text { July } 95 \\
1 \text { July } 95 \\
1 \text { July } 95\end{array}$ \\
\hline $\begin{array}{r}\text { Copiers-Tier } 1(2) \text { : } \\
1-20 \text { copies per minute } \\
21-44 \text { copies per minute } \\
>44 \text { copies per minute ( } 3)\end{array}$ & $\begin{array}{l}\text { Default time } \\
\text { to Low/Off } \\
\\
\text { NA/30 min. } \\
\text { NA } 60 \mathrm{~min} \text {. } \\
\text { NA/90 min. }\end{array}$ & $\begin{array}{c}\text { Max Power } \\
\text { Low/Off } \\
\text { NA/5W } \\
\text { NA/40W } \\
\text { NA/40W }\end{array}$ & $\begin{array}{l}1 \text { July } 95 \\
1 \text { July } 95 \\
1 \text { July } 95\end{array}$ \\
\hline $\begin{array}{r}\text { Copiers-Tier } 2(4) \text { : } \\
1-20 \text { copies per minute } \\
21-44 \text { copies per minute } \\
>44 \text { copies per minute }\end{array}$ & $\begin{array}{l}\mathrm{NA} / 30 \mathrm{~min} . \\
15 \mathrm{~min} . / 60 \mathrm{~min} . \\
15 \mathrm{~min} . / 90 \mathrm{~min} .\end{array}$ & $\begin{array}{c}\mathrm{NA} / 5 \mathrm{~W} \\
(3.85 \times \mathrm{cpm}+5 \mathrm{~W}) / 10 \mathrm{~W} \\
(3.85 \times \mathrm{cpm}+5 \mathrm{~W}) / 15 \mathrm{~W}\end{array}$ & $\begin{array}{l}1 \text { July } 97 \\
1 \text { July } 97 \\
1 \text { July } 97\end{array}$ \\
\hline
\end{tabular}

(1) Updated requirements for PCs and monitors went into effect 1 Oct 95 . The update requires that the equipment ship with the power saving features enabled and that those features must be tested in a networked environment.

(2) There are no low-power requirements for Tier 1 machines (only off-mode power requirements).

(3) Additional Tier 1 requirements for copiers include default duplexing for copiers with speeds greater than 44 copies per minute $(\mathrm{cpm})$. One double sided page $=$ two copies.

(4) Additional Tier 2 requirements for copiers include default duplexing for copiers with speeds greater than 44 copies per minute and a required recovery time of 30 seconds for mid-speed copiers (this recovery time is recommended for high speed copiers).

(5) "NA" means "Not Applicable", which implies that no requirement exists.

assess the progress in installing energy-efficient office equipment in Sweden (NUTEK 1995). Second, the Swiss Federal Institute of Technology recently announced target standby and off-power levels for 1999 for PC CPUs, monitors, printers, fax machines, and copiers that are much more stringent than the EPA's ENERGY STAR targets (McMahon et al. 1995).

\section{Purposes of This Study}

In spite of the recent activity to promote energy efficiency in office equipment, assessments of the potential impacts of these policies on energy use have, with few exceptions, been ad hoc and relatively crude. This analysis draws upon industry forecasts and previous analysis to assess potential savings from the ENERGY STAR Computers program and advanced technology in the most detailed manner justified by existing data. It also documents the 
calculations for use in end-use forecasting and policy analysis applications, and compiles the relevant data in a systematic form so that others may build on our work.

\section{Organization of the Report}

The next section summarizes the methodology used in the calculations (further described in Appendix A), and the Data Inputs section describes the myriad inputs required. The Results and Discussion sections summarize the policy-relevant results and conclusions emerging from our work. Finally, we outline several important areas for further study.

There are three appendices to this report. Appendix A describes in detail the methodology used in the development of the spreadsheet used for the calculations in this study. Appendix B contains instructions for obtaining the COMMEND 4.0 data file that was developed during the course of this research. Appendix $\mathrm{C}$ contains a complete set of briefing charts and tables for those wishing to present the results of our calculations for other purposes. ${ }^{1}$

\section{METHODOLOGY}

The appendices to this report fully explain the methodology used here and note differences between the approach taken in this study and that used for the New York report (Piette et al. 1995). We summarize the methodology briefly in this section. As described in Figures 1 and 2, we created a spreadsheet model that explicitly treats changes in power and usage for all relevant device types. We estimated base year office equipment densities by building type after reviewing recent surveys of office equipment ownership. These sources include studies from the Pacific Northwest (ADM Associates Inc. 1992), Sacramento, CA (ADM Associates Inc. 1990), New York (Michaels et al. 1990, XENERGY 1989), and the US as a whole (US DOE 1994). Growth rates in these densities are derived from industry forecasts of equipment sales (CBEMA 1994) and estimated lifetimes for each type of equipment (IRS 1989). For certain equipment types (PC CPUs, monitors, fax machines, and printers), industry projections extrapolated past 2005 would lead to numbers of devices per person that exceed reasonable levels (e.g., 2-3 PCs per person). We adjusted industry projected growth rates downward for those equipment types to reflect the likely saturation of such equipment in the commercial sector.

Power levels are estimated based on measured data, trade press assessments, personal communications from industry participants, and from the ENERGY STAR requirements themselves (Acquaviva and Hartman 1993, Arthur D. Little Inc. 1993, Dandridge 1994, Froning 1994, Ledbetter and Smith 1993, Lovins and Heede 1990, Nadel 1994, Newsham and Tiller 1994, Norford et al. 1990, Rose 1993, Szydlowski and W. D. Chvala 1994, Tiller and Newsham 1993). Usage for different types of equipment is derived from surveys in Canada and the US (Szydlowski and W. D. Chvala 1994, Tiller and Newsham 1993). Finally, projected commercial sector floor area is taken from the US Department of Energy's Annual Energy Outlook 1995 (US DOE 1995a).

\footnotetext{
${ }^{1}$ We sometimes refer in the main text to Tables or Figures that are in Appendix C. Such references appear as "Table C-1" or "Figure C-2", and should not be confused with references to Tables and Figures within the main text itself.
} 


\section{Figure 1: Calculation of Energy Use}

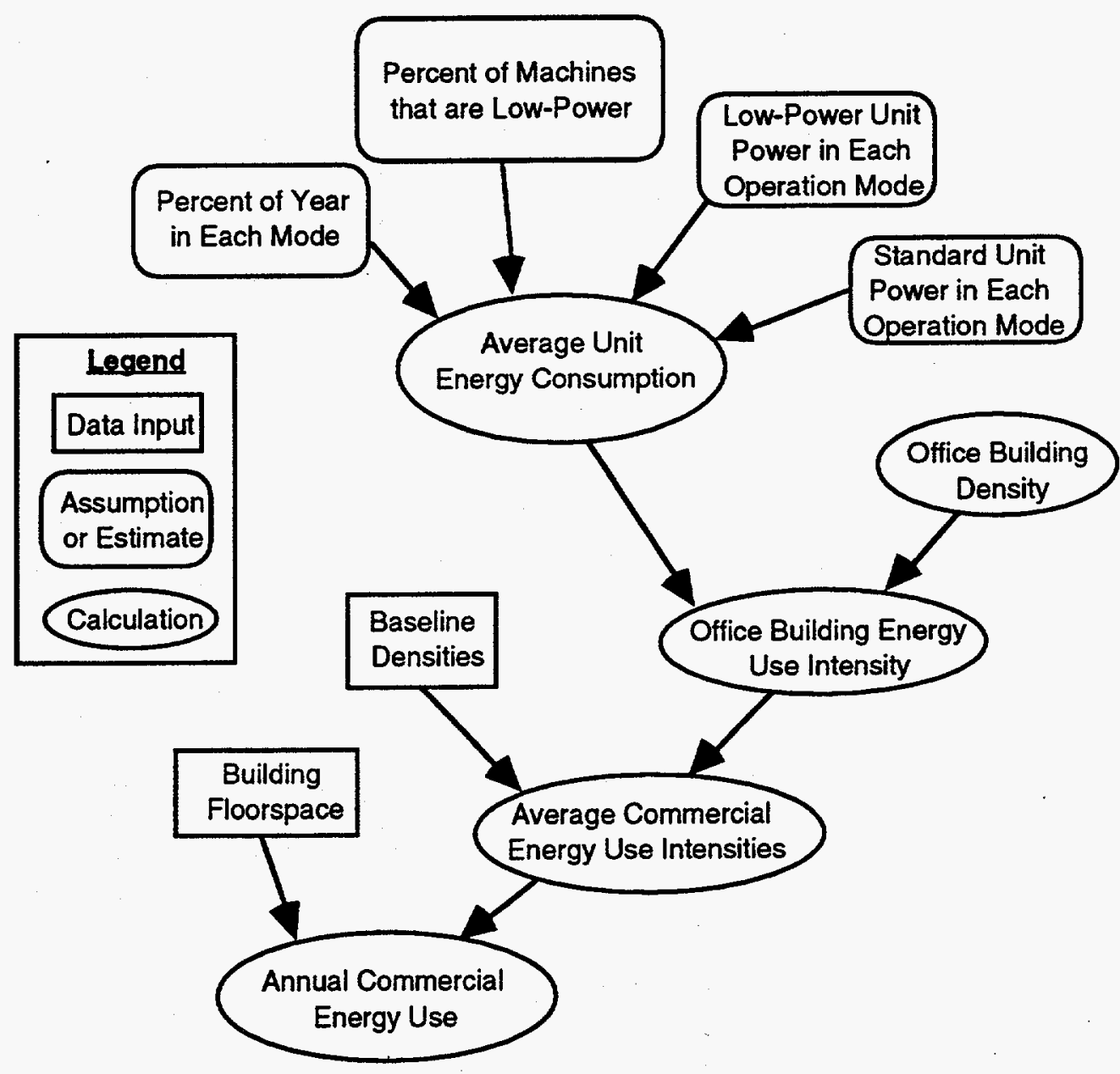

We combine these data to calculate unit energy consumption (UEC) for each type of equipment from the estimated power levels and hours of usage. Device densities are computed to be consistent with current and future commercial sector floor stock and industry projections of equipment sales. The UECs are then multiplied by the device densities and projected floor area in a given year for a given building type to get the total energy use by building type and device type.

\section{DATA INPUTS}

\section{Equipment Power Levels}

Table 2 shows the power levels for each equipment type for each scenario from 1985 to 2012 (for a discussion of the technologies corresponding to each power level, see Piette et al. (1995)). We define four distinct operating modes for each type of equipment (except for copiers, which have five operating modes): 


\section{Figure 2: Calculation of Equipment Densities}

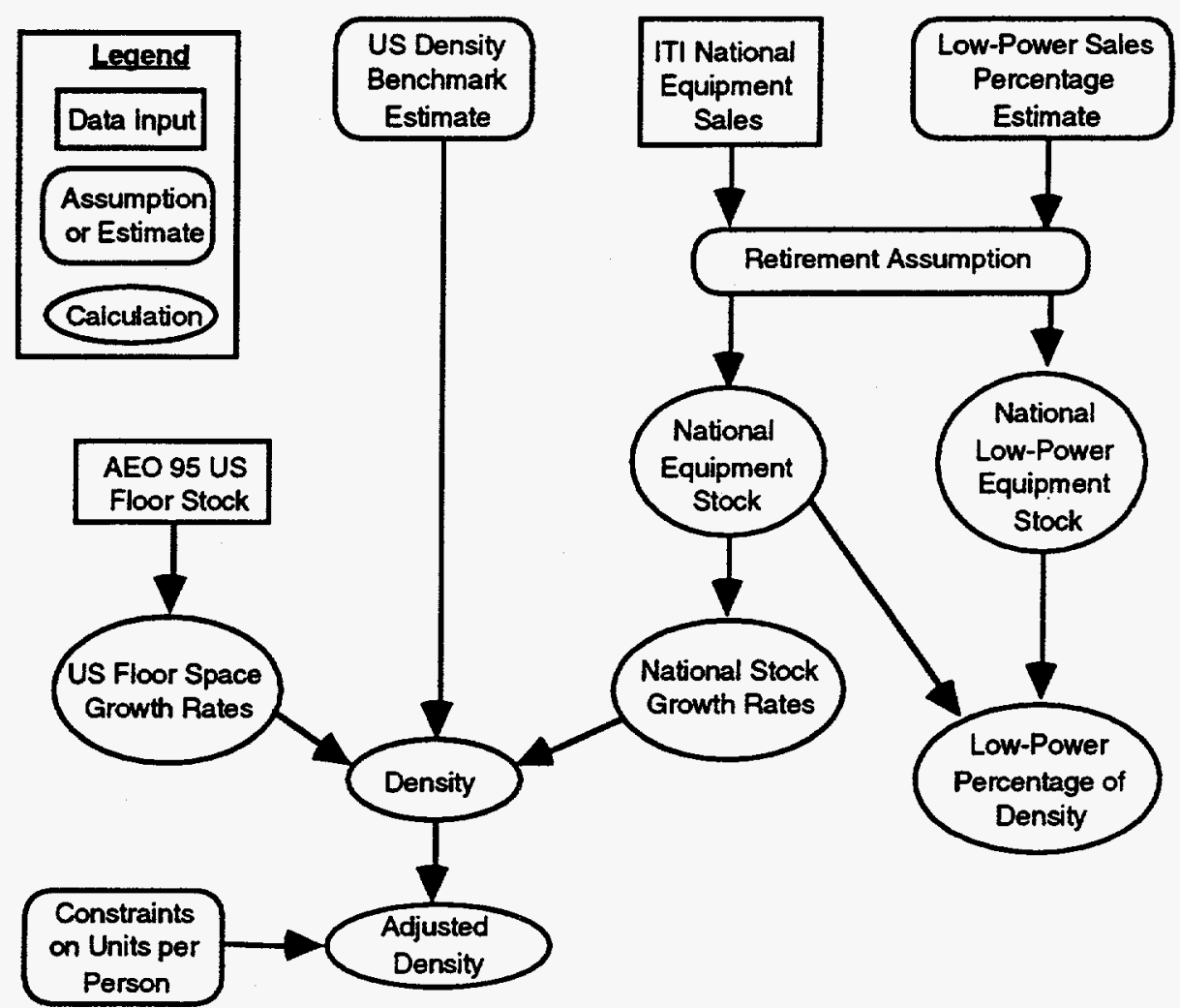

1) Active mode: This is the power of the device when in operation. For PC CPUs, active power can vary somewhat when different peripherals are in operation. Monitor power can also vary depending on the image being shown.

2) Standby mode: This mode represents an intermediate state which attempts to conserve power with instant recovery. The system is idle. If the device has no standby mode, this power level is equivalent to that of the active mode.

3) Suspend mode: This mode has the lowest power level (without being off) but has a longer recovery time than for standby.

4) Plug mode: The power in this mode is that drawn by copiers when they are switched off but still plugged in. This mode does not apply to other types of equipment.

5) Off mode: The power in this mode is that drawn (essentially zero) when the device is switched off, or for copiers when the device is unplugged.

The power levels shown in the Business-as-Usual case are the average for existing stock in that year, and they follow a linear trend between the years. For example, the power for PCs starts at $97 \mathrm{~W}$ in 1985 and linearly drops to $75 \mathrm{~W}$ by 1991 . It stays at $75 \mathrm{~W}$ until 1994, after which it linearly drops to $55 \mathrm{~W}$ by 1998 . It continues at $55 \mathrm{~W}$ thereafter. 
Table 2: Equipment power by device type

2a-PC CPU Equipment Power

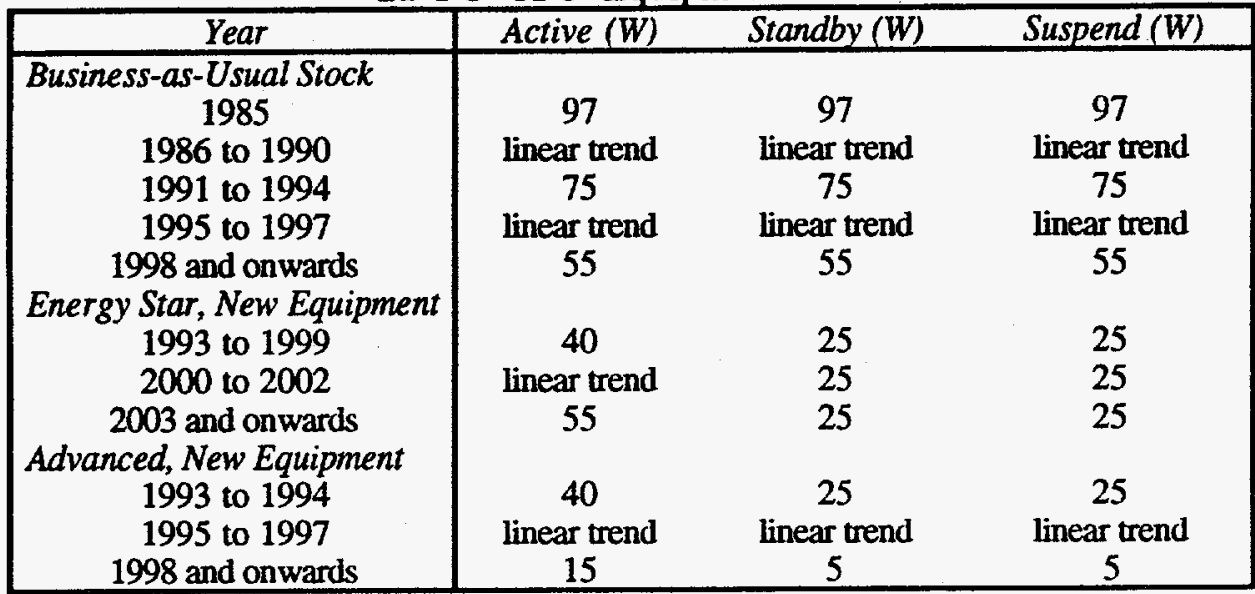

2b-Monitor Equipment Power

\begin{tabular}{|c|c|c|c|}
\hline Year & Active (W) & Standby (W) & Suspend (W) \\
\hline $\begin{array}{c}\text { Business-as-Usual Stock } \\
1985 \\
1986 \text { to } 1990 \\
1991 \\
1992 \text { to } 2000 \\
2001 \text { and onwards } \\
\text { Energy Star, New Equipment } \\
1993 \\
1994 \text { to } 2000 \\
2001 \text { and onwards } \\
\text { Advanced, New Equipment } \\
1993 \text { to } 1994 \\
1995 \text { to } 1997 \\
1998 \text { and onwards }\end{array}$ & $\begin{array}{c}28 \\
\text { linear trend } \\
55 \\
\text { linear trend } \\
65 \\
57 \\
\text { linear trend } \\
65 \\
57 \\
\text { linear trend } \\
23\end{array}$ & $\begin{array}{c}28 \\
\text { linear trend } \\
55 \\
\text { linear trend } \\
65 \\
43 \\
\text { linear trend } \\
51 \\
43 \\
\text { linear trend } \\
5\end{array}$ & $\begin{array}{c}28 \\
\text { linear trend } \\
55 \\
\text { linear trend } \\
65 \\
14 \\
\text { linear trend } \\
14 \\
14 \\
\text { linear trend } \\
5\end{array}$ \\
\hline
\end{tabular}

2c-Laser Printer Equipment Power

\begin{tabular}{|c|ccc|}
\hline Year & Active (W) & Standby $(W)$ & Suspend $(W)$ \\
\hline $\begin{array}{c}\text { Business-as-Usual Stock } \\
\text { 1985 and onwards }\end{array}$ & 250 & 80 & 80 \\
$\begin{array}{c}\text { Energy Star, New Equipment } \\
\text { 1993 and onwards }\end{array}$ & 250 & 80 & 25 \\
$\begin{array}{c}\text { Advanced, New Equipment } \\
1993 \text { to } 1995\end{array}$ & 250 & 80 & 25 \\
1996 to 1999 & $\begin{array}{c}\text { linear trend } \\
120\end{array}$ & $\begin{array}{c}\text { linear trend } \\
\text { 2000 and onwards }\end{array}$ & $\begin{array}{c}\text { linear trend } \\
5\end{array}$ \\
\hline
\end{tabular}

2d-Serial Printer Equipment Power

\begin{tabular}{|c|ccc|}
\hline Year & Active $(W)$ & Standby $(W)$ & Suspend $(W)$ \\
\hline Business-as-Usual Stock & & & \\
1985 to 1990 & 45 & 15 & 15 \\
1991 to 1999 & linear trend & linear trend & linear trend \\
2000 and onwards & 20 & 8 & 8 \\
\hline
\end{tabular}


Table 2: Equipment power by device type (continued)

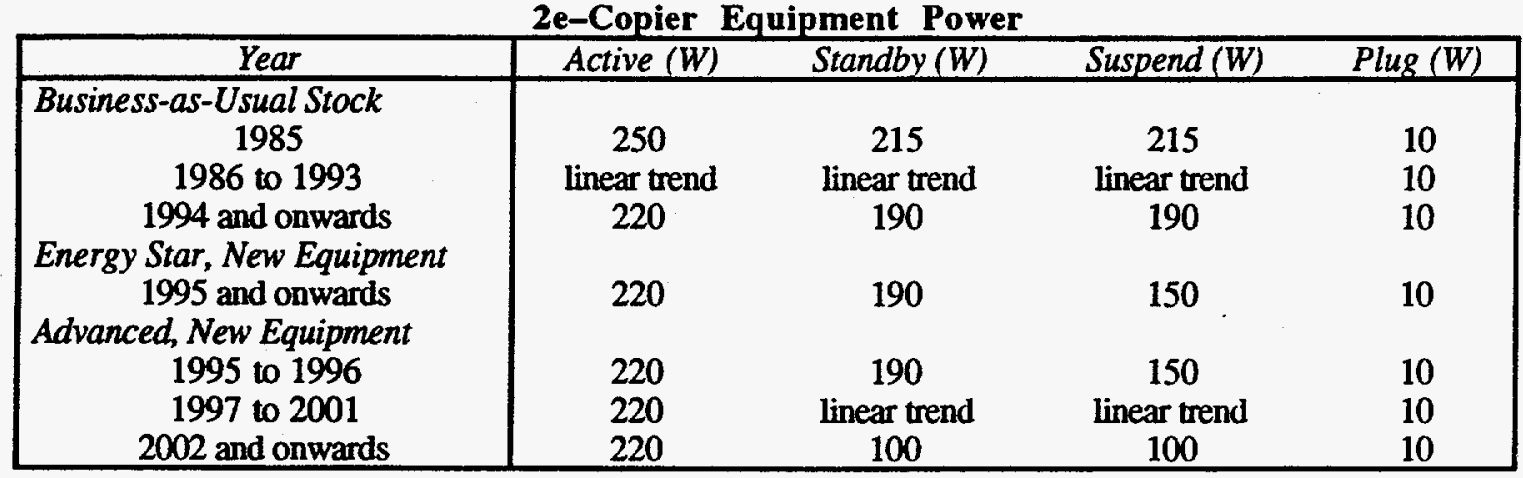

2f-Fax Equipment Power

\begin{tabular}{|c|cc|}
\hline Year & Active $(W)$ & Standby $(W)$ \\
\hline Business-as-Usual Stock & & \\
1985 & 175 & 20 \\
1986 to 1993 & 175 & linear trend \\
1994 and onwards & 175 & 35 \\
Energy Star, New Equipment & 175 & \\
1995 and onwards & & 15 \\
Advanced, New Equipment & 175 & 15 \\
1995 to 1996 & 175 & linear trend \\
1997 to 2001 & 175 & 5 \\
2002 and onwards &
\end{tabular}

2g-POS Terminal Equipment Power

\begin{tabular}{|c|cc|}
\hline Year & Active (W) & Standby (W) \\
\hline $\begin{array}{c}\text { Business-as-Usual Stock } \\
\text { 1985 and onwards } \\
\text { Advanced, New Equipment } \\
\text { 1993 and onwards }\end{array}$ & 130 & 130 \\
\hline
\end{tabular}

2h-Mainframe Equipment Power

\begin{tabular}{|c|cc|}
\hline Year & Active $(W)$ & Standby (W) \\
\hline Business-as-Usual Stock & & \\
1985 to 1990 & 25,000 & 12,500 \\
1991 to 1998 & linear trend & linear trend \\
1999 and onwards & 10,000 & 5,000 \\
\hline
\end{tabular}

2i-Mini-computer Equipment Power

\begin{tabular}{|c|cc|}
\hline Year & Active (W) & Standby (W) \\
\hline Business-as-Usual Stock & & \\
1985 to 1990 & 3,500 & 1,750 \\
1991 to 1997 & linear trend & linear trend \\
1998 and onwards & 1,250 & 625 \\
\hline
\end{tabular}


Some of the equipment types (serial printers, POS terminals, mainframes, and minicomputers) don't have ENERGY STAR or Advanced power levels, in which case we simply used the power levels from the Baseline scenario.

\section{Equipment Lifetimes}

Table 3 shows the lifetimes assumed in this report, which represent the average economic life of the equipment. The lifetimes for all equipment but mainframes and minicomputers are taken from the Internal Revenue Service's Depreciation Tables, which show "lives" of dozens of classes of commercial and industrial equipment (IRS 1989). Equipment lifetimes for mainframes and minicomputers are implicit in the stock and sales numbers in the Information Technology Industry Council (ITI) ${ }^{2}$ forecasts (CBEMA 1994), and we derive them from that source.

These lifetimes, in combination with projected equipment sales, are used to calculate the equipment stock in any year. Lifetimes are used in the forecast by assuming that equipment put in service in a given year is all retired at the end of its average lifetime. This approach, while crude, is a reasonable approximation in the face of the rapid turnover of the office equipment stock.

There lifetime estimates are uncertain. In particular, it is not known what fraction of the equipment actually lasts longer than these lifetimes, and how much of the equipment "retired" by its first owners finds new uses in other institutions. Somewhat longer lifetimes would reduce the speed at which new equipment penetrates the existing stock, but probably only by a year or two. Office equipment becomes obsolete so quickly that actual lifetimes are unlikely to significantly exceed those in Table 3.

Table 3: Average lifetimes for office equipment

\begin{tabular}{|c|c|}
\hline Device type & Lifetime (years) \\
\hline PC CPUs & 4 \\
Monitors & 4 \\
Laser Printers & 6 \\
Serial Printers & 6 \\
Copiers & 6 \\
Fax machines & 6 \\
POS terminals & 4 \\
Mainframes & 9 \\
Minicomputers & 8 \\
\hline
\end{tabular}

\section{Base Year Device and Occupant Densities}

The derivation of the base year densities in this study is broadly consistent with the methodology used in Piette et al. (1995). PC CPU densities are derived indirectly from the monitor densities in the 1992 Commercial Buildings Energy Consumption Survey (CBECS). The CBECS reports monitor densities that lump all terminals and monitors together. We use the ITI estimate for sales of "extra" monitors (i.e., those used as standalone terminals) and our lifetime assumption above to derive an estimate for the stock of

${ }^{2}$ The Computer and Business Equipment Manufacturers Association (CBEMA) has recently renamed itself the Information Technology Industry Council (ITI). 
extra monitors in 1992 . We allocate $25 \%$ of ITI's extra monitors to the industrial sector to account for those associated with mainframe and minicomputers in that sector. We assume that every PC CPU has a monitor and that extra monitors belong to mainframe and minicomputers. We then subtract the stock of extra commercial sector monitors from the total commercial sector monitors (from CBECS) to derive the stock and densities for PC CPUs and associated monitors in the commercial sector.

The densities for other equipment were chosen after reviewing a variety of sources (ADM Associates Inc. 1990, ADM Associates Inc. 1992, Michaels et al. 1990, US DOE 1994, XENERGY 1989), as summarized in Appendix A.

\section{Forecasted Equipment Densities}

Figure C-2 shows the equipment densities by building type for 1990, 2000, and 2010 . Offices have by far the greatest density of equipment, with base year densities a factor of three to five higher than those in the other building types. The types of equipment in the different building types also differ. Offices, hospitals, hotels, and retail show the vast majority of installed units being PC CPUs, monitors, and printers, while groceries and restaurants show point-of-sale (POS) terminals represent more than half of the number of units of existing office equipment. Mainframe and minicomputer densities barely show up on Figure C-2 because the number of units installed is small compared to other types of equipment. However, the large UEC of the big computers results in a measurable fraction of energy use being attributable to these computers. For each equipment type, the density growth is the same for all the building types.

The equipment densities in offices and an assumed occupant density of 27.9 square meters (300 square feet) per person implies the numbers of devices per person shown in Figure 3a. When we first calculated the densities using the ITI numbers, we found that the numbers of devices per person for PC CPUs, monitors, laser printers, and faxes exceeded what we thought were reasonable levels (Figure 3a). The forecasted densities of serial printers, copiers, minicomputers, and mainframes did not exceed any obvious thresholds, so we did not alter the industry forecasted growth rates for these equipment types. The numbers for the PC CPUs and monitors were most excessive, indicating more than 3 PC CPUs per person by 2010 . We adjusted the post-1998 industry forecast growth rates downward until the PC CPU and monitor densities per person saturated at just under 1.0 (Figure $3 \mathrm{~b}$ ) and the fax and laser printer densities per person saturated at about 0.2 and 0.4 , respectively. The revised growth rates imply the stocks shown below.

The use of a constant 27.9 square meters (300 square feet) per person occupant density represents a crude approximation. The current estimate from US DOE (1994) is that occupant densities in offices are roughly 37 square meters (400 square feet) per person, which includes all office buildings, both vacant and occupied: Because there are currently on the order of $20 \%$ vacancy rates in offices, the floor area per person is close to 27.9 square meters in occupied offices. In addition, the occupant density is changing over time as information technology continues to redefine the nature of the workplace, so any such estimate is inherently uncertain. For these reasons, we chose to simply use the estimate of 28 square meters per person in our density calculations. 


\section{Figure 3a: Equipment Densities in Offices Using ITI Growth}

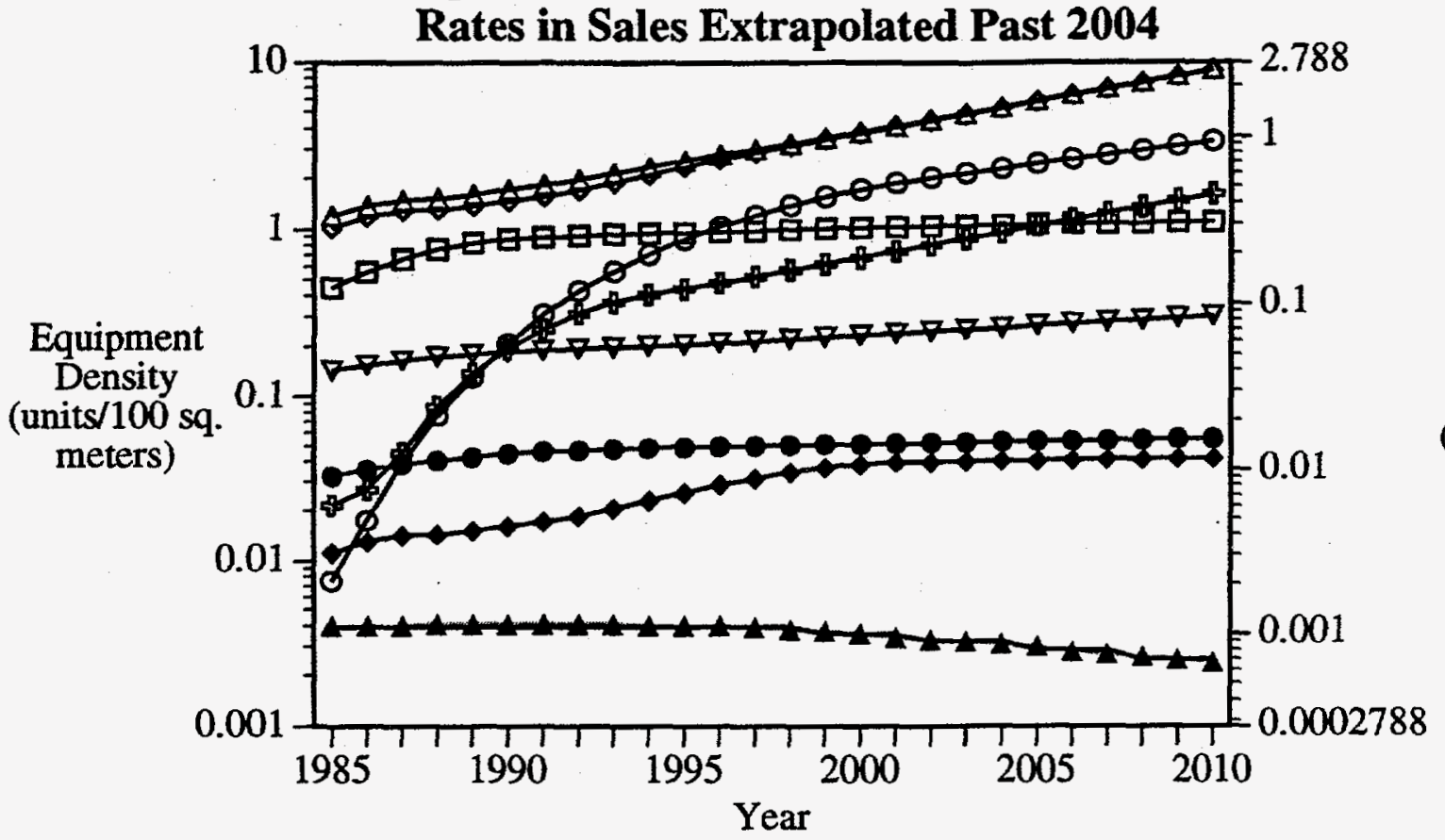
Equipment Density (units/person)

Figure 3b: Equipment Densities in Offices in This Study

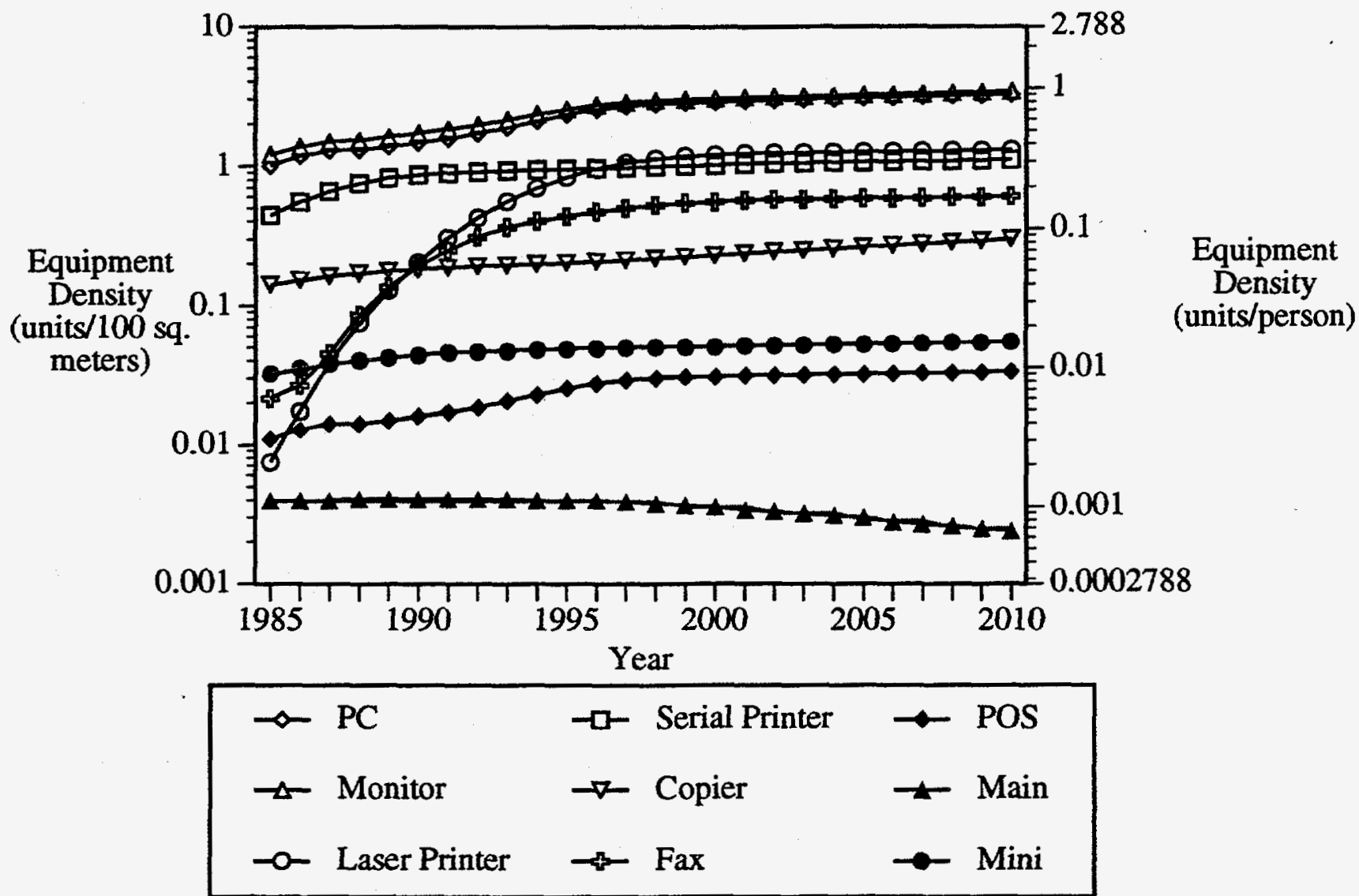

Units per person density assumes 300 square feet (27.88 sq. meters) per person. In our forecast, PC CPU and monitor sales are assumed to grow at $2 \%$ /year after 1998, while serial printer, laser printer, and fax sales are assumed to grow at the same rate that floor stock grows (about 1.5\%/yr) starting in 1998. ITI has no forecast for POS terminals, so we assume that they grow at the same rate as PC CPUs until 1998 and then grow at $1.5 \%$ /year thereafter. 1 square meter $=10.76$ square feet. 


\section{Equipment Stock Forecast}

We developed our stock forecast in an iterative manner. First, we used the ITI growth rates of equipment sales with our device lifetimes and base year densities to create a stock forecast. We modified the base year densities so that the stock forecast resulted in about $1 / 4$ of ITI's stock of copiers, faxes, and minicomputers, $10 \%$ of the mainframes, $50 \%$ of the serial printers, and about $1 / 3$ of the laser printers being outside the commercial sector.

We then assessed in offices the implied number of devices per person for this forecast. We modified the ITI growth rates as discussed above for PC CPUs, monitors, laser printers, and faxes (see Figure $3 \mathrm{a}$ and $3 \mathrm{~b}$ ) and calculated total device densities for each equipment type and building type, as shown in Figure $C-2$. Multiplying these densities by the projected floor area gives the total equipment stock in our forecast.

Table 4 summarizes our final estimates of equipment stock for the US commercial sector. After the mid-1990s we adjust the ITI growth rates in stocks to account for saturation of demand for PC CPUs, monitors, laser printers, and fax machines, which is why our forecast of stocks for those devices differs from a forecast based solely on ITI growth rates in later years.

Table 5 shows estimates of PC CPU stock by sector as estimated by Dataquest (1993) in comparison to the PC CPU stock estimated for the commercial sector in our study. Our commercial sector stocks are comparable to theirs, though there is significant uncertainty about the residential stocks. For example, the US DOE's Residential Energy Consumption Survey estimated the total number of computers in homes in 1990 to be 14.8 million units (US DOE 1992), more than twice the estimate from Dataquest for that year. Future Computing/Datapro Inc, as cited in the Statistical Abstract of the US 1990, estimated total home PC ownership in 1985 of about the same magnitude (14.9 million) as shown in RECS for 1990 , and estimated that growth by 1988 had brought the total home PC CPU stock to 22.4 million. This same source cited total workplace PC CPU ownership (less 5\% assumed to be in industry) to be about 22 million in 1988, which is consistent with the estimate for the commercial sector used in this study and with the Dataquest estimate summarized in Table 5.

Certain definitional problems lead to differences between estimates. The ITI estimates for PC CPUs exclude laptops and computers systems costing less than $\$ 1000$ (which presumably excludes many but by no means all home machines). Some respondents to the various surveys may be imprecise in their responses (listing game machines as personal computers, for example). In any case, as home offices become more prevalent and as the more powerful computers are commonly used in the home, the distinctions currently used by the various surveys and analyses will become more and more imprecise. Detailed tracking of sales data are required to allow compilation of a complete stock and flow assessment of where PC CPUs are installed and used. Such tracking becomes even more crucial in the face of the likely saturation of demand for PC CPUs in the commercial sector over the next decade (see below). 
Table 4: Equipment stocks (millions of units)

\begin{tabular}{|c|c|c|c|c|c|}
\hline & PCCPUs & Monitors: $P C s$ & Monitors: other & Mainframes & Minicomputers \\
\hline 1988 & 20 & 20 & 6.5 & 0.083 & 1.0 \\
\hline 1989 & 22 & 22 & 7.2 & 0.086 & 1.1 \\
\hline 1990 & 24 & 24 & 7.8 & 0.087 & 1.2 \\
\hline 1991 & 26 & 26 & 8.4 & 0.089 & 1.2 \\
\hline 1992 & 29 & 29 & 8.9 & 0.091 & 1.3 \\
\hline 1993 & 33 & 33 & 9.3 & 0.092 & 1.3 \\
\hline 1994 & 37 & 37 & 9.5 & 0.092 & 1.4 \\
\hline 1995 & 41 & 41 & 9.6 & 0.093 & 1.4 \\
\hline 1996 & 46 & 46 & 9.7 & 0.093 & 1.4 \\
\hline 1997 & 49 & 49 & 9.8 & 0.093 & 1.5 \\
\hline 1998 & 51 & 51 & 9.9 & 0.092 & 1.5 \\
\hline 1999 & 53 & 53 & 10 & 0.090 & 1.5 \\
\hline 2000 & 54 & 54 & 10 & 0.088 & 1.5 \\
\hline 2001 & 55 & 55 & 10 & 0.086 & 1.6 \\
\hline 2002 & 57 & 57 & 11 & 0.084 & 1.6 \\
\hline 2003 & 58 & 58 & 11 & 0.081 & 1.6 \\
\hline \multirow[t]{2}{*}{2004} & 59 & 59 & 11 & 0.079 & 1.6 \\
\hline & Laser Printers & Serial printers & Copiers & Faxes & POS \\
\hline 1988 & 1.5 & 15 & 5.1 & 1.7 & 4.3 \\
\hline 1989 & 2.6 & 17 & 5.5 & 2.8 & 4.5 \\
\hline 1990 & 4.3 & 18 & 5.7 & 4.1 & 5.0 \\
\hline 1991 & 6.5 & 19 & 6.0 & 5.4 & 5.4 \\
\hline 1992 & 9.2 & 20 & 6.2 & 6.8 & 6.0 \\
\hline 1993 & 12 & 20 & 6.4 & 8.1 & 6.7 \\
\hline 1994 & 16 & 21 & 6.6 & 9.1 & 7.7 \\
\hline 1995 & 19 & 21 & 6.8 & 10 & 8.7 \\
\hline 1996 & 22 & 22 & 7.0 & 11 & 9.6 \\
\hline 1997 & 24 & 23 & 7.3 & 12 & 10 \\
\hline 1998 & 26 & 23 & 7.6 & 12 & 11 \\
\hline 1999 & 28 & 24 & 7.8 & 13 & 11 \\
\hline 2000 & 29 & 24 & 8.1 & 14 & 12 \\
\hline 2001 & 30 & 25 & 8.4 & 14 & 12 \\
\hline 2002 & 30 & 25 & 8.7 & 14 & 12 \\
\hline 2003 & 31 & 26 & 9.0 & 14 & 13 \\
\hline 2004 & 31 & 26 & 9.3 & 15 & 13 \\
\hline
\end{tabular}

(1) Stock growth rates until 1998 are calculated from our base year densities, the ITUCBEMA (1994) forecast of the growth rate in equipment sales, and the lifetimes shown in Table 3.

(2) PC CPU and monitor sales are assumed to grow at 2\%/year after 1998, while serial printer, laser printer, and fax sales are assumed to grow at the same rate that floor stock grows (about 1.5\%/yr) starting in 1998. ITI has no forecast for POS terminals, so we assume that they grow at the same rate as PC CPUs until 1998 and then grow at $1.5 \% /$ year thereafter.

(3) PC CPU stocks exclude units costing less than $\$ 1000$, handheld computers, and laptops. 
Table 5: PC CPU stocks by sector (millions)

\begin{tabular}{|c|c|c|c|c|c|}
\hline & \multicolumn{4}{|c|}{ From Dataquest } & $\begin{array}{l}\text { This study } \\
\text { commercial }\end{array}$ \\
\hline 1990 & 6.5 & 1.3 & 24.9 & 32.7 & 24.2 \\
\hline 1991 & 7.0 & 1.4 & 26.7 & 35.1 & 26.2 \\
\hline 1992 & 7.6 & 1.5 & 29.1 & 38.2 & 28.9 \\
\hline 1993 & 8.5 & 1.7 & 32.4 & 42.6 & 32.5 \\
\hline 1994 & 9.7 & 2.0 & 37.1 & 48.7 & 36.7 \\
\hline 1995 & 10.8 & 2.2 & 40.9 & 53.9 & 41.4 \\
\hline 1996 & 11.8 & 2.4 & 44.9 & 59.1 & 45.6 \\
\hline 1997 & 12.8 & 2.6 & 48.8 & 64.2 & 48.7 \\
\hline
\end{tabular}

(1) Sectoral breakdown between home and non-home use stocks from Dataquest 1993.

(2) Dataquest only reports "non-home" stocks. To estimate commercial sector stocks implied by the Dataquest data, we assume that $5 \%$ of non-home PC CPUs go into the industrial sector and $95 \%$ go to the commercial sector.

\section{Equipment Usage}

Figure 4 shows our estimates of the percentage of the year each type of equipment spends in each of the various operating modes, taken from Piette et al. (1995). All types of equipment but copiers have four operating modes (active, standby, suspend, and off). Copiers have an additional mode (called "Plug" in Figure 4) because the equipment draws power even when it is switched off.

The percentage of time the equipment is in each operating mode is assumed to remain constant across the main scenarios (we explore the effect of changes in usage in the section on sensitivity cases, below). The only exception to this rule is copiers, where the ENERGY STAR and Advanced cases assume that all copiers have an "auto-off" function so the devices spend less time in Suspend mode and more time in Plug mode than in the Baseline case. PC CPUs, monitors, and printers all operate about 3000 hours per year, while copiers operate 3000-4000 hours/year in Active, Standby, or Suspend modes. POS terminals operate about half the year ( 4400 hours) while mainframes, minicomputers, and fax machines operate for just about the entire year.

\section{Unit Energy Consumption}

Figure 5 shows unit energy consumptions (UECs) for the different equipment types. The UECs are calculated from the power levels given in Table 1 and the operating hours in Figure 4 using Equation 1 (this equation is modified as appropriate to calculate energy use for copiers, which have the additional "Plug" operating mode):

$$
U E C_{i}=\frac{P_{i} \times\left(A_{i} \times H A_{i}+S B_{i} \times H S B_{i}+S P_{i} \times H S P_{i}\right)}{1000}
$$


where

UEC = Unit Energy Consumption for equipment type i $(\mathrm{kWh} /$ year)

$\mathrm{i}=\quad$ index for office equipment type (e.g., PC CPUs, monitors, etc.)

$P=\quad$ Peak power use of equipment type $i$ (W/unit)

$H A=$ Hours of operation in active mode for equipment type $i$ (hours/year)

HSB $=$ Hours of operation in standby mode for equipment type $i$ (hours/year)

HSP = Hours of operation in suspend mode for equipment type $i$ (hours/year)

$\mathrm{A}=\quad$ Average active mode power as a percent of peak for equipment type $\mathrm{i}(\%)$

$\mathrm{SB}=\quad$ Average standby mode power as a percent of peak for equipment type $\mathrm{i}(\%)$

$S P=$ Average suspend mode power as a percent of peak for equipment type $i(\%)$

Figure 4: Usage by device type (\% of year)

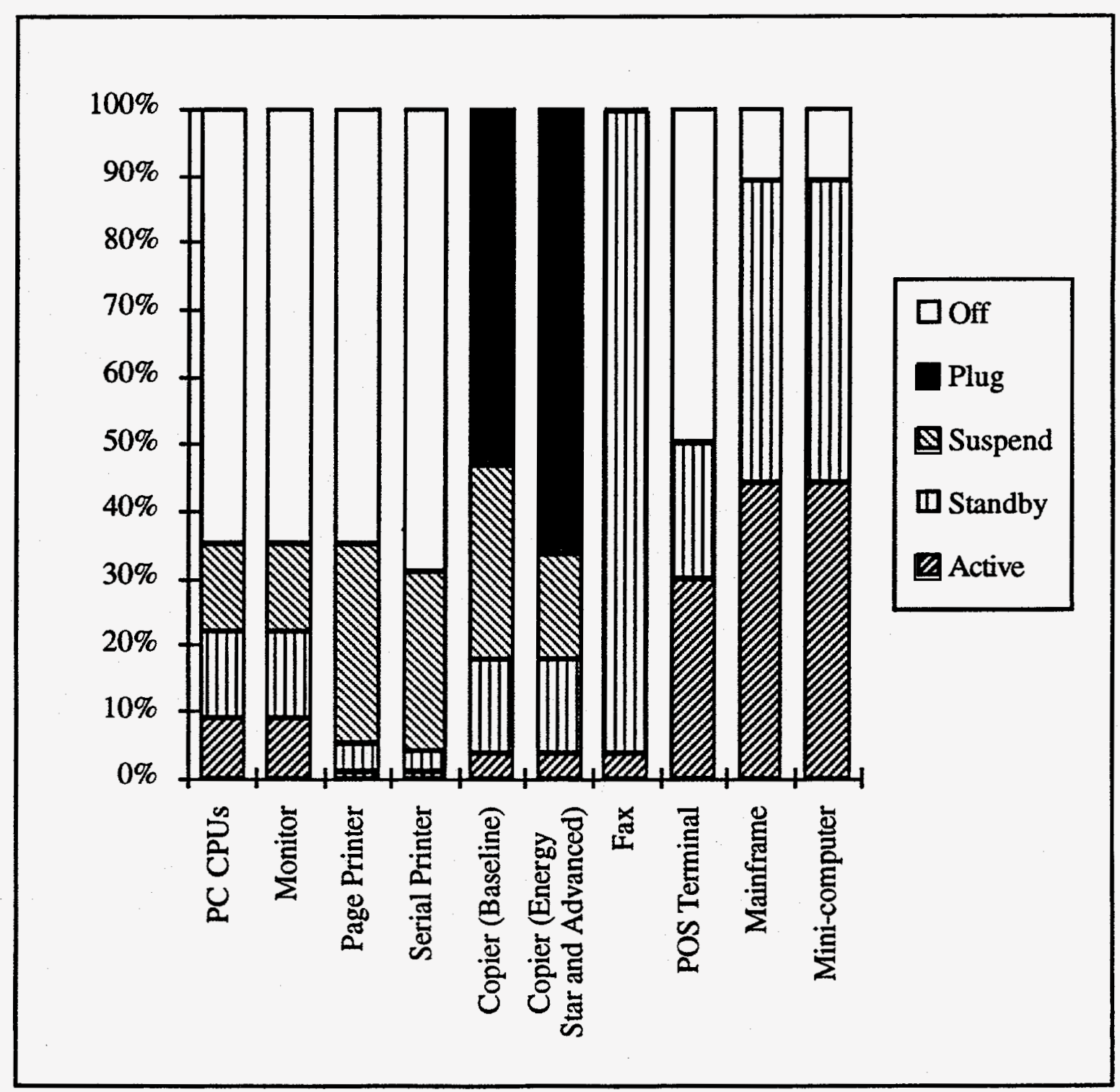



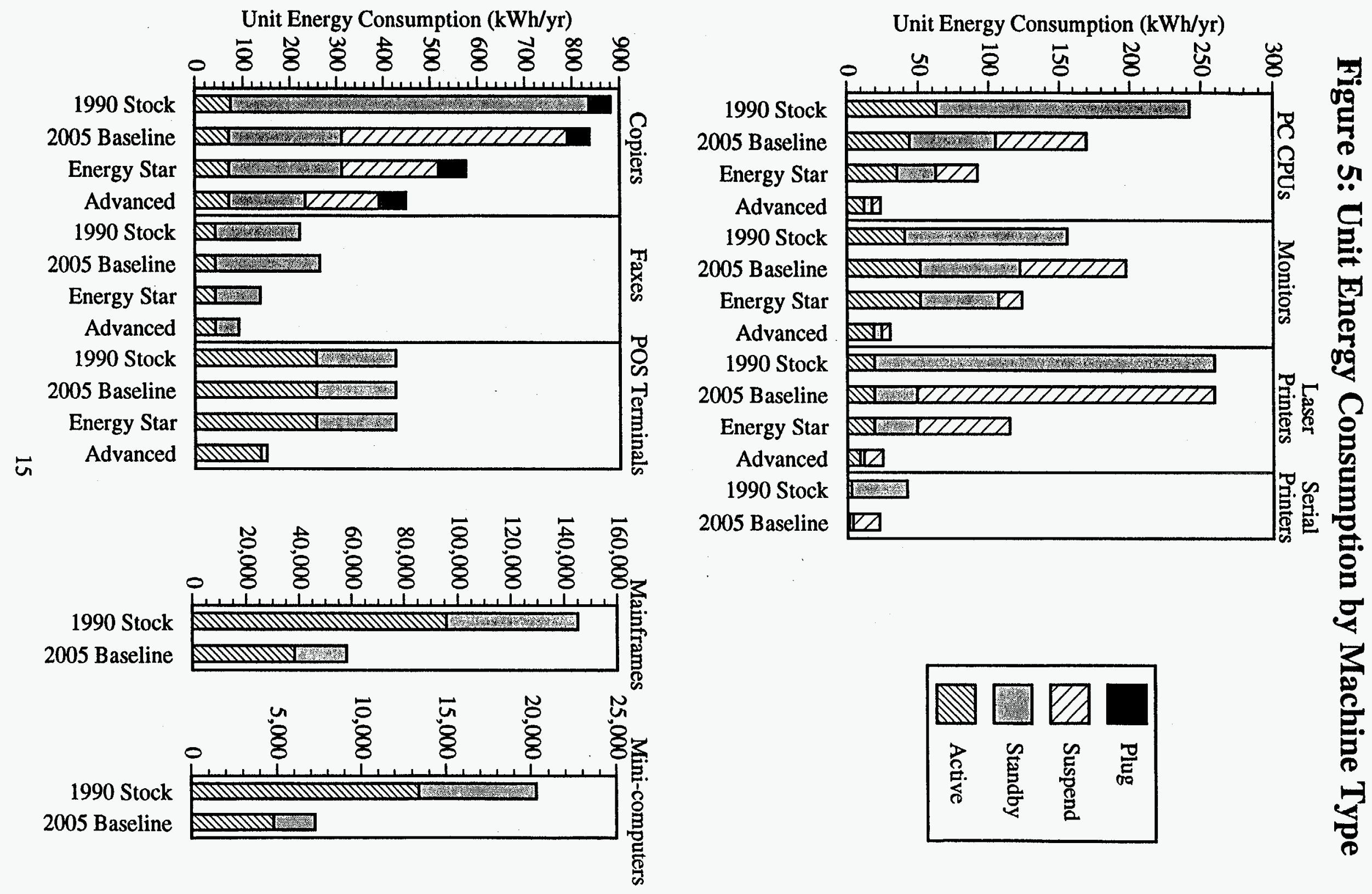
Typical baseline UECs for PC CPUs in 2005 are about $170 \mathrm{kWh} /$ year, with ENERGY STAR equipment reducing this by slightly less than $50 \%$, to $90 \mathrm{kWh} /$ year. Most of this reduction is attributable to savings in the Standby and Suspend modes, with only a slight reduction attributable to savings in Active mode power. Baseline PC CPUs show reductions in UECs relative to the 1990 stock of about $30 \%$, from $240 \mathrm{kWh} /$ year to $170 \mathrm{kWh} /$ year, which is caused by reductions in microprocessor and peripheral power use for desktop machines. These improvements have been driven by the economics of chip manufacturing as well as by the manufacturer's desires to fit more peripherals into smaller spaces (an effort that requires heat reductions and hence efficiency improvements).

Monitors show increasing UECs in the 2005 baseline relative to the 1990 stock. This increase is caused by the shift towards the almost universal use of color screens (and larger screens). Relative to the 2005 baseline, the ENERGY STAR case shows a UEC reduction of about 30\%, which is mainly the result of a reduction in Suspend mode power use. Active power use is not affected.

Laser printers show reductions in UECs of more than 50\% in the ENERGY STAR case relative to the 2005 baseline. These reductions are entirely the result of reductions in Suspend mode use. Active and Standby mode power use are not affected.

The UEC results for copiers are similar to those for printers in that only Suspend mode use is affected by the ENERGY STAR program. Savings are about $30 \%$ relative to the 2005 baseline UEC.

Fax machines show about a 50\% reduction in UEC relative to the 2005 baseline, with all of those savings coming from reductions in Standby mode power.

Minicomputer and mainframe UECs have been falling for years, as more and more of the functions previously handled by peripherals are integrated into fewer and fewer chips. Heat is an especially important issue in these machines (it reduces equipment lifetime), and the manufacturers have for this reason pushed to reduce energy use. We therefore expect 2005 baseline machines to show reductions in UECs of greater than $50 \%$ relative to the 1990 stock. UECs in Figure 5 only include direct power use of the computer equipment, and not any associated cooling energy required to keep the machines at their requisite temperatures. As smaller and smaller machines (especially parallel processing machines) take over the tasks previously assigned to large mainframes, the issue of secondary cooling will become less and less important for such computers.

The advanced scenario shows reductions in UECs relative to the ENERGY STAR case of about $75 \%$ for PC CPUs and monitors, $20-40 \%$ for copiers and fax machines, and about $60 \%$ for laser printers and POS terminals. This scenario does not consider costs, so it is only an estimate of what is technically possible, not what is practically or cost-effectively achievable.

\section{Business-As-Usual Energy Use Intensities}

Energy Use Intensities (EUIs) are simply the product of UECs and densities. Figure C-6 shows those intensities. As expected, offices have by far the largest overall intensities, totalling about $24.7 \mathrm{kWh} / \mathrm{square}$ meter/year $(2.3 \mathrm{kWh} / \mathrm{square}$ foot/year) over the analysis period. By 2010, PC CPUs, monitors, and laser printers contribute the lion's share of electricity intensity in offices (this result also holds for hospitals, schools, hotels, and miscellaneous). POS terminals are responsible for the vast majority of energy use intensity in restaurants and groceries, with the share of POS terminals growing substantially in retail 
(from about one quarter in 1990 to more than half in 2010). The contribution of mainframe and minicomputers to energy use intensities is declining substantially over time for all building types, as this equipment is replaced by more powerful desktop units in clientserver installations. Faxes, copiers, and serial printers account for a relatively small proportion of EUI in most building types, though in absolute terms the energy used by these devices can be significant in the aggregate.

\section{Floorspace Projections}

The floor areas by building type over time are given in Figure C-3. Floor area projections for the 1990 to 2010 period are taken from the Annual Energy Outlook 1995 (US DOE 1995a, US DOE 1995b). This source gives projected commercial sector floor area by building type. Retail, offices, miscellaneous, warehouses, and schools are the largest building types, in that order. The aggregate floor area of hotels, hospitals, restaurants, and groceries is significantly smaller than that of the first group of building types.

\section{Equipment Stock}

Multiplying the floor area by the equipment densities gives the total stock in millions of units, as shown in Figure C-4. Results by building type mimic those for densities.

\section{Sales of ENERGY STAR Equipment}

Table 6 contains our estimates of the penetration of ENERGY STAR-compliant office equipment by device type for all ENERGY STAR scenarios. By the year 2001, all devices sold in the US are assumed to meet or exceed ENERGY STAR levels. Copier and fax machine penetrations reflect the later start dates for the programs affecting these device types, but these programs ramp up rapidly.

Table 6: Estimated sales of ENERGY STAR-compliant equipment (\% of sales)

\begin{tabular}{|c|ccccc|}
\hline & $P C$ & Monitor & $\begin{array}{c}\text { Laser } \\
\text { Printer }\end{array}$ & Copier & Fax \\
\hline 1992 & $0 \%$ & $0 \%$ & $0 \%$ & $0 \%$ & $0 \%$ \\
1993 & $15 \%$ & $15 \%$ & $10 \%$ & $0 \%$ & $0 \%$ \\
1994 & $26 \%$ & $26 \%$ & $50 \%$ & $0 \%$ & $0 \%$ \\
1995 & $38 \%$ & $38 \%$ & $90 \%$ & $10 \%$ & $10 \%$ \\
1996 & $49 \%$ & $49 \%$ & $100 \%$ & $20 \%$ & $50 \%$ \\
1997 & $61 \%$ & $61 \%$ & $100 \%$ & $40 \%$ & $100 \%$ \\
1998 & $72 \%$ & $72 \%$ & $100 \%$ & $80 \%$ & $100 \%$ \\
1999 & $83 \%$ & $83 \%$ & $100 \%$ & $90 \%$ & $100 \%$ \\
2000 & $95 \%$ & $95 \%$ & $100 \%$ & $100 \%$ & $100 \%$ \\
2001 & $100 \%$ & $100 \%$ & $100 \%$ & $100 \%$ & $100 \%$ \\
& & & & & \\
\hline
\end{tabular}

Currently only a small fraction of ENERGY STAR CPUs and monitors ship with the power saving features enabled, but this is expected to change because the new ENERGY STAR memorandum of understanding (MOU), which requires all devices to ship enabled, took effect in Fall 1995. We expect that most of the early technical issues surrounding ENERGY STAR equipment will have been overcome by 2000 and that the energy saving features will be built into the equipment as a matter of course. Table 7 shows the percentage of ENERGY STAR Compliant equipment that we assume will be enabled in our various 
ENERGY STAR cases (see below for descriptions and forecasting results for each of these cases). These percentages are applied through the entire forecast period.

Table 7: Percent of ENERgy STAR Compliant Equipment Sold Assumed to be Enabled (By Policy Case)

\begin{tabular}{|c|c|c|c|c|c|}
\hline & \multicolumn{5}{|c|}{ Laser } \\
\hline & $P C$ & Monitor & Printer & Copier & Fax \\
\hline ENERGY STAR - Current Practice Continues & $10 \%$ & $10 \%$ & $100 \%$ & $50 \%$ & $100 \%$ \\
\hline ENERGY STAR - Worst Case & $25 \%$ & $50 \%$ & $100 \%$ & $75 \%$ & $100 \%$ \\
\hline ENERGY STAR - Most-Likely Case & $50 \%$ & $70 \%$ & $100 \%$ & $90 \%$ & $100 \%$ \\
\hline ENERGY STAR - Best Case & $100 \%$ & $100 \%$ & $100 \%$ & $100 \%$ & $100 \%$ \\
\hline
\end{tabular}

\section{RESULTS}

Figure 6a summarizes the results for the Business-As-Usual, ENERGY STAR MostLikely, and Advanced scenarios. It shows commercial sector floorspace, EUI, and TWh/year, normalized to 1990 . Floorspace is projected to grow by $33 \%$ over the 20 year analysis period. EUIs in the Business-As-Usual case go down slightly through the mid$1990 \mathrm{~s}$, and are stable through the rest of the analysis period. Total TWh growth by 2010 is less than the growth in floorstock because of the decline in EUIs.

Figure 6b shows the same trends for office equipment without mainframes or minicomputers. This figure reveals that the decline in overall EUI in the mid- to late-1990s is caused entirely by declines in the energy used by the larger computers. EUIs for the other equipment are growing rapidly through the late 1990s, and total energy is experiencing substantial growth throughout the analysis period.

The ENERGY STAR Most-Likely case, total office equipment EUIs decline about $30 \%$ by 2000 and are roughly constant after that time. This decline in EUIs is enough to keep total office equipment energy consumption at about 1990 levels through the year 2010.

The Advanced case, which illustrates the outer range of technological options without regard to cost, shows declines in EUI of more than $50 \%$ by just after 2000 . This decline is more than enough to compensate for the growth in commercial floor space, resulting in total energy use in 2010 of about $55 \%$ of 1990 levels. This level of energy use probably represents a lower bound to office equipment energy use in 2010, barring drastic changes in the equipment sales forecasts described above or large improvements in technology beyond those assumed in this scenario. 
Figure 6a: Normalized Trends in Floorspace, EUI, and Annual Energy Use

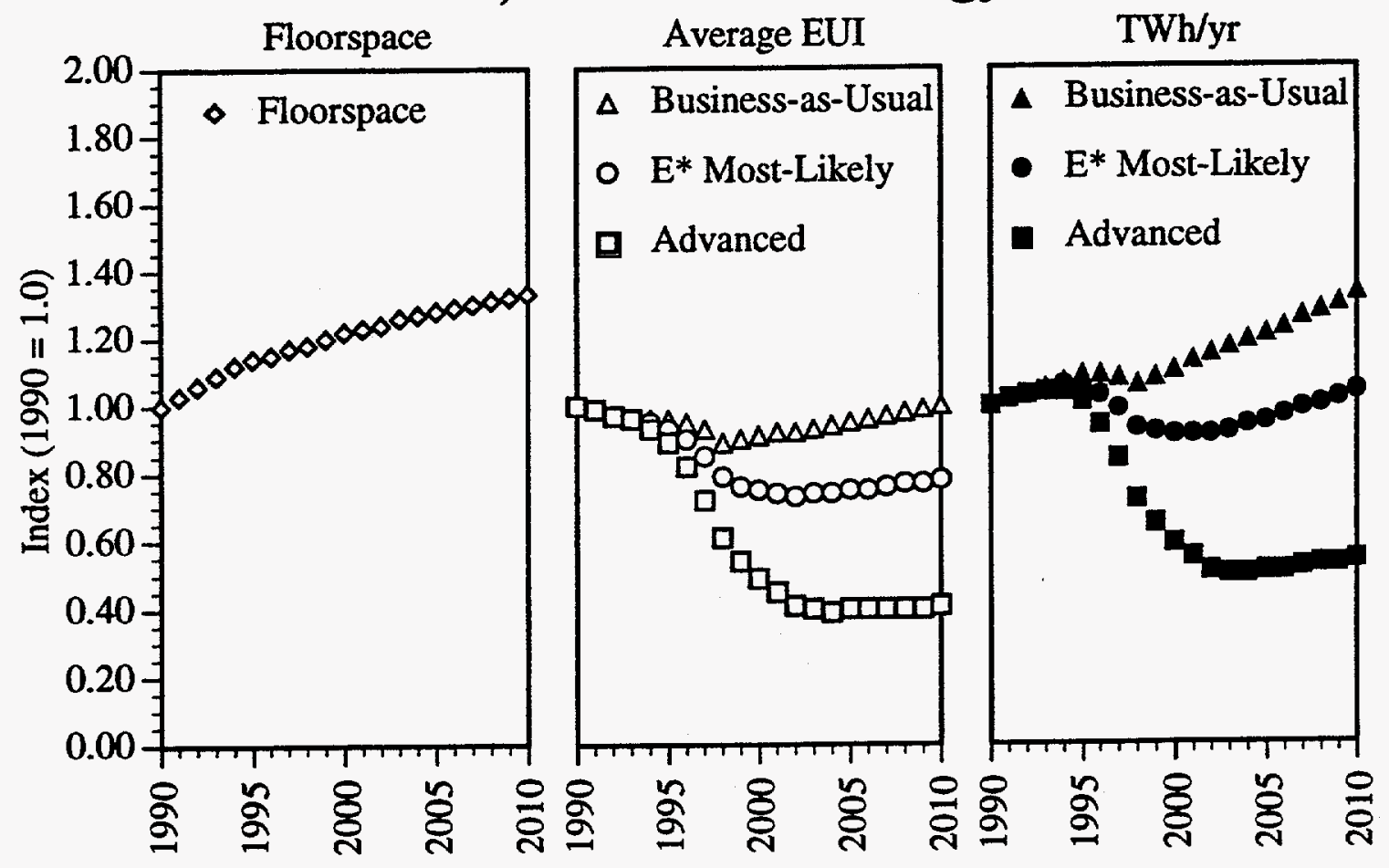

Figure 6b: Normalized Trends in Floorspace, EUI, and Annual Energy Use Without Mainframes or Mini-Computers

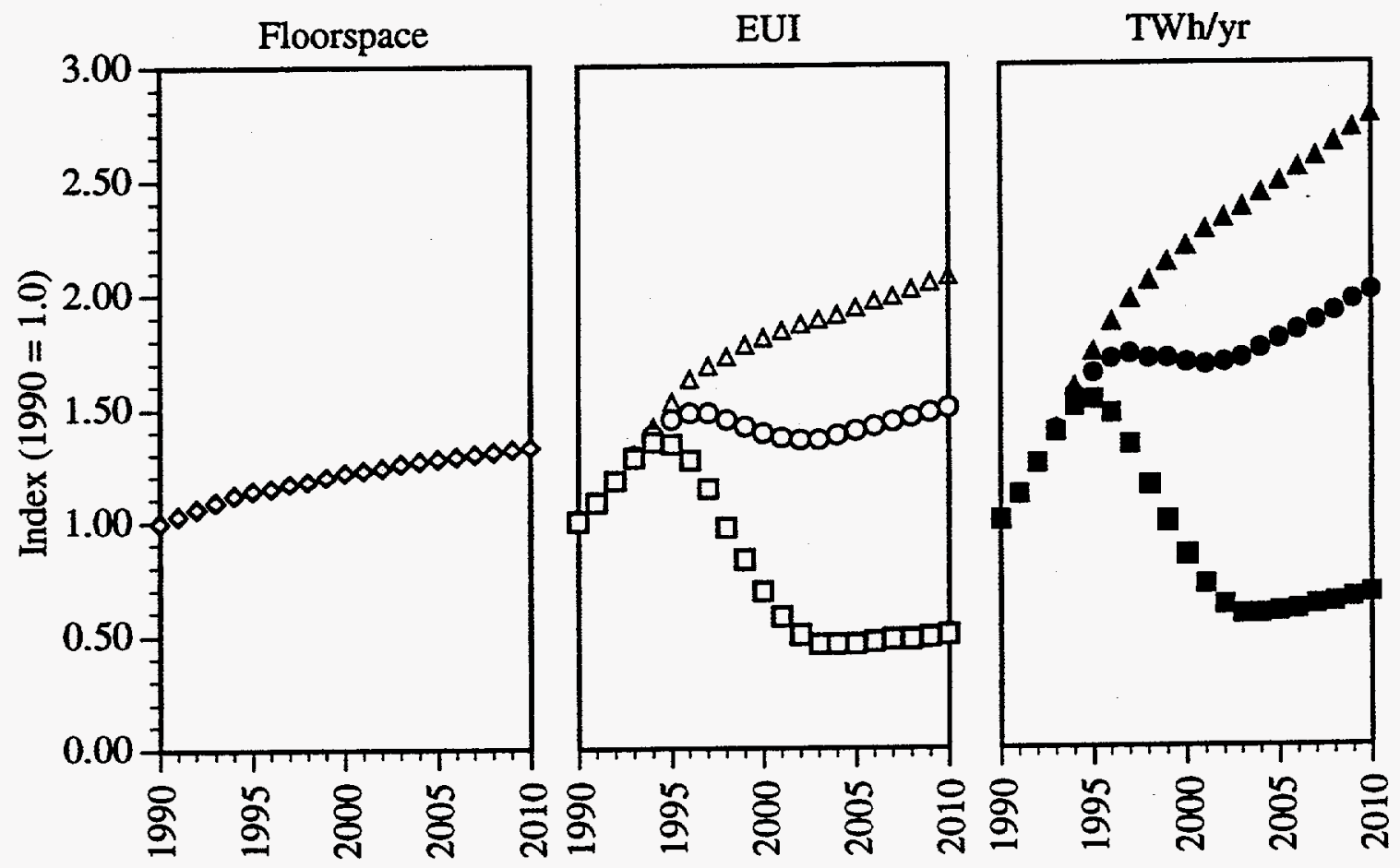

Average EUI equals TWh/yr divided by total floorspace. 


\section{Effect of ENERGY STAR Most-Likely and Advanced Scenario Assumptions}

Figure 7 shows the projected annual electricity use by equipment type for the baseline, ENERGY STAR Most-Likely, and Advanced cases. PC CPUs and monitors together comprise about one-third of the projected energy use in 2000 and 2010. Mainframe and minicomputer energy use declines by more than $50 \%$ from 1990 to 2000 , and remains roughly constant in absolute terms from 2000 through 2010.

Total annual savings attributable to the ENERGY STAR program are about 17 TWh in 2010. The Advanced case reduces total electricity use by about a factor of two relative to the ENERGY STAR Most-Likely case in 2010. Annual savings in electricity expenditures are about 1.4 billion 1995\$/year in 2010 for the ENERGY STAR Most-Likely case, and an additional 2.3 billion 1995\$/year for the Advanced case relative to the ENERGY STAR MostLikely case.

Figure 8 shows the breakdown of electricity savings by equipment type in 2010 . We show savings of the ENERGY STAR Most-Likely case relative to the Business-as-usual baseline, and savings of the Advanced case relative to the ENERGY STAR Most-Likely case. PC CPUs, monitors, and laser printers together account for about two-thirds of the energy savings attributable to the ENERGY STAR program, with faxes and copiers making up the remainder. About three-quarters of the savings of the Advanced case relative to the ENERGY STAR Most-Likely case are attributable to Monitors, PC CPUs, and POS terminals.

Figure 9 shows the percentage savings within each equipment type in the ENERGY STAR Most-Likely case. Laser printers show the largest savings, with ENERGY STAR printers saving about 55\% relative to baseline energy use. Faxes show savings of about 40 to $45 \%$, PC CPUs and monitors show savings of 20 to $25 \%$, and copiers show savings of 15 to $25 \%$. These results combine the effect of reduced UECs, the gradual ramping-up of the program, and the less than $100 \%$ enabling rates in Table 7.

Figures $C$ - 10 and $C$ - 11 summarize the annual energy use by building type in the Businessas-Usual and ENERGY STAR cases, respectively. PC CPUs, monitors, and printers dominate office equipment energy use in most building types, with POS terminals dominating in Retail, Restaurants, and Groceries. By 2000, the ENERGY STAR program has actually reduced or kept approximately constant office equipment energy use in all building types. Slight growth occurs in most building types over the 2000 to 2010 period. The building types that show growth over the 1990 to 2010 period in the ENERGY STAR case are those in which POS terminals (which are not subject to ENERGY STAR) are the dominant equipment type (Retail, Restaurants, and Groceries). This result suggests that EPA should explore expanding ENERGY STAR to include this equipment type. 
Figure 7: Comparison of Annual Electricity Use for US Office Equipment by Equipment Type in Business-AsUsual, ENERGY STAR, and Advanced Scenarios

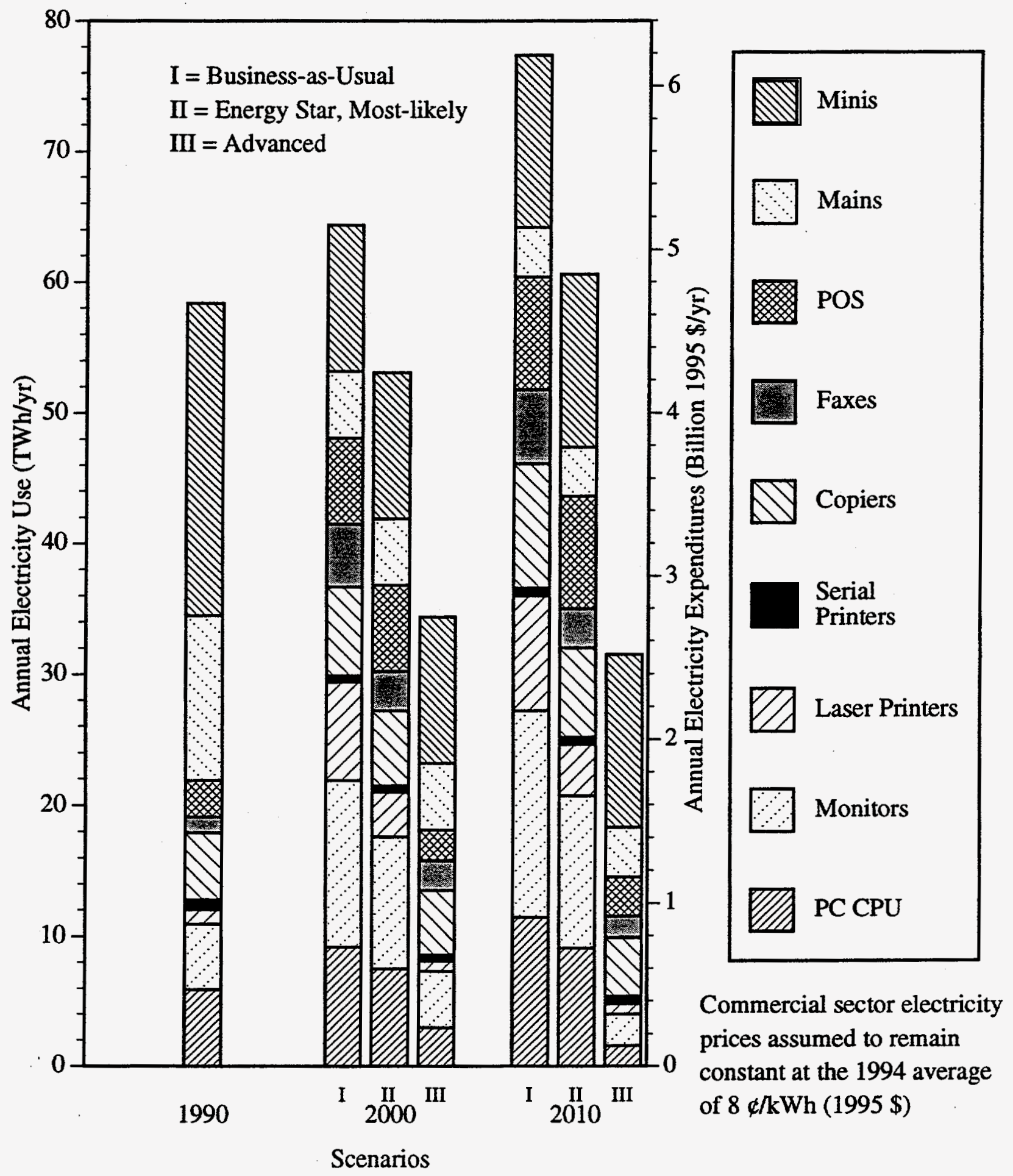




\section{Figure 8: Percentage of Total Electricity Savings by Equipment Type in 2010}

Savings from the ENERGY STAR Most-Likely case relative to the Business-as-Usual case

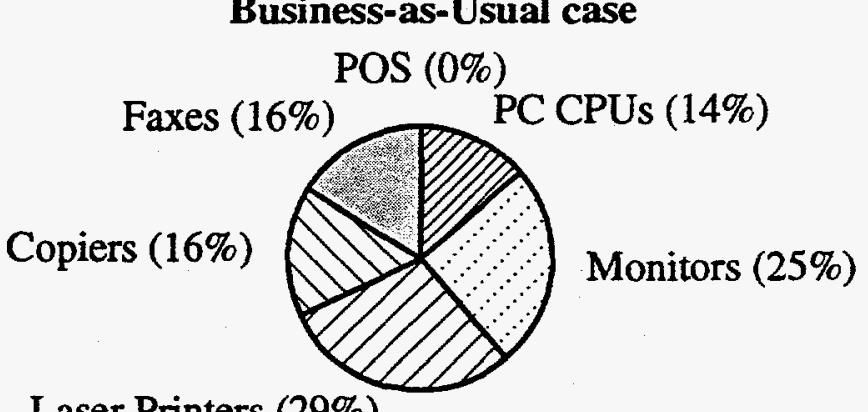

Laser Printers (29\%)

Total savings $=17 \mathrm{TWh}$

Savings from the Advanced case relative to ENERGY STAR MostLikely case

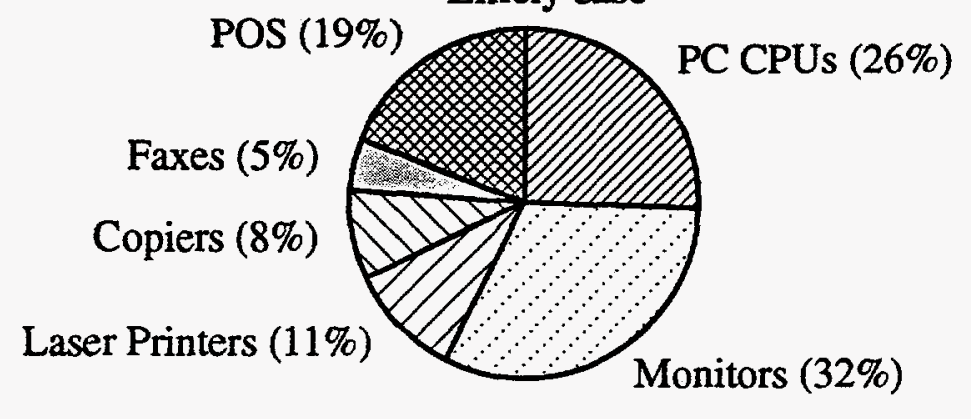

Total savings $=29 \mathrm{TWh}$ 
Figure 9: Savings by Equipment Type in the Energy Star MostLikely Case as a Percentage of Baseline Electricity Use

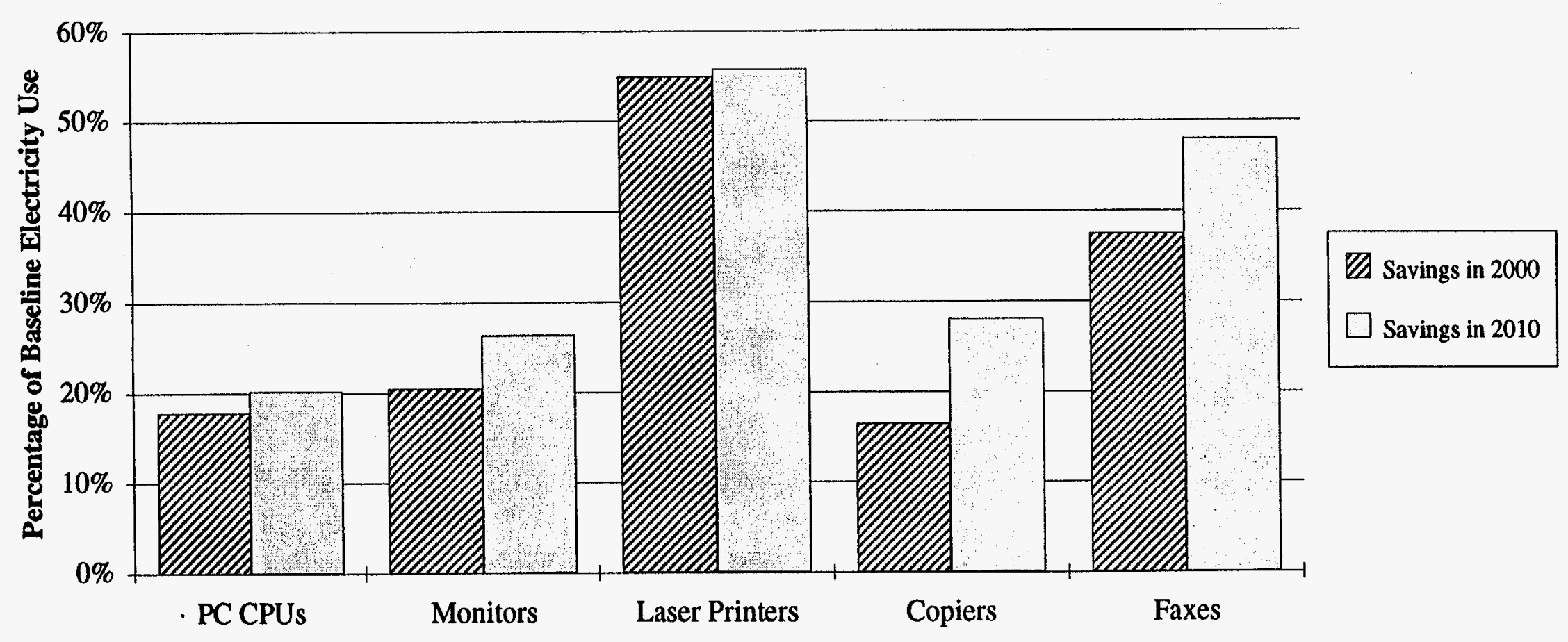




\section{Uncertainties in the Savings Calculations}

Figure 10 shows the results for six scenarios that account for the significant uncertainties in the estimation of savings from the ENERGY STAR program:

(I) Business-as-Usual case-this scenario assumes that ENERGY STAR and related Federal procurement policies for office equipment do not exist. In this case, annual electricity consumption grows by about 30\% over 1990 levels by 2010 .

(II) ENERGY STAR Current Practice Continues case-This scenario assesses the effect if current levels of enabling of ENERGY STAR equipment is unchanged in the future (see Table 7 for the enabling assumptions by equipment type). The annual savings in 2000 relative to the Business-as-Usual case are about 6 TWh and grow to about 10 TWh by 2010 . These annual savings are worth $\$ 500$ to $\$ 800$ million per year $(1995 \$)$ at current commercial sector electricity prices.

(III) ENERGY STAR Worst case-This case assumes that enabling of ENERGY STAR compliant equipment improves somewhat over the Current Practice Continues case (see Table 7) but that two additional factors increase energy use. First, we add the assumption of Minimum ENERGY STAR Compliance, in which the suspend power levels of PCs, monitors, and printers are $30 \mathrm{~W}$ instead of the lower values that manufacturers have achieved to date. Second, we assume that ownership of ENERGY STAR equipment lulls many users into believing that they do not need to turn their equipment off when they leave the office. We model this situation by assuming that twice the number of ENERGY STAR PC CPUs, monitors, and printers are left on at night and on the weekend than currently are. This case results in savings of $6 \mathrm{TWh} /$ year in 2000 and about $10 \mathrm{TWh} /$ year in 2010, which is about the same as for the Current Practice Continues case.

(IV) ENERGY STAR Most-Likely case-This scenario is our main ENERGY STAR case: About half of the ENERGY STAR PC CPUs are assumed to be enabled, as are 70\% of the monitors, $90 \%$ of the copiers, and $100 \%$ of the fax machines and laser printers (see Table 7). It results in annual savings of $11 \mathrm{TWh}$ in 2000 and $17 \mathrm{TWh}$ in 2010, savings that are worth 900 million $1995 \$$ year and 1.4 billion $1995 \$$ year for 2000 and 2010 , respectively.

(V) ENERGY STAR Best case-This Scenario assumes that 100\% of ENERGY STAR compliant equipment is enabled and that the program leads to behavioral changes that reinforce the energy savings attributable directly to the purchase of the more efficient equipment. It assumes that the ENERGY STAR program raises the awareness of all consumers about energy use, and reduces nightime and weekend diversity by about $75 \%$ (the assumption implies that $75 \%$ of owners of ENERGY STAR equipment who would not otherwise have done so turn off that equipment when they leave work). This case results in savings of $16 \mathrm{TWh} / \mathrm{year}$ in 2000 and about $23 \mathrm{TWh} / \mathrm{year}$ in 2010 . The savings are worth about 1.3 billion $1995 \$$ year and 1.8 billion $1995 \$ /$ year for 2000 and 2010 , respectively.

(VI) Advanced case-This case estimates office equipment electricity use assuming that best current technology is used regardless of economics. It results in savings beyond the ENERGY STAR Most-Likely case of about $18 \mathrm{TWh} / \mathrm{year}$ by 2000 and 29 TWh/year by 2010 . These savings are worth an additional 1.4 billion $1995 \$$ year and 2.3 billion $1995 \$$ year for 2000 and 2010 , respectively. 
Figure 10: Projected Annual Electricity Use and Electricity Expenditures for US Office Equipment, Sensitivity Analysis

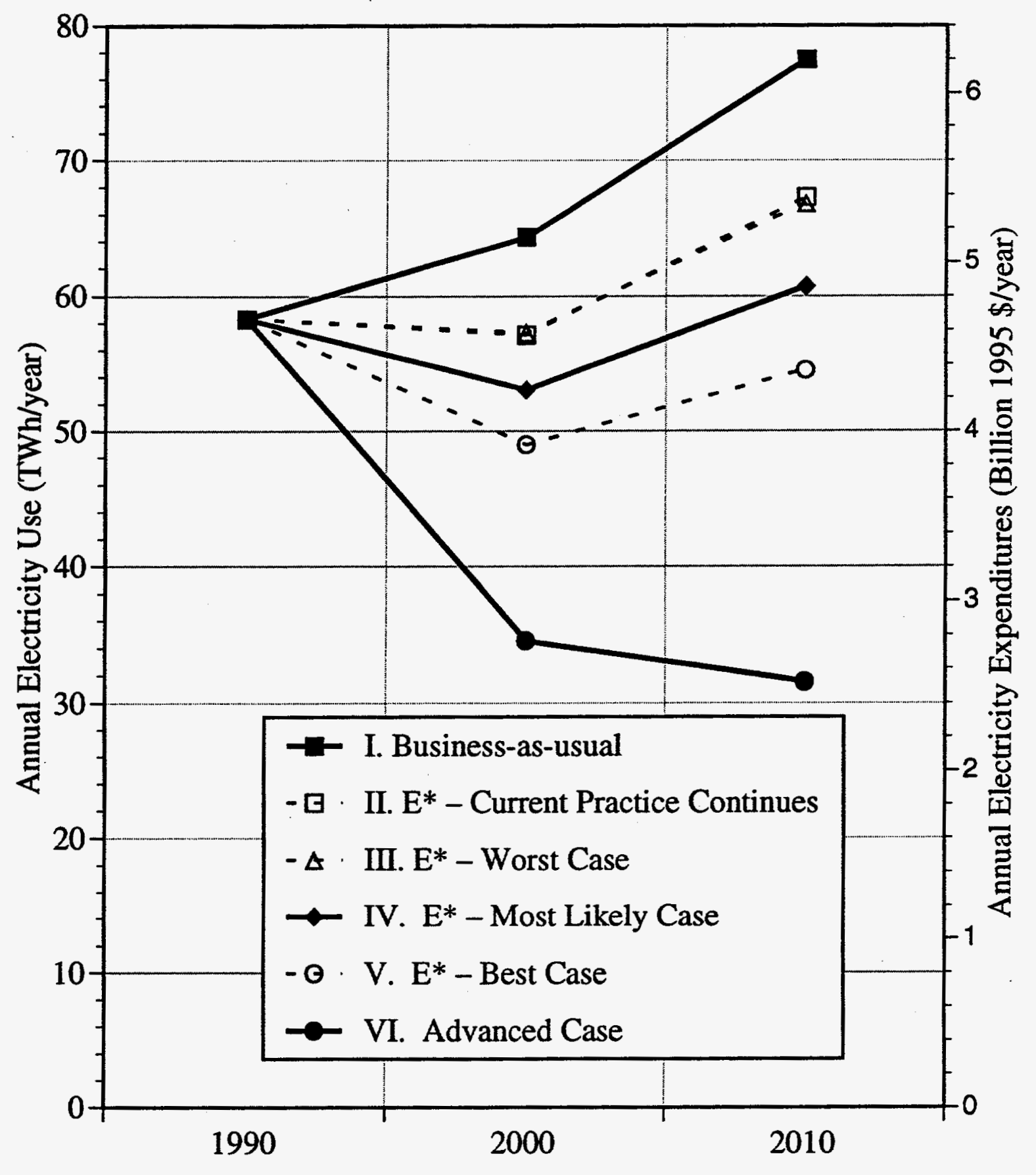


These calculations do not count any savings that will accrue in office equipment used in residences or in the industrial sector, nor do they count the savings in other countries that copy the ENERGY STAR regulations to harmonize their office equipment markets with that of the US. ${ }^{3}$ We also do not calculate the paper savings from the ENERGY STAR copier program or the benefits from reduced pollutant emissions, but the existence of these "spillover benefits" in other sectors implies that our Worst case/Current Practice estimates represent an absolute lower bound on expected savings. Actual savings for the US and for the world are almost certain to be larger than this lower bound.

\section{DISCUSSION}

\section{Cost effectiveness of ENERGY STAR Program}

The analysis above demonstrates that savings from the ENERGY STAR program are likely to be significant in both energy and dollar terms. However, the following components of cost-effectiveness need to be addressed to determine whether the ENERGY STAR policy is beneficial to society:

1) Direct costs of modifying the equipment and software to meet the ENERGY STAR Criteria: Extensive discussions with manufacturers during the design of the program showed that ENERGY STAR features could be added to PC CPUs and monitors at negligible cost to the purchaser (Johnson and Zoi 1992). Examination of data from a recent trade article showed that there was no cost difference between color monitors with powermanagement features and those without (Froning 1994). Data on direct costs for other equipment types are not available, but because the ENERGY STAR program is voluntary, and because the office equipment industry is highly competitive, it is reasonable to believe that manufacturers will not subscribe to program requirements that will increase costs to consumers and place the manufacturer at a competitive disadvantage.

The one case where we might expect additional costs for ENERGY STAR equipment would be copiers (because of the duplexing requirement for high speed copiers). Even here, however, the additional costs imposed by the program are likely to be small or negligible, because "almost all" such high speed copiers already have duplexing capability (Graff and Fishbein 1991). The main effect of requiring default duplexing is paper savings, which (at about 0.5-0.7 cents/sheet saved) would offset some or all of any additional cost for those few high speed copiers that do not already have duplexing. Mailing and storage savings for duplexed material can be even more significant than the initial cost to purchase the paper.

2) Indirect costs imposed on the user by equipment that does not work as advertised: Some manufacturers' early ENERGY STAR-compliant PC CPUs and monitors interfered with network services. Others take more than a second or two to return to a usable state from the sleep mode. We assume that the problems associated with the first incarnation of the program will have been eliminated by 2000 . This assumption is reasonable because the product life-cycles are so short in the computer industry, the new MOUs for PC CPUs and monitors (as well as MOUs for other equipment types) explicitly address these problems,

\footnotetext{
${ }^{3}$ Recent discussions at the International Energy Agency indicate that many European countries and Japan are likely to adopt the Energy Star requirements for office equipment purchased within their boundaries. Personal communication with James E. McMahon, Lawrence Berkeley Laboratory. 5 June 1995.
} 
and the manufacturers can more effectively incorporate power saving features into their equipment as they gain experience with the early versions of ENERGY STAR equipment.

3) Direct administrative costs of the program: The cumulative cost to the government for running this program is at most a few million dollars.

3) The expected direct dollar savings to consumers: we assess this above in the ENERGY STAR Most-Likely case as more than $\$ 1$ billion annually after the year 2000 (excluding paper savings). Even in the Worst/Current Practice Continues cases, savings are more than $\$ 0.5$ billion/year after 2000 . In the Best case, savings are more than $\$ 1.3$ billion/year after 2000

4) The dollar value of the external costs associated with emissions of criteria pollutants and greenhouse gases avoided by the energy savings: we do not assess these potential impacts here, but they make the policy more cost effective than it would be based simply on the expected direct dollar savings to consumers.

Adding these costs and benefits together reveals that this policy will save more than $\$ 1$ billion annually after the year 2000 , at a cumulative cost to society of a few million dollars. Put another way, a one-time per capita expenditure of roughly $\$ 0.02$ in the US has purchased annual monetary benefits per capita of about $\$ 4 /$ year for each and every US resident.

\section{The US Market for PCs, Monitors, Fax Machines and Laser Printers}

We found in our analysis of device densities per person that sales of PC CPUs, monitors, fax machines and laser printers in offices are likely to saturate over the next five to ten years. Assuming, as we do in this analysis, that relative densities between building types remain constant at 1988 levels, it is likely that sales to the entire commercial sector will saturate over the same period. This result may take longer to occur if densities of office equipment in other building types grow at a faster pace than in offices.

In any case, the industry forecasts seem to indicate higher levels of sales of this equipment than can be sustained based on sales to the commercial sector alone. If sales to homes and industry are assumed to make up the difference, then the computer industry can stave off the effect of this maturing market for a few more years. However, an inevitable slowdown in sales will occur when these markets also saturate. A shakeout will then ensue, with the larger international companies that have footholds in growing markets (Asia and to a lesser extent, Europe) being best able to weather the storm.

\section{Mainframes and Minicomputers}

We project that mainframe and minicomputer energy use will decline by more than $50 \%$ over the 1990 to 2000 period. This decline is entirely the result of a decrease in power levels for these machines. Equipment densities for mainframe computers remain roughly constant from 1990 to 2000 , while densities of minicomputers go up by almost $30 \%$. This growth in number of units is more than offset by a 60 to $65 \%$ reduction in per unit power (see Table 1 above). These estimates reflect current trends as embodied in industry projections, and include a substantial shift towards client-server computing and less energy-intensive parallel processing machines (Reinhardt 1995). The data on current densities and equipment power for these devices is relatively poor, and the characteristics of particular installations can vary by two orders of magnitude. Such variations and uncertainties highlight the need for further research and data collection in this area. 


\section{POS Terminals}

POS terminals account for 6.6 to $8.6 \mathrm{TWh} /$ year of electricity consumption in the 2000 to 2010 period. If these terminals were improved to the levels shown for our "advanced" equipment (about $60 \%$ savings in UEC relative to the baseline) then savings would be 4.3 to $5.6 \mathrm{TWh}$, which would add about $30 \%$ to the savings already attributable to ENERGY STAR by 2010. EPA should consider developing an ENERGY STAR program for these devices because of this untapped savings potential.

\section{Advanced Technology}

This scenario assumes the universal penetration of a variety of advanced technologies throughout the office equipment stock. These technologies include the use of Liquid Crystal Display (LCD) technologies in place of Cathode Ray Tubes (CRTs), the use of low power Complementary Metal Oxide Semiconductor (CMOS) chips, and a variety of other options. We show this scenario to characterize the outer bounds of what is possible given current technology, but it would be foolhardy to insist that these outer bounds will remain so for very long. This scenario does not, of course, deal with what is economically justified, only what is technically possible. The results do indicate that there is a technical potential for significant savings even beyond the ENERGY STAR Most-Likely case. The challenge is to achieve those savings at competitive costs.

One recent note regarding LCD screens deserves mention, because that technology is the one assumed for monitors in our Advanced scenario. Prices for these screens (now used almost exclusively in laptops) have been falling rapidly. Over the calender year 1995, prices for 10.4 inch active matrix screens dropped from over $\$ 1000$ to about $\$ 350$ (Crothers 1995). This price drop was caused by improvements in production processes and an increase in manufacturing capacity.

Several manufacturers are now producing larger screens that approach the usable screen area of the most common CRT systems, and the prices of these screens are also falling. One manufacturer (Sharp) is explictly targeting its larger LCD screens at the desktop monitor market, starting in 1996 (Crothers 1996). Only time will tell if these efforts are successful, but the inherent advantages of LCD screens (compact size, low mass, negligible electromagnetic emissions, and low power consumption) will make them attractive options if the price can be brought within about a factor of two of CRT screens.

\section{Comparison with Annual Energy Outlook 1995 Office Equipment Forecast}

Table 8 compares our analysis results to the commercial sector office equipment forecast contained in the Annual Energy Outlook 1995 of the US Department of Energy's (DOE's) Energy Information Administration (US DOE 1995a). This forecast is the current Business-as-Usual forecast of DOE. As the Table shows, AEO's early 1990s estimate for PC plus monitor energy use is more than four times higher than that calculated in this study's Business-as-Usual baseline. Non-PC energy use in the early 1990s is about $30 \%$ higher in the AEO's forecast than in our forecast. By 2010 the differences between the two forecasts have stayed about the same (PCs and monitors) or increased substantially (other office equipment).

It is not clear from the documentation if the AEO forecast is meant to capture the effects of all existing programs such as ENERGY STAR. Even if ENERGY STAR impacts are not included, the EIA estimate is too high in absolute terms for all equipment types and in expected growth rates over the 1993 to 2010 period for other office equipment. 


\begin{tabular}{|c|c|c|c|c|c|c|c|c|}
\hline & 1990 & 1993 & 2000 & 2010 & $2010 / 1993$ & $2010 / 2000$ & $\begin{array}{c}\text { \% annual } \\
\text { growth } \\
1993 \text { to } 2010\end{array}$ & $\begin{array}{c}\text { \% annual } \\
\text { growth } \\
2000 \text { to } 2010\end{array}$ \\
\hline \multicolumn{9}{|l|}{ This study (Business-as-usual) } \\
\hline Office equipment (PCs) & 11 & 14 & 22 & 27 & 1.92 & 1.24 & $3.9 \%$ & $2.2 \%$ \\
\hline Office equipment (non-PCs) & 47 & 46 & 42 & 50 & 1.09 & 1.18 & $0.5 \%$ & $1.7 \%$ \\
\hline Total & 58 & 60 & 64 & 77 & 1.29 & 1.20 & $1.5 \%$ & $1.9 \%$ \\
\hline \multicolumn{9}{|l|}{ This study (Energy Star "Most Likely") } \\
\hline Office equipment (PCs) & 11 & 13 & 18 & 21 & 1.61 & 1.18 & $2.8 \%$ & $1.6 \%$ \\
\hline Office equipment (non-PCs) & 47 & 44 & 35 & 40 & 0.91 & 1.13 & $-0.5 \%$ & $1.2 \%$ \\
\hline Total & 58 & 57 & 53 & 61 & 1.07 & 1.14 & $0.4 \%$ & $1.3 \%$ \\
\hline \multicolumn{9}{|l|}{ Annual Energy Outlook 1995} \\
\hline Office equipment (PCs) & N/A & 59 & 73 & 97 & 1.65 & 1.32 & $3.0 \%$ & $2.8 \%$ \\
\hline Office equipment (non-PCs) & N/A & 62 & 76 & 97 & 1.57 & 1.27 & $2.7 \%$ & $2.4 \%$ \\
\hline Total & N/A & 120 & 149 & 193 & 1.61 & 1.29 & $2.8 \%$ & $2.6 \%$ \\
\hline \multicolumn{9}{|l|}{ Indices (this study's baseline $=1.0$ ) } \\
\hline \multicolumn{9}{|l|}{ This study } \\
\hline Office equipment $(\mathrm{PCs})$ & 1.00 & 1.00 & 1.00 & 1.00 & & & & \\
\hline Office equipment (non-PCs) & 1.00 & 1.00 & 1.00 & 1.00 & & & & \\
\hline Total & 1.00 & 1.00 & 1.00 & 1.00 & & & & \\
\hline \multicolumn{9}{|l|}{ This study (Energy Star "Most Likely") } \\
\hline Office equipment (PCs) & 1.00 & 0.91 & 0.81 & 0.76 & & & & \\
\hline Office equipment (non-PCs) & 1.00 & 0.95 & 0.84 & 0.79 & & & & \\
\hline Total & 1.00 & 0.94 & 0.83 & 0.78 & & & & \\
\hline \multicolumn{9}{|l|}{ Annual Energy Outlook 1995} \\
\hline Office equipment (PCs) & & 4.15 & 3.36 & 3.56 & & & & \\
\hline Office equipment (non-PCs) & & 1.34 & 1.79 & 1.92 & & & & \\
\hline Total & & 2.00 & 2.32 & 2.50 & & & & \\
\hline
\end{tabular}

(1) 1993 values for this study interpolated linearly from 1990 and 2010 values

(2) We assume that PCs in the AEO context means PCs and monitors. 
If ENERGY STAR is meant to be included in the AEO forecast, then these differences are further exacerbated. In any case, the baseline AEO forecast should be adjusted (especially in the early years) to reflect the more detailed work described in this study, and the estimated impacts of ENERGY STAR should be explicitly shown (at least in a side calculation). 4

\section{FUTURE WORK}

\section{Mainframe and Minicomputers}

As we saw in our scenario results, some of the largest uncertainties in estimating total future electricity use for office equipment are introduced when estimating the future power and equipment densities for mainframe and minicomputers. Relatively little is known about changes in the characteristics of these devices over time. In particular, representative surveys of device densities in particular building types and of power levels for different devices need to be conducted so that utility planners can better understand how changes in office equipment energy use will affect their planning.

\section{POS Terminals}

Data are also poor for this equipment type. ITI does not forecast sales for these devices, and they vary widely in their configurations. Nevertheless, this equipment is an important energy user in certain building types (principally retail, restaurants, and groceries). Surveys of these devices should identify the relevant densities, power levels, and operating characteristics.

\section{Secondary HVAC Impacts}

Saving energy in office equipment will also affect space conditioning energy used in buildings (Sezgen and Huang 1994). Heating energy use will go up to compensate for the reduced internal gains, and cooling energy use will go down. Ventilation energy will generally go down as well because of these changes. The issue is a complex one because these effects vary regionally, by building type, and by equipment type. Preliminary calculations for large offices show average additional savings attributable to energy star of between 10 and $25 \%$ of direct savings in primary energy terms, with the lower savings accruing in Northern US (heating dominated) buildings and the higher savings accruing in the cooling-dominated buildings located in the Southern US (Cramer 1995). Further work is needed to assess these impacts for all building types and common equipment combinations.

\section{Office Equipment Densities and Stocks}

As we saw above, the estimates of total office equipment stock in all sectors are subject to significant uncertainty. More surveys are needed, especially in homes and in commercial sector building types outside of offices. Our assumption of a fixed relationship between equipment densities in offices and those in other commercial building types is a critical one that needs validation from stock surveys over time. The computer industry has an interest

\footnotetext{
${ }^{4}$ Steve Wade of EIA has indicated (after reviewing a draft of this report) that EIA is in the process of revising their Annual Energy Outlook 1996 forecast to better reflect our results.
} 
in such surveys because a saturating market affects their own sales forecasts and pricing strategies in a significant way.

\section{Paper savings}

There are direct cost savings (typically $0.5-0.7 \not /$ sheet), mailing and storage cost savings, and indirect energy savings (typically 20 Watt-hours/sheet) associated with ENERGY STAR copiers that are not assessed here. More work is needed on the effect of the default duplexing feature on total paper use.

\section{Multifunction Devices}

Recently, attention has been garnered in the media by machines that combine various functions. For example, several manufacturers have created combination fax/printers/copiers/scanners that are mainly targeted towards budget-conscious small business owners. Also, there are several printers that have an add-on device that allows the user to send and receive faxes on what was before simply a laser printer.

We do not account for widespread penetration of these combination devices in our main scenario calculations, in large part because we have no industry source for the expected penetration. There will be energy savings from the use of these combination devices to the extent that the fixed standby losses that would have been incurred for each of the separate devices are now reduced to the losses from one such device. On the other hand, the device must now operate 24 hours per day, where at least some of the separate devices might have been turned off at certain times.

Further, many of the people purchasing these multifunction devices might not have had some of the individual devices before, which implies that the level of service delivered to each of these consumers is increased compared to the case where these multi-function devices were not available. This increase in service is difficult to measure, but its importance cannot be discounted in assessing the future impacts of changes in device characteristics.

As these multifunction machines become more common, surveys are needed of their operating characteristics, power levels, and device densities. In addition, it will be important to differentiate between use of these devices in large businesses, small businesses, and homes. After we collect three to five years of sales data it will be possible to assess the trends to determine the likely impacts of the adoption of multifunction devices.

\section{CONCLUSIONS}

While energy use for this equipment has grown rapidly in recent years, this growth is likely to slow in the next decade because the US commercial sector market is becoming saturated (especially for PC CPUs and monitors). Significant uncertainties remain in creating such forecasts, particularly related to energy used in mainframe and minicomputers.

The likely energy and dollar savings in the commercial sector from the ENERGY STAR program are significant on a national scale. Total electricity savings will be between 10 and $23 \mathrm{TWh} /$ year in 2010 , and will most likely be about $17 \mathrm{TWh} / \mathrm{year}$ by 2010 . This level of savings represents the annual output of three $1000 \mathrm{MW}$ power plants, and results in net benefits to society exceeding $\$ 1$ billion per year after the year 2000 . Significant additional savings may be achieved from advanced technologies if these technologies can be reduced in cost from current levels. 


\section{ACKNOWLEDGEMENTS}

We are grateful to Richard Jones of the Office of Building Technologies, US Department of Energy, for funding this work, and to Norine Karins of New York State Energy Research and Development Authority (NYSERDA) and Mike Walsh of Consolidated Edison Co. for funding the New York Study. Special thanks to Cyane Dandridge (formerly of the US Environmental Protection Agency), and Jeff Harris (Ernest Orlando Lawrence Berkeley National Laboratory) for their ongoing assistance. Copious review comments were also provided by Bruce Nordman, Florentin Krause, and Jim McMahon of LBL, Steve Wade of EIA, and Dave Belzer of Pacific Northwest National Laboratory. We also wish to thank Amey Moot (formerly at Thinking Machines) for helping us to track down information on mainframe and minicomputer energy use.

This work was supported by the Assistant Secretary for Energy Efficiency and Renewable Energy, Office of Building Technologies of the U.S. Department of Energy under Contract No. DE-AC03-76SF00098. 


\section{REFERENCES}

Acquaviva, T., and G. C. Hartman. 1993. Survey of Energy and Power Usage in Copiers, Duplicators, and Electronic Reprographic Devices. Xerox Corporation, Webster, NY.

ADM Associates Inc. 1990. Commercial Energy Use Survey in the SMUD Service Territory. Prepared for the California Energy Commission and the Sacramento Municipal Utility District. November.

ADM Associates Inc. 1992. Primary Documentation for the Pacific Northwest NonResidential/ Commercial Energy Consumption Survey (PNNonRES), Data Management Plan for Phase II. Prepared for the Bonneville Power Administration, under contract DE-AC79-85BP23671. February.

Arthur D. Little Inc. 1993. Characterization of Commercial Building Appliances. Prepared for the Building Equipment Division, Office of Building Technologies, U.S. Department of Energy.

CBEMA. 1994. Information Technology Industry Data Book 1960 - 2004. Industry Marketing Statistics, Computer and Business Equipment Manufacturer's Association, Washington, DC.

Cramer, Michael. 1995. Secondary Savings of the Energy Star Program. M.S., Department of Mechanical Engineering Thesis, University of California, Berkeley.

Crothers, Brooke. 1995. "Color LCDs to ease notebook pricing: Active matrix screens are more plentiful, cheaper". InfoWorld. November 20, 1995. p. 12.

Crothers, Brooke. 1996. "Sharp, NEC, and IBM plan screen upgrades: Notebooks to get displays that match desktop-quality monitors". InfoWorld. December 25, 1995/January 1, 1996. p. 21.

Dandridge, Cyane B. 1994. Energy Efficiency in Office Technology. Masters Thesis, Massachusetts Institute of Technology.

Dataquest. 1993. The Green PC Revolution: Focus Report 1993. Dataquest Inc. PCISWW-FR-9301. October 11, 1993.

Froning, A. J. 1994. "Lab Report: 70 Color Monitors". Byte. January. p. 202.

Graff, Robert, and Bette Fishbein. 1991. Reducing Office Paper Waste. INFORM; NY, NY.

IRS. 1989. Depreciation: Table of Class Lives and Recovery Periods. Internal Revenue Service. Publication 534.

Johnson, Brian J., and Catherine R. Zoi. 1992. "EPA Energy Star Computers: The Next Generation of Office Equipment." In Proceedings of the 1992 ACEEE Summer Study on Energy Efficiency in Buildings. Asilomar, CA: American Council for an Energy Efficient Economy. 
Ledbetter, M, and L. Smith. 1993. Guide to Energy-Efficient Office Equipment. Washington, DC: American Council for an Energy-Efficient Economy, prepared for the Office Technology Consortium.

Lovins, Amory, and H. Heede. 1990. Electricity-Saving Office Equipment. Competitek/Rocky Mountain Institute. September.

McMahon, James E., Mary Ann Piette, and Johanna Kollar. 1995. Office Equipment: Market Characteristics, Energy Use, and Standards Harmonisation. Prepared for the International Energy Agency. April.

Michaels, Harvey, John DaSilva, and William Gould. 1990. "Electronic Equipment Load Growth (Study prepared by Xenergy for Consolidated Edison Company, Inc. of New York)." In Proceedings of the 1990 ACEEE Summer Study on Energy Efficiency in Buildings. Asilomar, CA: American Council for an Energy Efficient Economy.

Nadel, Brian. 1994. "Energy Star PCs, Power to the PC". PC Magazine. April 26, 1994.

Newsham, G., and D. Tiller. 1994. The Energy Conservation Potential of Power Management for Fax Machines. Institute for Research in Construction, National Research Council of Canada; prepared for the Canadian Electrical Association in Montreal, Quebec. June.

Norford, Les, A. Hatcher, Jeffrey Harris, Jacques Roturier, and O. Yu. 1990. "Electricity Use in Information Technologies." In Annual Review of Energy 1990. Edited by J. M. Hollander. Palo Alto, CA: Annual Reviews, Inc.

NUTEK. 1995. Market Survey: Introducing Energy Conservation Functions in Sweden. AB Stelacon Konsult for the NUTEK Department of Energy Efficiency. February/March.

Piette, Mary Ann, Mike Cramer, Joe Eto, and Jonathan Koomey. 1995. Office Technology Energy Use and Savings Potential in New York. Completed for the New York State Energy Research and Development Authority and Consolidated Edison by Lawrence Berkeley Laboratory. Contract \#1955-EEED-BES-93, also LBL-36752. January.

Reinhardt, Andy. 1995. "Your Next Mainframe". Byte. May. p. 48.

Rose, Manning. 1993. Personal Communication: "Discussion about POS terminals with MaryAnn Piette". NCR. November.

Sezgen, Osman, and Y. Joe Huang. 1994. "Lighting/HVAC Interactions and Their Effects on Annual and Peak HVAC Requirements in Commercial Buildings". Presented at ACEEE 1994 Summer Study on Energy Efficiency in Buildings in Asilomar, CA. Published by American Council for an Energy Efficiency Economy (also LBL36524).

Smith, Loretta A., Jeffrey P. Harris, and Morton H. Blatt. 1994. "Office Equipment Energy Efficiency: Taking the New Few Bytes". Presented at 1994 ACEEE Summer Study on Energy Efficiency in Buildings in Asilomar, CA. Published by American Council for an Energy Efficient Economy, Washington DC, (also LBL34835). 
Szydlowski, R. F. , and Jr. W. D. Chvala. 1994. Energy Consumption of Personal Computer Workstations. Pacific Northwest Laboratory in Richland, Washington. PNL-9061.

Tiller, D., and G. Newsham. 1993. Desktop Computers and Energy Consumption: A Study of Current Practice and Potential Energy Savings. Institute for Research in Construction, National Research Council of Canada; prepared for the Canadian Electrical Association in Montreal, Quebec. April.

US DOE. 1992. Residential Energy Consumption Survey (RECS): Housing Characteristics 1990. EIA, Energy Information Administration, U.S. Department of Energy, Washington, DC. DOE/EIA-0314(90). May.

US DOE. 1995a. Annual Energy Outlook 1995, with Projections to 2010. Energy Information Administration, U.S. Department of Energy, Washington, DC. DOE/EIA-0383(95). January.

US DOE. 1995b. Supplement to the Annual Energy Outlook 1995. Energy Information Administration, U.S. Department of Energy, Washington, DC. DOE/EIA0554(95). February.

US DOE, U.S. Department of Energy. 1988. Non-Residential Buildings Energy Consumption Survey: Characteristics of Commercial Buildings 1986. EIA, Energy Information Administration. DOE/EIA-0246(86). September.

US DOE, U.S. Department of Energy. 1991. Commercial Buildings Energy Consumption Survey: Commercial Buildings Characteristics 1989. Energy Information Administration. DOE/EIA-0246(89). June.

US DOE, U.S. Department of Energy. 1994. Commercial Buildings Energy Consumption Survey: Commercial Buildings Characteristics 1992. Energy Information Administration. DOE/EIA-0246(92). April.

XENERGY. 1989. Market Study of Load Growth and Conservation in the Large Commercial Population from 1985 to 1988. Prepared for Consolidated Edison Company, Inc. of New York. December. 


\section{APPENDIX A: DEVELOPMENT OF THE OFFICE EQUIPMENT ENERGY-USE MODEL}

\section{Introduction}

This appendix outlines the structure of, and catalogs improvements to, the Office Equipment Energy-Use Model (OFEEM). The first version of this model is described in "Office Technology Energy Use and Saving Potential in New York" (Piette et al. 1995). Since then substantial changes have been made to the structure and inputs of the model to improve its accuracy. The spreadsheets upon which the model is based have been changed: a new device type, serial printers, has been added; several changes to the power inputs have been made; the density inputs have been reexamined; and the resulting stock forecasts have been checked against other national forecasts.

This appendix first provides an overview of the model theory and structure. Descriptions and examples of each spreadsheet and workbook, including the development of the inputs, are then presented to enable working with the OFEEM. All OFEEM inputs necessary for reproducing these results are given.

\section{Model Theory and Data Flow}

OFEEM forecasts density and power requirements for each equipment type (PC CPUs, monitors, laser and serial printers, copiers, faxes, point-of-sale terminals, mainframes, and mini-computers), which it then uses with floor space information for each building type (offices, groceries, hospitals, hotels, miscellaneous, restaurants, retail, schools, and warehouses) to forecast electricity use in the commercial sector. This section details the development of the density and energy forecasts. First the mathematical basis for the density forecast is elaborated, and then the flowchart for the density calculations is explained. The power equations follow, and are combined with density information to expand the forecast to all building types. Finally we arrive at office equipment energy use for the commercial sector.

The density calculation is based on the following equations and involves floor space information, sales information, and initial density benchmarks. We start by remembering the definition of percentage change (the percentage change of a variable $\mathrm{X}$ is the quantity of its final value minus its initial value, all divided by its initial value, or Equation A-1),

$$
\% \Delta \mathrm{X}=\frac{\mathrm{X}_{\text {final }}-\mathrm{X}_{\text {initial }}}{\mathrm{X}_{\text {initial }}} \text { or } \mathrm{X}_{\text {final }}=\mathrm{X}_{\text {initial }}(1+\% \Delta \mathrm{X})
$$

Equipment density for year $i$ is the stock of machines in year $i$ divided by the floor space in year $i$. The stock and floor space in year i can also be expressed as the previous year's value multiplied by the quantity of one plus the percentage increase in the value as shown in Equation A-1, giving

$$
\text { Density }_{i}\left[\frac{\text { units }}{f t^{2}}\right]=\frac{\text { Stock }_{\mathrm{i}}\left[\text { units }^{2}\right]}{\text { Floorspace }_{i}\left[f t^{2}\right]}=\frac{\text { Stock }_{\mathrm{i}-1}\left(1+\% \Delta \text { Stock }_{\mathrm{i}}\right)}{\text { Floorspace }_{\mathrm{i}-1}\left(1+\% \Delta \text { Floorspace }_{\mathrm{i}}\right)}
$$

The previous year's stock divided by the previous year's floor space is equivalent to the previous year's density, giving 


$$
\text { Density }_{i}=\text { Density }_{i-1} \frac{\left(1+\% \Delta \text { Stock }_{i}\right)}{\left(1+\% \Delta \text { Floorspace }_{i}\right)} .
$$

So each year's density is derived from the previous year's, using the percentage change in stock and floor space.

The stock development is shown graphically in Figure A-1. Floor stock is taken from the 1995 AEO estimate from which is derived the percentage change in floor stock every year. Stock growth rates are derived using sales data from the Information Technology Industry Council (ITI) along with a retirement assumption. We reduce the implied growth rates in the ITI forecasts when they imply numbers of devices per person that exceed reasonable bounds. For equipment retirement we use the Internal Revenue Service (IRS) depreciation lifetimes for the different machine types: four years for PC CPUs and monitors, six years for printers, copiers, faxes, and point-of-sale terminals. We derive lifetimes of nine and eight years, respectively, for mainframes and mini-computers as explained later. Using sales figures and assuming a lifetime, we derive a national stock for each equipment type, giving a national stock growth rate for each. The stock growth rate and the floor space growth rate are combined with an estimate of an initial density to arrive at our density forecast for offices.

\section{Figure A-1. Flow chart showing the development of equipment densities.}

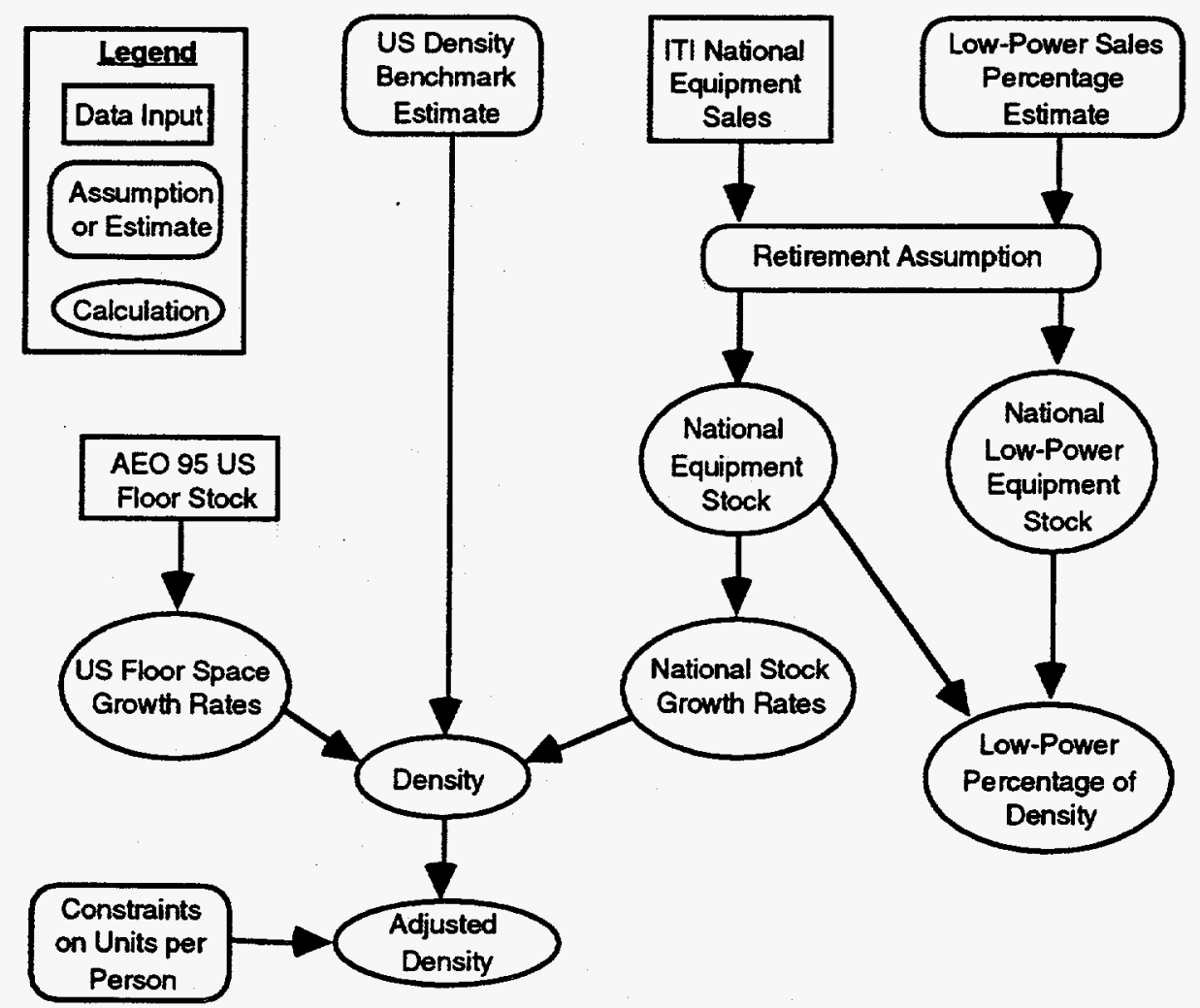

Deriving the fraction of low-power machines in the stock starts with an assumption of what percentage of sales low-power machines make up each year. These assumptions are described in the New York paper and shown in Table A-12. Low-power sales are subjected to the same retirement assumption as the standard machines, giving a low-power 
equipment stock estimate. This is divided by the national equipment stock to determine the low-power percentage of the equipment density.

The most critical value in this forecast is the initial density, as the forecast for each equipment type is essentially a multiple of this value. Several studies have been made to benchmark the equipment densities, and these are described in the New York paper and discussed later in this appendix. Uncoupling the stock and the floor space by combining their growth rates with an initial equipment density assumption makes OFEEM much more versatile because we can model any region if we know the floor space and assume that sales grow at the same rate as in the nation.

We expand our density forecast from offices to all other building types using a ratio of the initial densities. The equipment density in any building type $m$ in year $i$ equals that equipment density in offices in year $i$ multiplied by the ratio of the equipment baseline densities in the building type $m$ and in offices, as shown in Equation A-4:

$$
\text { Density }_{i, m}=\text { Density }_{i, o f i c e} \times \frac{\text { Density }_{1988, m}}{\text { Density }_{1988, \text { office }}}
$$

The following energy equations combine with the density forecast to make up the rest of the model. The unit energy consumption (UEC in $\mathrm{kWh} / \mathrm{yr}$ ) shows how much energy the average machine $n$ consumes in a year,

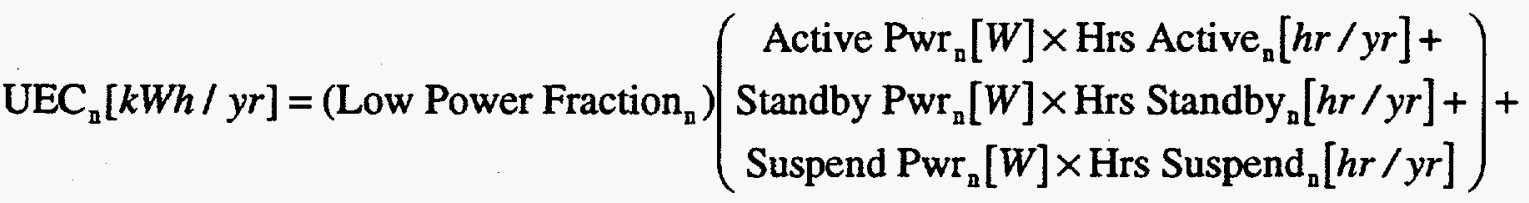

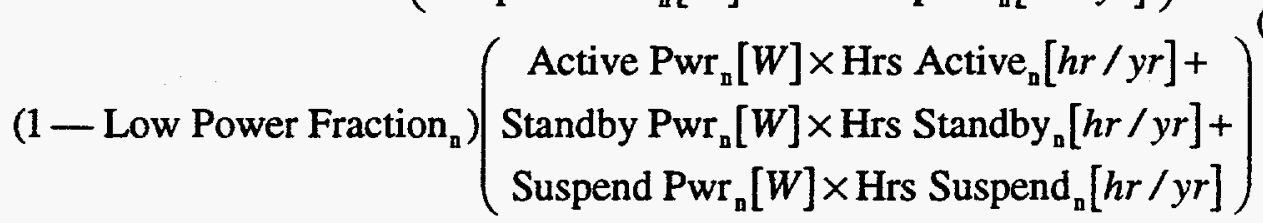

Equation A-5 provides the UEC for the average machine in the stock, taking into account the fraction of low-power machines using the low-power percentage of the density.

The UEC of machine $n$ combined with the density of machine $n$ in building $\mathrm{m}$ gives the energy use intensity (EUI in $\mathrm{W} / \mathrm{ft}^{2}$ ), which shows the concentration of energy use over a building's floor area.

$$
\mathrm{EUI}_{\mathrm{m}, \mathrm{n}}\left[\mathrm{kWh} / \mathrm{ft}^{2}\right]=\text { Density }_{\mathrm{m}, \mathrm{n}}\left[\text { units } / f t^{2}\right] \times \mathrm{UEC}_{\mathrm{n}}[\mathrm{kWh} / \mathrm{yr}]
$$

Actually, only the EUI of offices is calculated this way. The densities and EUIs in other building types are generated by taking the density of a particular machine type in offices and multiplying it by the ratio of the baseline densities in the other building type and offices, or Equation A-7:

$$
\mathrm{EUI}_{\mathrm{m}}=\mathrm{EUI}_{\mathrm{office}} \times \frac{\text { Density }_{1988, \mathrm{~m}}}{\text { Density }_{1988, \text { office }}}
$$


The EUI is combined with the floor space of the building types to get the energy use in building type $m$ by machine type $n$.

$$
\text { Energy }_{\mathrm{m}, \mathrm{n}}[k W h / y r]=\mathrm{EUI}_{\mathrm{m}, \mathrm{n}}\left[k W h / f t^{2}\right] \times \text { Floorspace }{ }_{m}\left[f^{2}\right]
$$

From here, the energy for each building and each machine are added up to arrive at the output.

Using these basic equations, the rest of the method can be shown in a flowchart, Figure A-2. Using estimates of the power for the standard and low-power equipment, estimates for the percentage of year spent in the different modes, and the low-power percentage of the density, an average UEC is calculated for each machine type, as shown in Equation A5. The UEC is combined with the office density as in Equation A-6 to arrive at the EUI for each equipment type in offices. Using ratios of baseline equipment densities in the other building types to those in offices, the EUIs are expanded to cover all the building types, as in Equation A-7. Finally, following Equation A-8, the EUIs are combined with the floor stock values to arrive at an estimate of energy used in each building type by each equipment type.

\section{Model Explanation and Inputs}

OFEEM has five workbooks (a workbook being a set of spreadsheets): Density, Power, and three scenarios, Business-As-Usual, Energy Star, and Advanced Energy Efficiency. The Density and Power workbooks are used for inputting settings for the scenarios, and each of the scenarios shares the same format. There are also two spreadsheets: Set-Up and Floor Space, which are shared among the workbooks. Using this structure, it is easy to change inputs for all the scenarios at once, and dividing the data up allows the spreadsheet to be easily transported from one computer to another (the entire model is more than nine megabytes). This structure is significantly different from the first version, which included a workbook for each of the three scenarios, the density and power information being repeated in the scenario workbooks. Following are notes on how the model has changed from version one and an example and a description of each shared page and workbook.

This section describes first how the model was changed from the first version and then goes on to describe each part of the model. Example tables are given as well as all inputs required to duplicate our results.

\section{Changes from Version 1}

The structure of the spreadsheet has changed substantially to facilitate working with the different scenarios. The scenarios were originally independent, duplicating much of their information, such as the set-up spreadsheet, the development of the equipment densities, and the power requirements. To make working with the model easier, each scenario was broken up into smaller pieces, the duplicated parts being combined and shared among the scenarios. Besides restructuring the model, serial printers were added as a new equipment type and the power levels have been updated to reflect new information. Also, the baseline densities have been checked against other estimates, as discussed in the density forecast section. 
Figure A-2. Flowchart of the development of the energy forecast.

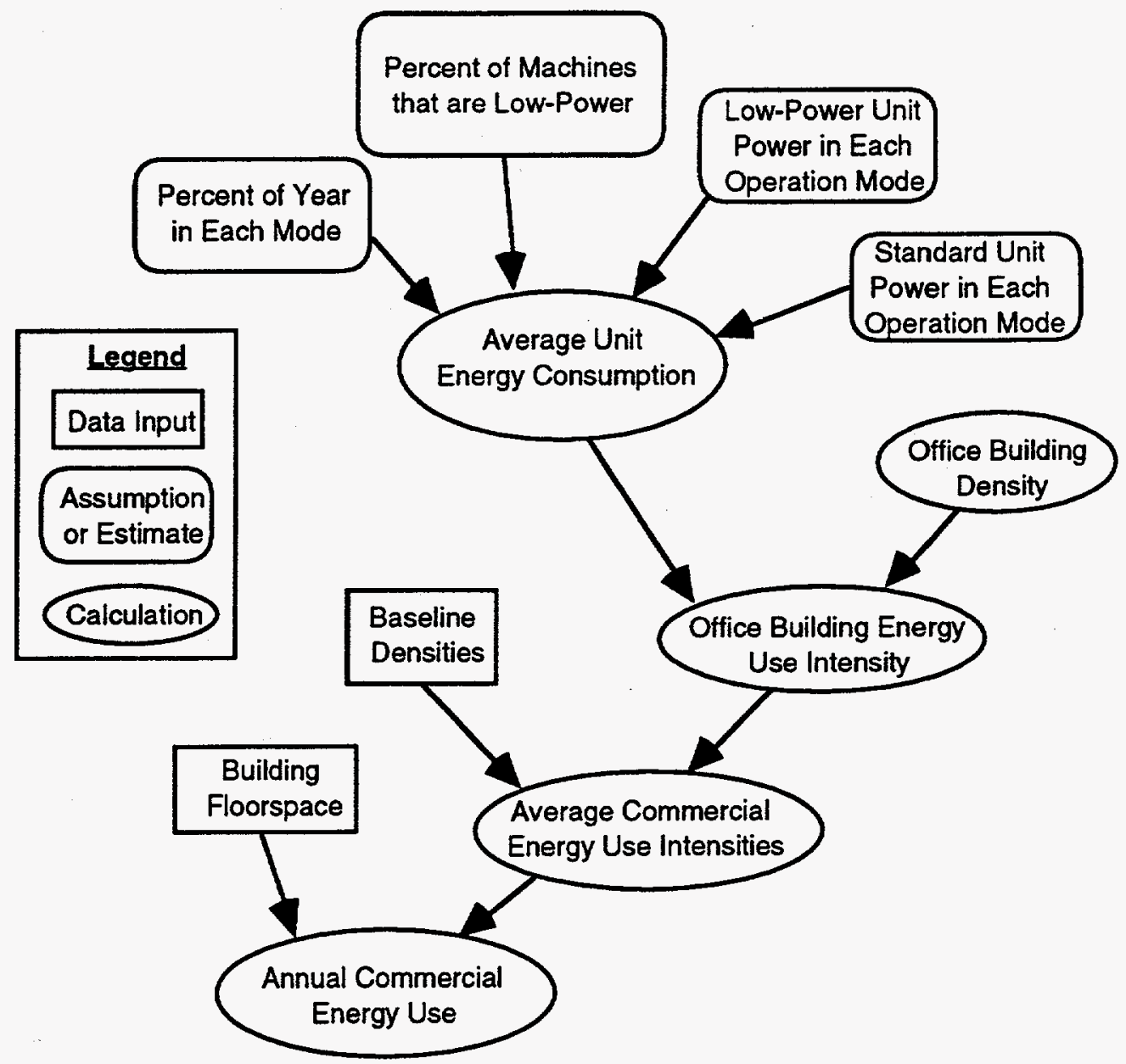

In the first version of OFEEM, all printers were modeled as one device type. A wide variety of printers were generalized to an average printer, as if different types of printers were spread homogeneously across different building types. In expanding the model to forecast for the entire United States, we realized that we were missing many of the serial printers and there is a bimodal distribution of printer power, as some building types were much more likely to have low-power serial printers instead of high-power page printers and vice versa.

Given the structure of OFEEM, it is very difficult to create a method to have different power levels for different building types, and to have the densities for the different building types reflect the bimodal nature of the power is difficult. The best option was to add another device type. So the former printer category was split into laser printers and serial printers. Power inputs for serial printers were taken from Piette et al. 1995, with the average power shifting from the $35 \mathrm{~W}$ active power of dot-matrix printers to the $20 \mathrm{~W}$ active 
power of ink-jet printers through the 1990s. The density inputs will be discussed later in the density evaluation section.

\section{Density Forecast}

The Density workbook forecasts the density growth for each equipment type in each building type. Each equipment spreadsheet in the workbook has two pages: one shows the development of the equipment density in offices, and the other expands the office densities to the other building types. Included in the workbook are the Set-Up and the Floor Space spreadsheets. The explanation here will closely follow Figure A-1, starting with the density benchmarks, continuing with the floor space and stock growth, and concluding with comparisons with other forecasts.

\section{Initial Densities: The Set-Up Page}

In version one of OFEEM, there was a set-up page with each of the three scenarios, so any change to one variable required updating all three scenarios. In version two, a single set-up page is shared with each scenario and the Density workbook, and gives an easy way to set important variables throughout the model. There are four sections, one for each workbook; the section for the density workbook is shown as Table A-1 while those for the scenarios are shown later in Table A-15.

The density set-up begins with the occupant density in the commercial sector, $28 \mathrm{~m}^{2}(300$ $\mathrm{ft}^{2}$ ) per person. Next come the sales growth rates after 1998 and lifetimes for each equipment category. Last are the 1988 stock densities for each of the equipment types in each of the building types. (Note that the baseline densities for mainframe and minicomputer densities are for 1989 instead of 1988.)

\section{Table A-1: The density section of the Set-Up page for OFEEM} Density Set-Up

\begin{tabular}{|r|c|c|c|c|c|c|c|c|c|}
\hline Variable & PCs & Monitors & $\begin{array}{c}\text { Laser } \\
\text { Printers }\end{array}$ & $\begin{array}{c}\text { Serial } \\
\text { Printers }\end{array}$ & Copiers & Faxes & $\begin{array}{c}\text { POS } \\
\text { Terminals }\end{array}$ & Mains & Minis \\
\hline Sales growth after 1998 (3) & $2.0 \%$ & $2.0 \%$ & $1.5 \%$ & $1.5 \%$ & $3.5 \%$ & $1.5 \%$ & $1.5 \%$ & $-3.1 \%$ & $1.6 \%$ \\
Years until retirement (4) & 4 & 4 & 6 & 6 & 6 & 6 & 4 & 9 & 8 \\
1988 stock densities & & & & & & & & \\
Office & 1.217 & 1.420 & 0.071 & 0.705 & 0.160 & 0.080 & 0.013 & 0.0038 & 0.039 \\
Retail & 0.133 & 0.170 & 0.011 & 0.105 & 0.055 & 0.011 & 0.250 & 0.0007 & 0.011 \\
Grocery 0.115 & 0.115 & 0.005 & 0.045 & 0.004 & 0.001 & 0.300 & 0.0000 & 0.000 \\
School 0.284 & 0.540 & 0.017 & 0.173 & 0.067 & 0.021 & 0.000 & 0.0015 & 0.023 \\
Hospital 0.061 & 0.255 & 0.041 & 0.413 & 0.080 & 0.030 & 0.027 & 0.0006 & 0.010 \\
Hotel 0.201 & 0.265 & 0.006 & 0.060 & 0.012 & 0.010 & 0.013 & 0.0004 & 0.006 \\
Miscellaneous 0.099 & 0.115 & 0.014 & 0.135 & 0.100 & 0.010 & 0.013 & 0.0003 & 0.004 \\
Restaurant 0.110 & 0.110 & 0.002 & 0.023 & 0.007 & 0.002 & 0.450 & 0.0000 & 0.000 \\
Warehouse 0.027 & 0.120 & 0.016 & 0.158 & 0.060 & 0.030 & 0.000 & 0.0014 & 0.022
\end{tabular}

The lifetime for each machine type was taken from the IRS depreciation lifetimes as mentioned above, except for mainframes and mini-computers. The Databook (CBEMA, 1994) provides several years of stock information for mainframes and mini-computers, and, using the sales data from earlier years, we estimated the average lifetime for those machines.

The 1988 density values have been taken from other benchmark studies and evaluated by comparison with industry forecasts of national stock. We have been able to check our 
densities with forecasts by several marketing companies, including DataQuest and InfoCorp. The density of each equipment type except point-of-sale terminals was checked against the stock implied by the ITI sales and our lifetime assumptions. Point-of-sale terminals are not included because ITI does not provide sales information for them, and we were unable to find other data sources.

\section{Monitors}

The Department of Energy's Commercial Buildings Energy Consumption Survey (CBECS) provided information on the stock of monitors by building type. We divide the number of monitors for each building type by the total floor area for that building type to derive monitor densities by building type. The CBECS data is for 1992, while the base year in OFEEM is 1988 . We adjusted the 1988 data until the densities for 1992 closely matched those from the CBECS data.

Table A-2 shows the baseline densities for monitors. The first column shows the building type. Columns two through four show the baseline densities examined in Piette et al. 1995, while column five shows the densities used in the first version of OFEEM. Column six shows the 1988 OFEEM densities that were used in the second version and that correspond to the 1992 CBECS densities. The resulting stock averages about $95 \%$ of that using ITI sales forecasts with a four-year lifetime for monitors.

As will be shown later, all sales inputs were taken from the 1994 ITI Databook (CBEMA, 1994). This includes data up to 1993, and projected sales and growth rates through 2004. ITI summarizes projected sales after 1998 with a growth rate. OFEEM follows that example and specifies a post-1998 growth rate as shown in Table A-1. In some cases, we reduced the ITI post-1998 growth rates to reflect saturating markets for certain equipment types (see Table A-12, below).

Table A-2: Baseline densities for monitors (\# units/kft ${ }^{2}$ )

\begin{tabular}{|l|c|c|c|c|c|c|c|}
\hline $\begin{array}{c}\text { Building } \\
\text { Type }\end{array}$ & $\begin{array}{c}1988 \\
\text { SMUD }\end{array}$ & $\begin{array}{c}1988 \\
\text { NW }\end{array}$ & $\begin{array}{c}1988 \\
\text { CE }\end{array}$ & $\begin{array}{c}1988 \\
\text { OFEEM i }\end{array}$ & $\begin{array}{c}1988 \\
\text { OFEEM ii }\end{array}$ & $\begin{array}{c}1992 \\
\text { CBECS }\end{array}$ & $\begin{array}{c}1992 \\
\text { OFEEM ii }\end{array}$ \\
\hline Office & 2.27 & 1.63 & 0.69 & 1.120 & 1.420 & 1.87 & 1.85 \\
Retail & 0.30 & 0.46 & 0.11 & 0.246 & 0.170 & 0.22 & 0.22 \\
Grocery & 0.02 & 0.05 & 0.02 & 0.027 & 0.115 & 0.15 & 0.15 \\
School & 0.87 & & 1.10 & 0.469 & 0.540 & 0.71 & 0.71 \\
Hospital & 0.64 & & 1.12 & 0.560 & 0.255 & 0.34 & 0.33 \\
Hotel & 0.13 & & 0.03 & 0.082 & 0.265 & 0.35 & 0.35 \\
Miscellaneous & 0.18 & 0.31 & & 0.229 & 0.115 & 0.15 & 0.15 \\
Restaurant & 0.02 & 0.08 & & 0.048 & 0.110 & 0.14 & 0.14 \\
Warehouse & 0.42 & 0.26 & & 0.181 & 0.120 & 0.16 & 0.16 \\
\hline
\end{tabular}

\section{Mainframes and Mini-Computers}

The densities for mainframes and minicomputers were generated for the New York study using a top-down approach. The problem was to distribute the total stock among the building types. CBECS has statistics on computer room floor space for each building type, so we assumed that mains and minis would be distributed among the building types by the same ratios as computer room floor space is distributed. Knowing what fraction of mainframes and mini-computers were in each building type, the total number of each machine type, and the total floor space for each type, we were able to generate average density values for each building type. The mainframe and mini-computer densities are shown in Table A-1 (above). 
For the national version of OFEEM, we needed a better idea of the number of mains and minis used in industrial venues, rather than in commercial. Through personal communication with IBM and DataQuest we found that about $20 \%$ of mainframes and $50 \%$ of mini-computers are used in "technical" venues, as opposed to "business". We chose to cut these values in half, as "industrial" is more specific than "technical". The densities were chosen so that the OFEEM mainframe stock was $90 \%$ of the stock implied by the ITI sales, and the mini-computer stock was $75 \%$ of the stock implied by the ITI sales.

The number of assumptions made in determining mainframe and mini-computer densities underscore the large amount of uncertainty involved in dealing with these equipment types. In addition, their power levels cover three orders of magnitude, so there is a large uncertainty there as well.

\section{PC CPUs}

PC CPU densities were derived from monitor densities with some input from mainframes and minicomputers. We assume that every PC CPU has a monitor and that extra monitors belong to mainframe and mini-computers. By evaluating the number of extra monitors in 1992, we can subtract those from the total monitors to derive densities for PC CPUs. ITI gives stand-alone monitor sales, and, using a four-year retirement rate, we estimate that there are about 8,500,000 extra monitors in the nation in 1992 . We assume that $25 \%$ of these would be going to the industrial sector. The rest were split among the different building types using the same method as the mainframes and mini-computers were: according to fractions of national computer room floor space. The data are shown in Table A-3.

\section{Table A-3. Building area computer room floor space and extra monitor} density in 1988

\begin{tabular}{|c|c|c|c|c|}
\hline Building Type & $\begin{array}{l}\text { Building Area } \\
\left(\text { million } \mathrm{ft}^{2}\right)\end{array}$ & $\begin{array}{c}\text { \% Computer Room } \\
\text { Floor space }\end{array}$ & $\begin{array}{c}\text { Number of extra } \\
\text { monitors }\end{array}$ & $\begin{array}{c}\text { Density } \\
\text { (units/kft }\end{array}$ \\
\hline Office & 12,635 & $40 \%$ & $3,426,519$ & 0.271 \\
\hline Retail & 13,467 & $8 \%$ & 671,891 & 0.050 \\
\hline Grocery & 904 & & 0 & 0.000 \\
\hline School & 9,612 & $16 \%$ & $1,354,856$ & 0.141 \\
\hline Hospital & 2,264 & $7 \%$ & 586,366 & 0.259 \\
\hline Hotel & 3,928 & $4 \%$ & 337,176 & 0.086 \\
\hline Miscellaneous & 11,599 & $3 \%$ & 243,653 & 0.021 \\
\hline Restaurant & 1,327 & & 0 & 0.000 \\
\hline Warehouse & 10,272 & $15 \%$ & $1,279,176$ & 0.125 \\
\hline Other & & $7 \%$ & 610,362 & \\
\hline Total: & & $100 \%$ & $8,510,000$ & \\
\hline
\end{tabular}

With the number of extra monitors in each building type and floor space information, we generate an "extra" monitor density by building type for 1992. So the PC CPU densities equal the monitor densities minus 75 percent of the extra monitor densities in each building type (the other $25 \%$ percent going to industry). Table A-4 shows the PC CPU densities from the three baseline studies as well as the first version of OFEEM. The sixth column shows the densities for the second version of OFEEM, and column seven shows the monitor densities as in Table A-2 (which include both stand-alone terminals and monitors associated with PC CPUs). PC CPUs in educational buildings were decreased an extra 0.15 units $/ \mathrm{kft}^{2}$ to match the school stock estimates by DataPro (1993 Statistical Abstract, 
Table 1278, p.761). These values compare favorably with industry estimates of total stock, although some discrepancies arise because of differing definitions of PCs.

Table A-4: PC CPU densities in 1988 (\# units/kft ${ }^{2}$ )

\begin{tabular}{|l|ccc|cc|c|}
\hline Building & SMUD & NW & CE & OFEEM i & OFEEM ii & Monitors \\
\hline Office & 1.72 & 0.93 & 0.41 & 0.667 & 1.217 & 1.420 \\
Retail & 0.24 & 0.30 & 0.09 & 0.146 & 0.133 & 0.170 \\
Grocery & 0.02 & 0.04 & 0.01 & 0.016 & 0.115 & 0.115 \\
School & 0.72 & & 0.61 & 0.279 & 0.284 & 0.540 \\
Hospital & 0.61 & & 0.37 & 0.333 & 0.061 & 0.255 \\
Hotel & 0.07 & & 0.03 & 0.049 & 0.201 & 0.265 \\
Miscellaneous & 0.18 & 0.19 & & 0.136 & 0.099 & 0.115 \\
Restaurant & 0.02 & 0.04 & & 0.029 & 0.110 & 0.110 \\
Warehouse & 0.37 & 0.15 & & 0.108 & 0.027 & 0.120 \\
\hline
\end{tabular}

Page (Laser) and Serial Printers

Page printer (or laser printer) densities were derived by taking $7.5 \%$ of the highest benchmark value of printer density for each building type so that there are about two PCs for every page printer in the mid 1990s. This results in the page printer stock being about two thirds of the stock using ITI sales and a six-year lifetime. Table A-5 shows both laser and serial printer densities.

Table A-5: Printer densities in 1988 (\# units/kft ${ }^{2}$ )

\begin{tabular}{|l|ccc|c|ccc|}
\hline Building & $\begin{array}{c}\text { SMUD } \\
\text { All } \\
\text { printers }\end{array}$ & $\begin{array}{c}\text { NW } \\
\text { All }\end{array}$ & $\begin{array}{c}\text { CE } \\
\text { All }\end{array}$ & $\begin{array}{c}\text { OFEEM } \\
\text { All } \\
\text { printers }\end{array}$ & $\begin{array}{c}\text { OFEEM ii } \\
\text { Laser } \\
\text { printers }\end{array}$ & $\begin{array}{c}\text { OFEEM ii } \\
\text { Serial } \\
\text { printers }\end{array}$ & $\begin{array}{c}\text { OFEEM ii } \\
\text { All } \\
\text { printers }\end{array}$ \\
\hline Office & 0.94 & 0.62 & 0.12 & 0.240 & 0.071 & 0.705 & 0.776 \\
Retail & 0.10 & 0.14 & 0.01 & 0.053 & 0.011 & 0.105 & 0.116 \\
Grocery & 0.06 & 0.03 & 0.00 & 0.006 & 0.005 & 0.045 & 0.050 \\
School & 0.23 & & 0.18 & 0.100 & 0.017 & 0.173 & 0.190 \\
Hospital & 0.55 & & 0.05 & 0.120 & 0.041 & 0.413 & 0.454 \\
Hotel & 0.08 & & 0.01 & 0.018 & 0.006 & 0.060 & 0.066 \\
Miscellaneous & 0.15 & 0.18 & & 0.049 & 0.014 & 0.135 & 0.149 \\
Restaurant & 0.01 & 0.03 & & 0.010 & 0.002 & 0.023 & 0.025 \\
Warehouse & 0.21 & 0.11 & & 0.039 & 0.016 & 0.158 & 0.174 \\
\hline
\end{tabular}

Serial printer densities were derived by taking $75 \%$ of the highest benchmark value. This gives stock values that are about $50 \%$ of the ITI value, which would fit with about $35 \%$ of printers going to home use and another small fraction to the industrial sector, most of which are assumed to be serial printers.

\section{Faxes}

The fax densities in offices, hospitals, hotels, and warehouses were increased from the initial OFEEM version to those in the SMUD survey. This estimate should be a little lower than that generated from the ITI sales values because a significant fraction of fax machines goes to home use. About $2 \%$ of homes have fax machines according to Appliance magazine, and there were about 100 million homes in the U.S. in 1992, so these stock values are about 2 million fewer than ITI numbers in 1992. Table A-6 shows fax densities. 


\section{Copiers}

Copier densities were left mostly unchanged from the first cut of OFEEM. Retail, miscellaneous, and warehouse building densities were increased to come closer to the average of the benchmark studies. Appliance magazine estimates that about $4 \%$ of U.S. homes have copiers in 1992, or about 4,000,000 copiers. Our estimate is different from the stock generated using ITI sales with a six year lifetime by about $50 \%$ of that. Table A-7 shows copier densities.

Table A-6: Fax densities in 1988 (\# units/kft ${ }^{2}$ )

\begin{tabular}{|c|c|c|c|c|}
\hline Building & SMUD & NW $\quad \mathrm{CE}$ & OFEEM i & OFEEM ii \\
\hline Office & 0.12 & & 0.050 & 0.080 \\
\hline Retail & 0.00 & & 0.011 & 0.011 \\
\hline Grocery & 0.00 & & 0.001 & 0.001 \\
\hline School & 0.00 & & 0.021 & 0.021 \\
\hline Hospital & 0.18 & & 0.025 & 0.030 \\
\hline Hotel & 0.01 & & 0.004 & 0.010 \\
\hline Miscellaneous & 0.00 & & 0.010 & 0.010 \\
\hline Restaurant & 0.00 & & 0.002 & 0.002 \\
\hline Warehouse & 0.03 & & 0.008 & 0.030 \\
\hline
\end{tabular}

Table A-7: Copier densities in 1988 (\# units/kft ${ }^{2}$ )

\begin{tabular}{|l|ccc|cc|}
\hline Building & SMUD & NW & CE & OFEEM i & OFEEM ii \\
\hline Office & 0.27 & 0.18 & 0.08 & 0.160 & 0.160 \\
Retail & 0.06 & 0.05 & 0.01 & 0.035 & 0.055 \\
Grocery & 0.03 & 0.05 & 0.00 & 0.004 & 0.004 \\
School & 0.06 & & 0.08 & 0.067 & 0.067 \\
Hospital & 0.23 & & 0.08 & 0.080 & 0.080 \\
Hotel & 0.01 & & 0.01 & 0.012 & 0.012 \\
Miscellaneous & 0.07 & 0.12 & & 0.033 & 0.100 \\
Restaurant & 0.00 & 0.03 & & 0.007 & 0.007 \\
Warehouse & 0.06 & 0.06 & & 0.026 & 0.060 \\
\hline
\end{tabular}

\section{Point-of-Sale Terminals}

Our estimate of point-of-sale terminal stock is based on the least information of any machine. ITI does not provide sales estimates, so the stock here is generated using an initial stock density estimate combined with PC CPU sales from 1975 onwards. This gives the appearance of a very fast growth rate until the mid-1990s when the market saturates and sales growth decreases. Table A-8 shows point-of-sale terminal densities in 1988.

\section{Floor Space Page}

Following the flow chart in Figure A-1, the floor space and equipment stock growth rates are needed to forecast the density growth. In the first version of OFEEM, the floor space data were incorporated separately into each scenario. In this version, a single page is shared among the workbooks, as with the Set-Up page. The Floor Space page is shown. 
Table A-8: Point-of-sale terminal densities in 1988 (\# units/kft ${ }^{2}$ )

\begin{tabular}{|l|ccc|cc|}
\hline Building & SMUD & NW & CE & OFEEM i & OFEEM ii \\
\hline Office & 0.00 & 0.13 & & 0.013 & 0.013 \\
Retail & 0.30 & 0.21 & & 0.250 & 0.250 \\
Grocery & 0.43 & 0.23 & & 0.300 & 0.300 \\
School & 0.02 & & & 0.000 & 0.000 \\
Hospital & 0.02 & & & 0.027 & 0.027 \\
Hotel & 0.02 & & & 0.013 & 0.013 \\
Miscellaneous & 0.00 & 0.13 & & 0.013 & 0.013 \\
Restaurant & 0.64 & 0.30 & & 0.450 & 0.450 \\
Warehouse & 0.00 & 0.00 & & 0.000 & 0.000 \\
\hline
\end{tabular}

in Table A-9. The 1986 and 1989 floor stocks are taken from US DOE (1988) and US DOE (1991), respectively. The 1987 and 1988 stocks are linearly interpolated between the 1986 and 1989 stocks, while the 1985 stock is backcast using that same linear annual growth. Stocks from 1990 onwards are taken from the Annual Energy Outlook 1995 (US DOE 1995a, US DOE 1995b). Floor stocks for 2011 and 2012 are generated by applying the 1992 to 2010 absolute annual growth rates to the 2010 stock.

Table A-9: National floor stock for OFEEM in billion $\mathbf{f t}^{2}$

\begin{tabular}{|c|c|c|c|c|c|c|c|c|c|c|}
\hline Year & Offices & Retail & Grocery & Schools & Hospitals & Hotels & Miscellaneous & Restaurants & Warehouse & Total \\
\hline 1985 & 8.8 & 13.0 & 0.7 & 7.4 & 2.1 & 2.6 & 11.8 & 1.3 & 8.9 & 56.6 \\
1986 & 9.5 & 12.8 & 0.7 & 7.7 & 2.1 & 2.8 & 12.3 & 1.3 & 9.0 & 58.2 \\
1987 & 10.3 & 12.7 & 0.7 & 8.0 & 2.1 & 3.0 & 12.8 & 1.2 & 9.1 & 59.9 \\
1988 & 11.1 & 12.5 & 0.8 & 8.2 & 2.1 & 3.2 & 13.3 & 1.2 & 9.2 & 61.5 \\
1989 & 11.8 & 12.4 & 0.8 & 8.5 & 2.1 & 3.5 & 13.8 & 1.2 & 9.3 & 63.2 \\
1990 & 12.0 & 12.7 & 0.8 & 8.5 & 2.1 & 3.5 & 13.9 & 1.2 & 9.5 & 64.3 \\
1991 & 12.2 & 12.9 & 0.8 & 8.6 & 2.2 & 3.6 & 14.0 & 1.2 & 9.7 & 65.2 \\
1992 & 12.4 & 13.2 & 0.8 & 8.7 & 2.3 & 3.7 & 14.0 & 1.2 & 9.8 & 66.1 \\
1993 & 12.7 & 13.5 & 0.9 & 8.8 & 2.4 & 3.7 & 14.0 & 1.3 & 10.0 & 67.0 \\
1994 & 12.9 & 13.8 & 0.9 & 8.9 & 2.5 & 3.8 & 13.9 & 1.3 & 10.1 & 67.9 \\
1995 & 13.1 & 14.1 & 0.9 & 8.9 & 2.5 & 3.8 & 13.9 & 1.3 & 10.2 & 68.8 \\
1996 & 13.4 & 14.4 & 0.9 & 8.9 & 2.6 & 3.9 & 13.9 & 1.3 & 10.4 & 69.6 \\
1997 & 13.6 & 14.7 & 0.9 & 8.9 & 2.7 & 3.9 & 13.8 & 1.3 & 10.5 & 70.3 \\
1998 & 13.8 & 15.0 & 0.9 & 8.8 & 2.7 & 4.0 & 13.8 & 1.4 & 10.7 & 71.0 \\
1999 & 14.0 & 15.3 & 1.0 & 8.8 & 2.8 & 4.0 & 13.7 & 1.4 & 10.8 & 71.7 \\
2000 & 14.2 & 15.7 & 1.0 & 8.7 & 2.8 & 4.1 & 13.6 & 1.4 & 10.9 & 72.3 \\
2001 & 14.4 & 16.0 & 1.0 & 8.7 & 2.8 & 4.1 & 13.6 & 1.4 & 11.1 & 73.0 \\
2002 & 14.5 & 16.3 & 1.0 & 8.6 & 2.9 & 4.1 & 13.5 & 1.5 & 11.2 & 73.6 \\
2003 & 14.7 & 16.7 & 1.0 & 8.6 & 2.9 & 4.2 & 13.4 & 1.5 & 11.3 & 74.2 \\
2004 & 14.9 & 17.0 & 1.0 & 8.5 & 2.9 & 4.2 & 13.3 & 1.5 & 11.4 & 74.8 \\
2005 & 15.1 & 17.4 & 1.1 & 8.4 & 3.0 & 4.2 & 13.2 & 1.5 & 11.5 & 75.4 \\
2006 & 15.2 & 17.8 & 1.1 & 8.4 & 3.0 & 4.2 & 13.1 & 1.5 & 11.6 & 75.9 \\
2007 & 15.4 & 18.2 & 1.1 & 8.3 & 3.1 & 4.3 & 13.0 & 1.6 & 11.7 & 76.5 \\
2008 & 15.6 & 18.6 & 1.1 & 8.2 & 3.1 & 4.3 & 12.9 & 1.6 & 11.8 & 77.1 \\
2009 & 15.7 & 19.0 & 1.1 & 8.2 & 3.2 & 4.3 & 12.8 & 1.6 & 11.9 & 77.8 \\
2010 & 15.9 & 19.4 & 1.1 & 8.1 & 3.2 & 4.3 & 12.7 & 1.6 & 11.9 & 78.4 \\
2011 & 16.1 & 19.8 & 1.2 & 8.1 & 3.3 & 4.4 & 12.6 & 1.7 & 12.1 & 79.2 \\
2012 & 16.3 & 20.3 & 1.2 & 8.1 & 3.4 & 4.4 & 12.5 & 1.7 & 12.2 & 80.1
\end{tabular}




\section{Sales, Stock, and Density}

In addition to the floor space information, stock growth rates are required to forecast the equipment densities. We generate stock growth rates by combining sales data and lifetime assumptions, as shown in Figure A-1. Table A-10 shows the sales figures for each of the equipment types from the ITI data book (CBEMA 1994). Note that there are none for point-of-sale terminals as the Databook does not provide these. The values are actual data until 1993, and then ITI projects future sales figures. However, using these sales numbers implies far too many PC CPUs, monitors, laser printers, and fax machines per person (assuming $300 \mathrm{ft}^{2} /$ person occupancy). So we decreased the sales growth of these equipment types between 1994 and 1997 to arrive at a more reasonable number of units per person. Table A-11 shows our final estimates for the projected annual growth in equipment sales after 1993. Sales growth for the rest of the equipment types (copiers, mainframes, and minicomputers) were left as in the Databook. Table A-12 shows the fraction of the sales that are low-power machines. Table A-13 shows the fraction of ENERGY STAR compliant devices assumed to be enabled in our various policy cases (see main text for details).

Table A-10: Sales forecasts from the ITI Databook

\begin{tabular}{|c|c|c|c|c|c|c|c|c|}
\hline Year & PC CPUs & Terminals & $\begin{array}{c}\text { Laser } \\
\text { Printers }\end{array}$ & $\begin{array}{c}\text { Serial } \\
\text { Printers }\end{array}$ & Copiers & Faxes & Mainframes & $\begin{array}{c}\text { Mini- } \\
\text { Computers }\end{array}$ \\
\hline & Millions & Millions & Millions & Millions & Millions & Millions & Thousands & Thousands \\
\hline 1975 & 0.01 & 0.21 & 0 & 0.29 & 0.36 & 0.024 & 6.7 & 27 \\
1976 & 0.05 & 0.35 & 0.0001 & 0.32 & 0.39 & 0.025 & 6.8 & 39 \\
1977 & 0.12 & 0.59 & 0.0003 & 0.36 & 0.43 & 0.026 & 8.9 & 57 \\
1978 & 0.24 & 0.82 & 0.0005 & 0.45 & 0.46 & 0.033 & 7.5 & 68 \\
1979 & 0.33 & 1.0 & 0.0009 & 0.68 & 0.55 & 0.045 & 7.2 & 81 \\
1980 & 0.80 & 1.7 & 0.0015 & 0.87 & 0.62 & 0.062 & 9.9 & 106 \\
1981 & 1.2 & 2.3 & 0.0022 & 1.3 & 0.71 & 0.068 & 10.7 & 122 \\
1982 & 2.0 & 3.3 & 0.0027 & 1.8 & 0.80 & 0.080 & 10.6 & 128 \\
1983 & 3.2 & 4.8 & 0.0054 & 2.9 & 0.89 & 0.095 & 10.0 & 147 \\
1984 & 5.2 & 7.0 & 0.063 & 4.4 & 1.1 & 0.12 & 11.3 & 205 \\
1985 & 4.8 & 6.6 & 0.13 & 5.2 & 1.1 & 0.14 & 10.9 & 191 \\
1986 & 5.1 & 7.0 & 0.30 & 5.6 & 1.2 & 0.22 & 11.0 & 198 \\
1987 & 5.5 & 7.7 & 0.65 & 5.9 & 1.3 & 0.58 & 11.2 & 206 \\
1988 & 6.0 & 8.4 & 1.2 & 6.3 & 1.3 & 1.3 & 11.5 & 218 \\
1989 & 6.5 & 9.2 & 1.7 & 6.6 & 1.3 & 1.6 & 11.9 & 228 \\
1990 & 7.1 & 9.9 & 2.6 & 6.7 & 1.4 & 1.8 & 12.1 & 232 \\
1991 & 7.5 & 10.5 & 3.5 & 6.8 & 1.4 & 2.0 & 12.3 & 237 \\
1992 & 8.7 & 11.9 & 4.3 & 6.9 & 1.5 & 2.1 & 12.2 & 242 \\
1993 & 10.3 & 13.5 & 5.3 & 7.1 & 1.5 & 2.4 & 12.0 & 247 \\
1994 & 11.3 & 14.6 & 6.0 & 7.3 & 1.6 & 2.6 & 11.7 & 252 \\
1995 & 12.2 & 15.6 & 6.6 & 7.5 & 1.6 & 2.8 & 11.4 & 256 \\
1996 & 12.9 & 16.4 & 7.0 & 7.7 & 1.7 & 3.0 & 11.1 & 260 \\
1997 & 13.3 & 16.8 & 7.1 & 7.9 & 1.8 & 3.1 & 10.8 & 264 \\
1998 & 13.4 & 17.0 & 7.2 & 8.1 & 1.8 & 3.1 & 10.5 & 268 \\
1999 & 13.6 & 17.2 & 7.3 & 8.3 & 1.9 & 3.2 & 10.1 & 272 \\
2000 & 13.7 & 17.4 & 7.4 & 8.5 & 2.0 & 3.2 & 9.8 & 276 \\
2001 & 13.8 & 17.5 & 7.4 & 8.7 & 2.0 & 3.2 & 9.5 & 281 \\
2002 & 14.0 & 17.7 & 7.5 & 8.9 & 2.1 & 3.3 & 9.2 & 285 \\
2003 & 14.1 & 17.9 & 7.6 & 9.1 & 2.2 & 3.3 & 8.9 & 290 \\
2004 & 14.3 & 18.1 & 7.7 & 9.4 & 2.2 & 3.3 & 8.7 & 294 \\
& & & & & & & & \\
\hline
\end{tabular}


Table A-11. OFEEM equipment sales growth rates, adjusted from ITI growth rates

\begin{tabular}{|c|c|c|c|c|c|c|c|c|c|}
\hline Year & PC CPUs & Monitors & $\begin{array}{c}\text { Laser } \\
\text { Printers }\end{array}$ & $\begin{array}{c}\text { Serial } \\
\text { Printers }\end{array}$ & Copiers & Faxes & $\begin{array}{c}\text { POS } \\
\text { Terminals }\end{array}$ & Mains & Minis \\
\hline 1990 & $8.0 \%$ & $7.9 \%$ & $49.6 \%$ & $1.1 \%$ & $4.1 \%$ & $10.0 \%$ & $8.0 \%$ & $2.0 \%$ & $1.9 \%$ \\
1991 & $7.0 \%$ & $6.6 \%$ & $35.7 \%$ & $2.0 \%$ & $3.1 \%$ & $9.0 \%$ & $7.0 \%$ & $1.0 \%$ & $2.0 \%$ \\
1992 & $15.6 \%$ & $12.4 \%$ & $24.1 \%$ & $1.3 \%$ & $1.5 \%$ & $8.9 \%$ & $15.6 \%$ & $-0.8 \%$ & $2.5 \%$ \\
1993 & $17.5 \%$ & $13.8 \%$ & $20.9 \%$ & $2.9 \%$ & $3.9 \%$ & $11.4 \%$ & $17.5 \%$ & $-1.2 \%$ & $1.7 \%$ \\
1994 & $10.0 \%$ & $8.2 \%$ & $15.0 \%$ & $2.8 \%$ & $4.3 \%$ & $10.0 \%$ & $10.0 \%$ & $-2.5 \%$ & $2.2 \%$ \\
1995 & $8.0 \%$ & $6.6 \%$ & $10.0 \%$ & $2.8 \%$ & $3.6 \%$ & $8.0 \%$ & $8.0 \%$ & $-2.6 \%$ & $1.5 \%$ \\
1996 & $6.0 \%$ & $5.1 \%$ & $5.0 \%$ & $2.9 \%$ & $3.6 \%$ & $6.0 \%$ & $6.0 \%$ & $-2.6 \%$ & $1.5 \%$ \\
1997 & $3.0 \%$ & $2.8 \%$ & $2.5 \%$ & $2.4 \%$ & $3.6 \%$ & $3.0 \%$ & $3.0 \%$ & $-2.9 \%$ & $1.5 \%$ \\
1998 & $2.0 \%$ & $2.0 \%$ & $1.5 \%$ & $2.5 \%$ & $3.4 \%$ & $1.5 \%$ & $2.0 \%$ & $-3.1 \%$ & $1.5 \%$ \\
$\leq 1999$ & $2.0 \%$ & $2.0 \%$ & $1.5 \%$ & $1.5 \%$ & $3.5 \%$ & $1.5 \%$ & $1.5 \%$ & $-3.1 \%$ & $1.6 \%$ \\
\end{tabular}

(1) Historical data are in italics.

(2) POS terminal growth rates are assumed to be the same as that for PC CPUs through 1998, and 1.5\% per year after that.

Table A-12: Low-Power Equipment Sales as a Percentage of Total Sales

\begin{tabular}{|ccc|c|c|c|}
\hline Year & PC CPUs & Monitors & Laser Printers & Copiers & Faxes \\
\hline 1992 & $0 \%$ & $0 \%$ & $0 \%$ & $0 \%$ & $0 \%$ \\
1993 & $15 \%$ & $15 \%$ & $10 \%$ & $0 \%$ & $0 \%$ \\
1994 & $26 \%$ & $26 \%$ & $50 \%$ & $0 \%$ & $0 \%$ \\
1995 & $38 \%$ & $38 \%$ & $90 \%$ & $10 \%$ & $10 \%$ \\
1996 & $49 \%$ & $49 \%$ & $100 \%$ & $20 \%$ & $50 \%$ \\
1997 & $61 \%$ & $61 \%$ & $100 \%$ & $40 \%$ & $100 \%$ \\
1998 & $72 \%$ & $72 \%$ & $100 \%$ & $80 \%$ & $100 \%$ \\
1999 & $83 \%$ & $83 \%$ & $100 \%$ & $90 \%$ & $100 \%$ \\
2000 & $95 \%$ & $95 \%$ & $100 \%$ & $100 \%$ & $100 \%$ \\
2001 & $100 \%$ & $100 \%$ & $100 \%$ & $100 \%$ & $100 \%$ \\
\end{tabular}

Table A-13: Percent of Energy STAR Compliant Equipment Sold Assumed to be Enabled (By Policy Case)

\begin{tabular}{|l|c|c|c|c|c|}
\hline \multicolumn{1}{|c|}{ Year } & PC & Monitors & Laser & Copiers & Faxes \\
\hline ENERGY STAR - Current Practice Continues & $10 \%$ & $10 \%$ & $100 \%$ & $50 \%$ & $100 \%$ \\
ENERGY STAR - Worst Case & $25 \%$ & $50 \%$ & $100 \%$ & $75 \%$ & $100 \%$ \\
ENERGY STAR - Most-Likely Case & $50 \%$ & $70 \%$ & $100 \%$ & $90 \%$ & $100 \%$ \\
ENERGY STAR - Best Case & $100 \%$ & $100 \%$ & $100 \%$ & $100 \%$ & $100 \%$
\end{tabular}

Table A-14 shows the first page of the PC CPU spreadsheet as an example, essentially unchanged from the first version of OFEEM. This page forecasts the density growth in offices. the next page expands the forecast to the other building types. Columns 2 and 3 show the floor space forecast for offices and the annual growth rate. Column 4 shows the sales estimate from the ITI Databook for PC CPUs (their estimate of commercial sales), while column 5 shows the annual growth rate and column six shows an estimate of the percentage of that sales that are low-power machines. Column 7 shows the stock estimate, derived from adding up the sales from a previous number of years equivalent to the lifetime of the machine type. In other words, for PC CPUs the lifetime is four years, so the stock 
in 1995 is the sum of the sales from 1992 until 1995. Column 8 shows the annual stock growth.

Column 9 shows our estimate of the stock in number of machines per $\mathrm{kft}^{2}$, derived using Equation A-3, and using as input columns 3 and 8 and the 1988 density from the Set-Up page. Column 10 shows the percentage of the stock that is low-power equipment, a calculation similar to the stock calculation. The number of low-power machines in each year is the low-power sales percentage multiplied by the sales for that year. Like the stock calculation, these products are summed over the number of most recent years equivalent to the lifetime, giving the low-power stock. This stock is then divided by the total stock to get the low-power percentage of the density. Finally, column 11 gives a check of the density, showing the number of people per unit. For PC CPUs, that value changes from 3.6 in 1985 to 1.5 in 1995 , showing that the market is rapidly saturating.

Table A-14: Density forecast of PC CPUs in offices from the Density workbook

\begin{tabular}{|c|c|c|c|c|c|c|c|c|c|c|}
\hline \multirow{2}{*}{$\frac{C 1}{\text { Year }}$} & \multirow{2}{*}{\multicolumn{2}{|c|}{$\begin{array}{cc}\text { C2 } & \text { C3 } \\
\text { Total Floorspace }\end{array}$}} & \multirow{2}{*}{\multicolumn{3}{|c|}{$\begin{array}{ccc}\mathrm{C} 4 & \mathrm{C5} & \mathrm{C} 6 \\
\text { Total Comml Sales }\end{array}$}} & \multirow{2}{*}{\multicolumn{2}{|c|}{$\begin{array}{cc}\text { C7 } & \text { C8 } \\
\text { Total Comml Stock }\end{array}$}} & \multirow{2}{*}{\multicolumn{2}{|c|}{$\begin{array}{l}\text { C9 } \quad \text { C10 } \\
\text { Office Density }\end{array}$}} & \multirow{3}{*}{ 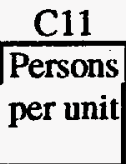 } \\
\hline & & & & & & & & & & \\
\hline & (Msqft) & $\begin{array}{c}\text { Growth } \\
(\%)\end{array}$ & $\begin{array}{l}\text { Total } \\
\text { (units) }\end{array}$ & $\begin{array}{c}\text { Growth } \\
(\%)\end{array}$ & $\begin{array}{c}\text { Low-Power } \\
(\%)\end{array}$ & $\begin{array}{l}\text { Total } \\
\text { (units) }\end{array}$ & $\begin{array}{c}\text { Growth } \\
(\%)\end{array}$ & $\begin{array}{c}\text { Stock } \\
(\# / k s q f t)\end{array}$ & $\begin{array}{c}\text { Low-Power } \\
(\%)\end{array}$ & \\
\hline 1975 & & & 10500 & & $0 \%$ & 10500 & & & & \\
\hline 1976 & & & 53100 & $405.7 \%$ & $0 \%$ & 63600 & $505.7 \%$ & & & \\
\hline 1977 & & & 120400 & $126.7 \%$ & $0 \%$ & 184000 & $189.3 \%$ & & & \\
\hline 1978 & & & 237900 & $97.6 \%$ & $0 \%$ & 421900 & $129.3 \%$ & & & \\
\hline 1979 & & & 329400 & $38.5 \%$ & $0 \%$ & 740800 & $75.6 \%$ & & & \\
\hline 1980 & & & 796000 & $141.7 \%$ & $0 \%$ & 1483700 & $100.3 \%$ & & & \\
\hline 1981 & & & 1157000 & $45.4 \%$ & $0 \%$ & 2520300 & $69.9 \%$ & & & \\
\hline 1982 & & & 1950000 & $68.5 \%$ & $0 \%$ & 4232400 & $67.9 \%$ & & & \\
\hline 1983 & & & 3249000 & $66.6 \%$ & $0 \%$ & 7152000 & $69.0 \%$ & & & \\
\hline 1984 & & & 5190000 & $59.7 \%$ & $0 \%$ & 11546000 & $61.4 \%$ & & & \\
\hline 1985 & 56,577 & & 4750000 & $-8.5 \%$ & $0 \%$ & 15139000 & $31.1 \%$ & 0.94 & $0.0 \%$ & 3.54 \\
\hline 1986 & 58,229 & $2.92 \%$ & 5060000 & $6.5 \%$ & $0 \%$ & 18249000 & $20.5 \%$ & 1.10 & $0.0 \%$ & 3.02 \\
\hline 1987 & 59,881 & $2.84 \%$ & 5460000 & $7.9 \%$ & $0 \%$ & 20460000 & $12.1 \%$ & 1.20 & $0.0 \%$ & 2.77 \\
\hline 1988 & 61,532 & $2.76 \%$ & 5990000 & $9.7 \%$ & $0 \%$ & 21260000 & $3.9 \%$ & 1.22 & $0.0 \%$ & 2.74 \\
\hline 1989 & 63,184 & $2.68 \%$ & 6530000 & $9.0 \%$ & $0 \%$ & 23040000 & $8.4 \%$ & 1.28 & $0.0 \%$ & 2.60 \\
\hline 1990 & 64,270 & $1.72 \%$ & 7050000 & $8.0 \%$ & $0 \%$ & 25030000 & $8.6 \%$ & 1.37 & $0.0 \%$ & 2.43 \\
\hline 1991 & 65,240 & $1.51 \%$ & 7540000 & $7.0 \%$ & $0 \%$ & 27110000 & $8.3 \%$ & 1.46 & $0.0 \%$ & 2.28 \\
\hline 1992 & 66,090 & $1.30 \%$ & 8720000 & $15.6 \%$ & $0 \%$ & 29840000 & $10.1 \%$ & 1.59 & $0.0 \%$ & 2.10 \\
\hline 1993 & 67,020 & $1.41 \%$ & 10250000 & $17.5 \%$ & $15 \%$ & 33560000 & $12.5 \%$ & 1.76 & $4.6 \%$ & 1.89 \\
\hline 1994 & 67,890 & $1.30 \%$ & 11275000 & $10.0 \%$ & $26 \%$ & 37785000 & $12.6 \%$ & 1.96 & $11.9 \%$ & 1.70 \\
\hline 1995 & 68,760 & $1.28 \%$ & 12177000 & $8.0 \%$ & $38 \%$ & 42422000 & $12.3 \%$ & 2.17 & $21.5 \%$ & 1.53 \\
\hline 1996 & 69,580 & $1.19 \%$ & 12907620 & $6.0 \%$ & $49 \%$ & 46609620 & $9.9 \%$ & 2.36 & $33.2 \%$ & 1.41 \\
\hline 1997 & 70,340 & $1.09 \%$ & 13294849 & $3.0 \%$ & $61 \%$ & 49654469 & $6.5 \%$ & 2.49 & $44.3 \%$ & 1.34 \\
\hline 1998 & 71,040 & $1.00 \%$ & 13560746 & $2.0 \%$ & $72 \%$ & 51940214 & $4.6 \%$ & 2.57 & $55.4 \%$ & 1.29 \\
\hline 1999 & 71,710 & $0.94 \%$ & 13831960 & $2.0 \%$ & $83 \%$ & 53595175 & $3.2 \%$ & 2.63 & $66.6 \%$ & 1.27 \\
\hline 2000 & 72,340 & $0.88 \%$ & 14108600 & $2.0 \%$ & $95 \%$ & 54796154 & $2.2 \%$ & 2.67 & $78.0 \%$ & 1.25 \\
\hline 2001 & 72,980 & $0.88 \%$ & 14390772 & $2.0 \%$ & $100 \%$ & 55892077 & $2.0 \%$ & 2.70 & $87.8 \%$ & 1.24 \\
\hline 2002 & 73,580 & $0.82 \%$ & 14678587 & $2.0 \%$ & $100 \%$ & 57009919 & $2.0 \%$ & 2.73 & $94.7 \%$ & 1.22 \\
\hline 2003 & 74,160 & $0.79 \%$ & 14972159 & $2.0 \%$ & $100 \%$ & 58150117 & $2.0 \%$ & 2.76 & $98.7 \%$ & 1.21 \\
\hline 2004 & 74,750 & $0.80 \%$ & 15271602 & $2.0 \%$ & $100 \%$ & 59313120 & $2.0 \%$ & 2.79 & $100.0 \%$ & 1.19 \\
\hline 2005 & 75,350 & $0.80 \%$ & 15577034 & $2.0 \%$ & $100 \%$ & 60499382 & $2.0 \%$ & 2.83 & $100.0 \%$ & 1.18 \\
\hline 2006 & 75,930 & $0.77 \%$ & 15888575 & $2.0 \%$ & $100 \%$ & 61709370 & $2.0 \%$ & 2.86 & $100.0 \%$ & 1.16 \\
\hline 2007 & 76,530 & $0.79 \%$ & 16206346 & $2.0 \%$ & $100 \%$ & 62943557 & $2.0 \%$ & 2.90 & $100.0 \%$ & 1.15 \\
\hline 2008 & 77,140 & $0.80 \%$ & 16530473 & $2.0 \%$ & $100 \%$ & 64202428 & $2.0 \%$ & 2.93 & $100.0 \%$ & 1.14 \\
\hline 2009 & 77,770 & $0.82 \%$ & 16861083 & $2.0 \%$ & $100 \%$ & 65486477 & $2.0 \%$ & 2.97 & $100.0 \%$ & 1.12 \\
\hline 2010 & 78,400 & $0.81 \%$ & 17198304 & $2.0 \%$ & $100 \%$ & 66796206 & $2.0 \%$ & 3.00 & $100.0 \%$ & 1.11 \\
\hline 2011 & 79,227 & $1.05 \%$ & 17542270 & $2.0 \%$ & $100 \%$ & 68132131 & $2.0 \%$ & 3.03 & $100.0 \%$ & 1.10 \\
\hline 2012 & 80,071 & $1.07 \%$ & 17893116 & $2.0 \%$ & $100 \%$ & 69494773 & $2.0 \%$ & 3.06 & $100.0 \%$ & 1.09 \\
\hline
\end{tabular}


The second page of each device spreadsheet in the Density workbook is the buildings page, which expands the results of the density calculation for offices to the rest of the building types using Equation A-4. Table A-15 shows the first five columns of the buildings page for PC CPUs. Shown are the floor space and stock in offices and retail buildings. The floor space values are taken from the Floor Space spreadsheet in Table A-10. The stock values for the office are the floor space multiplied by the density from the office density forecast, as shown in Table A-14. The stock for retail buildings is calculated the same way (floor space multiplied by density), except that the retail density is equivalent to the office density multiplied by the ratio of the base year (1988) PC CPU retail density to the base year PC CPU office density, or Equation A-4. The stock is developed for the rest of the building types using the same equation.

Table A-15: Example of an office equipment density expanded for another building type (PC CPUs)

\begin{tabular}{|c|c|c|c|c|}
\hline Year & \multicolumn{2}{|c|}{ Office } & \multicolumn{2}{c|}{ Retail } \\
\cline { 2 - 5 } & $\begin{array}{c}\text { Floor Space } \\
\text { (Msqft) }\end{array}$ & $\begin{array}{c}\text { Stock } \\
\text { (units) }\end{array}$ & $\begin{array}{c}\text { Floor Space } \\
\text { (Msqft) }\end{array}$ & $\begin{array}{c}\text { Stock } \\
\text { (units) }\end{array}$ \\
\hline 1985 & 8,794 & 8285786 & 12,952 & 1329857 \\
1986 & 9,546 & 10534495 & 12,805 & 1539941 \\
1987 & 10,298 & 12389804 & 12,658 & 1659664 \\
1988 & 11,050 & 13443573 & 12,512 & 1658822 \\
1989 & 11,802 & 15153869 & 12,365 & 1730192 \\
1990 & 12,040 & 16510932 & 12,650 & 1890461 \\
1991 & 12,230 & 17895118 & 12,920 & 2060169 \\
1992 & 12,420 & 19745913 & 13,170 & 2281779 \\
1993 & 12,650 & 22304917 & 13,470 & 2588272 \\
1994 & 12,880 & 25241900 & 13,770 & 2940846 \\
1995 & 13,120 & 28502415 & 14,080 & 3333363 \\
1996 & 13,350 & 31489441 & 14,380 & 3696364 \\
1997 & 13,570 & 33730935 & 14,690 & 3979261 \\
1998 & 13,770 & 35450901 & 15,010 & 4211203 \\
1999 & 13,980 & 36791347 & 15,330 & 4396558 \\
2000 & 14,170 & 37794968 & 15,650 & 4548944 \\
2001 & 14,350 & 38698207 & 15,990 & 4699153 \\
2002 & 14,540 & 39668666 & 16,320 & 4852164 \\
2003 & 14,710 & 40614967 & 16,670 & 5015811 \\
2004 & 14,890 & 41603208 & 17,030 & 5185360 \\
2005 & 15,060 & 42577995 & 17,390 & 5357868 \\
2006 & 15,230 & 43584309 & 17,770 & 5541787 \\
2007 & 15,400 & 44599793 & 18,160 & 5731392 \\
2008 & 15,570 & 45630264 & 18,570 & 5930734 \\
2009 & 15,740 & 46669893 & 18,990 & 6136054 \\
2010 & 15,900 & 47700773 & 19,420 & 6349063 \\
2011 & 16,120 & 48812208 & 19,844 & 6548215 \\
2012 & 16,342 & 49944483 & 20,276 & 6752929 \\
& & & & \\
\hline
\end{tabular}

\section{Power Forecast}

The Power workbook develops the power information for each machine. Here all the power requirements for each equipment type are cataloged, and UECs are calculated. This is very different from the first version of the model in which each scenario had the power levels built into it, resulting in much repetition and making it time consuming to update the whole model. This section shows the rest of the Set-Up page, and then the PC CPU page 
as an example of the inputs and calculations. Following that are the power inputs for each of the devices.

The Set-Up page is used in this workbook to provide operation variables necessary in determining the energy use by the equipment. Following the density set-up are the operation variables, diversity and the fraction of the year spent in each mode, for the three scenarios. Diversity is the fraction of machines that are on at a given time. Fraction of the year in active, standby, and suspend modes splits a typical work day up into the times spent in the different modes and expresses them as percentages of the 8,760 hours in a year. These are the same for the three scenarios, except that copiers have a lower suspend time because the Energy Star and Advanced models are assumed to have an auto-off function. Table A-16 shows the second half of the Set-Up page.

Table A-16: The operation section of the Set-Up page for OFEEM

\begin{tabular}{|c|c|c|c|c|c|c|c|c|c|}
\hline Variable & $\mathrm{PCs}$ & Terminals & $\begin{array}{c}\text { Laser } \\
\text { Printers } \\
\end{array}$ & \begin{tabular}{|c|} 
Serial \\
Printers \\
\end{tabular} & Copiers & Faxes & $\begin{array}{c}\text { POS } \\
\text { Terminals } \\
\end{array}$ & Mainframes & $\begin{array}{c}\text { Mini- } \\
\text { Computers }\end{array}$ \\
\hline \multicolumn{10}{|c|}{ Business-As-Usual Set-Up } \\
\hline Daytime Diversity & $76 \%$ & $76 \%$ & $76 \%$ & $60 \%$ & $100 \%$ & $100 \%$ & $100 \%$ & $100 \%$ & $100 \%$ \\
\hline Weekend Diversity & $20 \%$ & $20 \%$ & $20 \%$ & $20 \%$ & $20 \%$ & $100 \%$ & $0 \%$ & $0 \%$ & $0 \%$ \\
\hline Fraction of year active & $9 \%$ & $9 \%$ & $1 \%$ & $1 \%$ & $3.7 \%$ & $3.7 \%$ & $30 \%$ & $44 \%$ & $44 \%$ \\
\hline Fraction of year standby & $13 \%$ & $13 \%$ & $4 \%$ & $3 \%$ & $14 \%$ & $96 \%$ & $20 \%$ & $45 \%$ & $45 \%$ \\
\hline \multicolumn{10}{|l|}{ Energy Star Set-Up } \\
\hline Daytime Diversity & $76 \%$ & $76 \%$ & $76 \%$ & $60 \%$ & $100 \%$ & $100 \%$ & $100 \%$ & $100 \%$ & $100 \%$ \\
\hline Nighttime Diversity & $18 \%$ & $18 \%$ & $18 \%$ & $18 \%$ & $20 \%$ & $100 \%$ & $0 \%$ & $80 \%$ & $80 \%$ \\
\hline Weekend Diversity & $20 \%$ & $20 \%$ & $20 \%$ & $20 \%$ & $20 \%$ & $100 \%$ & $0 \%$ & $0 \%$ & $0 \%$ \\
\hline Fraction of year active & $9 \%$ & $9 \%$ & $1 \%$ & $1 \%$ & $3.7 \%$ & $3.7 \%$ & $30 \%$ & $44 \%$ & $44 \%$ \\
\hline \multicolumn{10}{|c|}{ Advanced Energy Efficiency Set-Up } \\
\hline Daytime Diversity & $76 \%$ & $76 \%$ & $76 \%$ & $60 \%$ & $100 \%$ & $100 \%$ & $100 \%$ & $100 \%$ & $100 \%$ \\
\hline Nighttime Diversity & $18 \%$ & $18 \%$ & $18 \%$ & $18 \%$ & $20 \%$ & $100 \%$ & $0 \%$ & $80 \%$ & $80 \%$ \\
\hline Weekend Diversity & $20 \%$ & $20 \%$ & $20 \%$ & $20 \%$ & $20 \%$ & $100 \%$ & $0 \%$ & $0 \%$ & $0 \%$ \\
\hline Fraction of year active & $9 \%$ & $9 \%$ & $1 \%$ & $1 \%$ & $3.7 \%$ & $3.7 \%$ & $30 \%$ & $44 \%$ & $44 \%$ \\
\hline Fraction of year standby & $13 \%$ & $13 \%$ & $4 \%$ & $3 \%$ & $14 \%$ & $96 \%$ & $20 \%$ & $45 \%$ & $45 \%$ \\
\hline Fraction of year suspend & $13 \%$ & $13 \%$ & $30 \%$ & $27 \%$ & $16 \%$ & $0 \%$ & $0 \%$ & $0 \%$ & $0 \%$ \\
\hline Fraction of the year on & $35 \%$ & $35 \%$ & $35 \%$ & $31 \%$ & $34 \%$ & $100 \%$ & $50 \%$ & $89 \%$ & $89 \%$ \\
\hline
\end{tabular}

Table A-17a shows the first 13 columns from the PC CPU page from the power workbook. Power levels for standard, low-power, and advanced low-power PC CPUs are shown. Given first is the peak power in watts, followed by the active, standby, and suspend power levels as percentages of the peak power. No power levels are shown for the low-power or advanced low-power units between 1985 and 1992 as none existed then. One final note is that the copier page has three extra columns, one for the plug load of each type of unit. 
Table A-17a: Power input for PC CPUs

\begin{tabular}{|c|c|c|c|c|c|c|c|c|c|c|c|c|}
\hline \multirow{3}{*}{$\frac{\mathrm{C} 12}{\text { Year }}$} & $\mathrm{C} 13$ & $\mathrm{C} 14$ & C15 & $\mathrm{C} 16$ & $\mathrm{C} 17$ & C18 & C19 & $\mathrm{C} 20$ & $\mathrm{C} 21$ & $\mathrm{C} 22$ & C23 & C24 \\
\hline & \multicolumn{4}{|c|}{ Standard Units } & \multicolumn{4}{|c|}{ Low-Power Units } & \multicolumn{4}{|c|}{ Advanced Low-Power Units } \\
\hline & $\begin{array}{l}\text { Peak } \\
\text { (W) }\end{array}$ & $\begin{array}{c}\text { Active } \\
\text { (\% peak) }\end{array}$ & $\begin{array}{l}\text { Standby } \\
\text { (\% peak) }\end{array}$ & $\begin{array}{l}\text { Suspend } \\
\text { (\% peak) }\end{array}$ & $\begin{array}{l}\text { Peak } \\
\text { (W) }\end{array}$ & $\begin{array}{c}\text { Active } \\
\text { (\% peak) }\end{array}$ & $\begin{array}{l}\text { Standby } \\
\text { (\% peak) }\end{array}$ & $\begin{array}{l}\text { Suspend } \\
\text { (\% peak) }\end{array}$ & $\begin{array}{l}\text { Peak } \\
\text { (W) }\end{array}$ & $\begin{array}{c}\text { Active } \\
\text { (\% peak) }\end{array}$ & $\begin{array}{l}\text { Standby } \\
\text { (\% peak) }\end{array}$ & $\begin{array}{l}\text { Suspend } \\
\text { (\% peak) }\end{array}$ \\
\hline 1985 & 97 & $100 \%$ & $100 \%$ & $100 \%$ & & & & & & & & \\
\hline 1986 & 93 & $100 \%$ & $100 \%$ & $100 \%$ & & & & & & & & \\
\hline 1987 & 90 & $100 \%$ & $100 \%$ & $100 \%$ & & & & & & & & \\
\hline 1988 & 86 & $100 \%$ & $100 \%$ & $100 \%$ & & & & & & & & \\
\hline 1989 & 82 & $100 \%$ & $100 \%$ & $100 \%$ & & & & & & & & \\
\hline 1990 & 79 & $100 \%$ & $100 \%$ & $100 \%$ & & & & & & & & \\
\hline 1991 & 75 & $100 \%$ & $100 \%$ & $100 \%$ & & & & & & & & \\
\hline 1992 & 75 & $100 \%$ & $100 \%$ & $100 \%$ & & & & & & & & \\
\hline 1993 & 75 & $100 \%$ & $100 \%$ & $100 \%$ & 40 & $100 \%$ & $63 \%$ & $63 \%$ & 40 & $100 \%$ & $63 \%$ & $63 \%$ \\
\hline 1994 & 75 & $100 \%$ & $100 \%$ & $100 \%$ & 40 & $100 \%$ & $63 \%$ & $63 \%$ & 40 & $100 \%$ & $63 \%$ & $63 \%$ \\
\hline 1995 & 70 & $100 \%$ & $100 \%$ & $100 \%$ & 40 & $100 \%$ & $63 \%$ & $63 \%$ & 34 & $100 \%$ & $55 \%$ & $55 \%$ \\
\hline 1996 & 65 & $100 \%$ & $100 \%$ & $100 \%$ & 40 & $100 \%$ & $63 \%$ & $63 \%$ & 28 & $100 \%$ & $48 \%$ & $48 \%$ \\
\hline 1997 & 60 & $100 \%$ & $100 \%$ & $100 \%$ & 40 & $100 \%$ & $63 \%$ & $63 \%$ & 21 & $100 \%$ & $41 \%$ & $41 \%$ \\
\hline 1998 & 55 & $100 \%$ & $100 \%$ & $100 \%$ & 40 & $100 \%$ & $63 \%$ & $63 \%$ & 15 & $100 \%$ & $33 \%$ & $33 \%$ \\
\hline 1999 & 55 & $100 \%$ & $100 \%$ & $100 \%$ & 40 & $100 \%$ & $63 \%$ & $63 \%$ & 15 & $100 \%$ & $33 \%$ & $33 \%$ \\
\hline 2000 & 55 & $100 \%$ & $100 \%$ & $100 \%$ & 44 & $100 \%$ & $57 \%$ & $57 \%$ & 15 & $100 \%$ & $33 \%$ & $33 \%$ \\
\hline 2001 & 55 & $100 \%$ & $100 \%$ & $100 \%$ & 48 & $100 \%$ & $53 \%$ & $53 \%$ & 15 & $100 \%$ & $33 \%$ & $33 \%$ \\
\hline 2002 & 55 & $100 \%$ & $100 \%$ & $100 \%$ & 51 & $100 \%$ & $49 \%$ & $49 \%$ & 15 & $100 \%$ & $33 \%$ & $33 \%$ \\
\hline 2003 & 55 & $100 \%$ & $100 \%$ & $100 \%$ & 55 & $100 \%$ & $45 \%$ & $45 \%$ & 15 & $100 \%$ & $33 \%$ & $33 \%$ \\
\hline 2004 & 55 & $100 \%$ & $100 \%$ & $100 \%$ & 55 & $100 \%$ & $45 \%$ & $45 \%$ & 15 & $100 \%$ & $33 \%$ & $33 \%$ \\
\hline 2005 & 55 & $100 \%$ & $100 \%$ & $100 \%$ & 55 & $100 \%$ & $45 \%$ & $45 \%$ & 15 & $100 \%$ & $33 \%$ & $33 \%$ \\
\hline 2006 & 55 & $100 \%$ & $100 \%$ & $100 \%$ & 55 & $100 \%$ & $45 \%$ & $45 \%$ & 15 & $100 \%$ & $33 \%$ & $33 \%$ \\
\hline 2007 & 55 & $100 \%$ & $100 \%$ & $100 \%$ & 55 & $100 \%$ & $45 \%$ & $45 \%$ & 15 & $100 \%$ & $33 \%$ & $33 \%$ \\
\hline 2008 & 55 & $100 \%$ & $100 \%$ & $100 \%$ & 55 & $100 \%$ & $45 \%$ & $45 \%$ & 15 & $100 \%$ & $33 \%$ & $33 \%$ \\
\hline 2009 & 55 & $100 \%$ & $100 \%$ & $100 \%$ & 55 & $100 \%$ & $45 \%$ & $45 \%$ & 15 & $100 \%$ & $33 \%$ & $33 \%$ \\
\hline 2010 & 55 & $100 \%$ & $100 \%$ & $100 \%$ & 55 & $100 \%$ & $45 \%$ & $45 \%$ & 15 & $100 \%$ & $33 \%$ & $33 \%$ \\
\hline 2011 & 55 & $100 \%$ & $100 \%$ & $100 \%$ & 55 & $100 \%$ & $45 \%$ & $45 \%$ & 15 & $100 \%$ & $33 \%$ & $33 \%$ \\
\hline 2012 & 55 & $100 \%$ & $100 \%$ & $100 \%$ & 55 & $100 \%$ & $45 \%$ & $45 \%$ & 15 & $100 \%$ & $33 \%$ & $33 \%$ \\
\hline
\end{tabular}

Adjacent to the power levels are UECs for each device, as shown in Table A-17b. For each unit type, standard, low-power, and advanced low-power, is shown the modal UEC, or the amount of energy spent in a year in active, standby, or suspend mode. These are calculated using Equation A-5, except that there is no low-power fraction and only one mode. Again, this is the same for the other devices except copiers, which have in addition UECs for the plug load. 
Table A-17b: UECs for PC CPUs by unit type and mode

\begin{tabular}{|c|c|c|c|c|c|c|c|c|c|c|c|c|}
\hline \multirow[t]{2}{*}{ Year } & \multicolumn{4}{|c|}{ Standard Units UEC } & \multicolumn{4}{|c|}{ Low-Power Units UEC } & \multicolumn{4}{|c|}{ Advanced Low-Power Units UEC } \\
\hline & $\begin{array}{c}\text { Active } \\
\text { (kWh/yr) }\end{array}$ & \begin{tabular}{|l|} 
Standby \\
$(\mathrm{kWh} / \mathrm{yr})$
\end{tabular} & $\begin{array}{l}\text { Suspend } \\
(\mathrm{kWh} / \mathrm{yr})\end{array}$ & \begin{tabular}{|c|} 
Total \\
$(\mathrm{kWh} / \mathrm{yr})$
\end{tabular} & $\begin{array}{c}\begin{array}{c}\text { Active } \\
(\mathrm{kWh} / \mathrm{yr})\end{array} \\
\end{array}$ & \begin{tabular}{|l|} 
Standby \\
$(\mathrm{kWh} / \mathrm{yr})$
\end{tabular} & \begin{tabular}{|c|} 
Suspend \\
$(\mathrm{kWh} / \mathrm{yr})$
\end{tabular} & $\begin{array}{c}\text { Total } \\
(\mathrm{kWh} / \mathrm{yr})\end{array}$ & $\begin{array}{c}\text { Active } \\
\text { (kWh/yr) }\end{array}$ & \begin{tabular}{|c|} 
Standby \\
$(\mathrm{kWh} / \mathrm{yr})$
\end{tabular} & $\begin{array}{l}\text { Suspend } \\
(\mathrm{kWh} / \mathrm{yr})\end{array}$ & $\begin{array}{c}\text { Total } \\
(\mathrm{kWh} / \mathrm{yr})\end{array}$ \\
\hline 1985 & 78 & 107 & 114 & 299 & & & & & & & & \\
\hline 1986 & 75 & 103 & 110 & 287 & & & & & & & & \\
\hline 1987 & 72 & 99 & 105 & 276 & & & & & & & & \\
\hline 1988 & 69 & 95 & 101 & 265 & & & & & & & & \\
\hline 1989 & 66 & 91 & 97 & 254 & & & & & & & & \\
\hline 1990 & 63 & 87 & 92 & 242 & & & & & & & & \\
\hline 1991 & 60 & 83 & 88 & 231 & & & & & & & & \\
\hline 1992 & 60 & 83 & 88 & 231 & & & & & & & & \\
\hline 1993 & 60 & 83 & 88 & 231 & 32 & 28 & 29 & 89 & 32 & 28 & 29 & 89 \\
\hline 1994 & 60 & 83 & 88 & 231 & 32 & 28 & 29 & 89 & 32 & 28 & 29 & 89 \\
\hline 1995 & 56 & 77 & 82 & 216 & 32 & 28 & 29 & 89 & 27 & 21 & 22 & 70 \\
\hline 1996 & 52 & 72 & 76 & 200 & 32 & 28 & 29 & 89 & 22 & 15 & 15 & 52 \\
\hline 1997 & 48 & 66 & 70 & 185 & 32 & 28 & 29 & 89 & 17 & 10 & 10 & 37 \\
\hline 1998 & 44 & 61 & 65 & 169 & 32 & 28 & 29 & 89 & 12 & 6 & 6 & 23 \\
\hline 1999 & 44 & 61 & 65 & 169 & 32 & 28 & 29 & 89 & 12 & 6 & 6 & 23 \\
\hline 2000 & 44 & 61 & 65 & 169 & 35 & 28 & 29 & 92 & 12 & 6 & 6 & 23 \\
\hline 2001 & 44 & 61 & 65 & 169 & 38 & 28 & 29 & 95 & 12 & 6 & 6 & 23 \\
\hline 2002 & 44 & 61 & 65 & 169 & 41 & 28 & 29 & 98 & 12 & 6 & 6 & 23 \\
\hline 2003 & 44 & 61 & 65 & 169 & 44 & 28 & 29 & 101 & 12 & 6 & 6 & 23 \\
\hline 2004 & 44 & 61 & 65 & 169 & 44 & 28 & 29 & 101 & 12 & 6 & 6 & 23 \\
\hline 2005 & 44 & 61 & 65 & 169 & 44 & 28 & 29 & 101 & 12 & 6 & 6 & 23 \\
\hline 2006 & 44 & 61 & 65 & 169 & 44 & 28 & 29 & 101 & 12 & 6 & 6 & 23 \\
\hline 2007 & 44 & 61 & 65 & 169 & 44 & 28 & 29 & 101 & 12 & 6 & 6 & 23 \\
\hline 2008 & 44 & 61 & 65 & 169 & 44 & 28 & 29 & 101 & 12 & 6 & 6 & 23 \\
\hline 2009 & 44 & 61 & 65 & 169 & 44 & 28 & 29 & 101 & 12 & 6 & 6 & 23 \\
\hline 2010 & 44 & 61 & 65 & 169 & 44 & 28 & 29 & 101 & 12 & 6 & 6 & 23 \\
\hline 2011 & 44 & 61 & 65 & 169 & 44 & 28 & 29 & 101 & 12 & 6 & 6 & 23 \\
\hline 2012 & 44 & 61 & 65 & 169 & 44 & 28 & 29 & 101 & 12 & 6 & 6 & 23 \\
\hline
\end{tabular}

Following are the power levels for each equipment type for each scenario. The power levels shown in the Business-as-Usual case are for the average stock in that year, and they follow a linear trend between the years. For example in Table A-18a, the power for PC CPUs starts at $97 \mathrm{~W}$ in 1985 and linearly drops to $75 \mathrm{~W}$ by 1991 . It stays at $75 \mathrm{~W}$ until 1994 , after which it linearly drops to $55 \mathrm{~W}$ by 1998 . It continues at $55 \mathrm{~W}$ thereafter.

Some of the equipment types (serial printers, mainframes, and mini-computers) don't have Energy Star or Advanced power levels, in which case we simply used the power levels from the Business-as-Usual scenario. 
Table A-18: Stock equipment power by device type

A-18a-PC CPU Equipment Power

\begin{tabular}{|c|ccc|}
\hline Year & Active $(W)$ & Standby $(W)$ & Suspend $(W)$ \\
\hline Business-as-Usual Stock & & & \\
1985 & 97 & 97 & 97 \\
1986 to 1990 & linear trend & linear trend & linear trend \\
1991 to 1994 & 75 & 75 & 75 \\
1995 to 1997 & linear trend & linear trend & linear trend \\
1998 and onwards & 55 & 55 & 55 \\
Energy Star, New Equipment & & & \\
1993 to 1999 & 40 & 25 & 25 \\
2000 to 2002 & linear trend & 25 & 25 \\
2003 and onwards & 55 & 25 & 25 \\
Advanced, New Equipment & & & \\
1993 to 1994 & 40 & 25 & 25 \\
1995 to 1997 & linear trend & linear trend & linear trend \\
1998 and onwards & 15 & 5 & 5 \\
\hline
\end{tabular}

\begin{tabular}{|c|ccc|}
\hline \multicolumn{4}{|c|}{ A-18b-Monitor Equipment Power } \\
\hline Year & Active $(W)$ & Standby $(W)$ & Suspend $(W)$ \\
\hline Business-as-Usual Stock & & & \\
1985 & 28 & 28 & 28 \\
1986 to 1990 & linear trend & linear trend & linear trend \\
1991 & 55 & 55 & 55 \\
1992 to 2000 & linear trend & linear trend & linear trend \\
2001 and onwards & 65 & 65 & 65 \\
Energy Star, New Equipment & 57 & 43 & 14 \\
1993 & linear trend & linear trend & linear trend \\
2001 and onwards & 65 & 51 & 14 \\
Advanced, New Equipment & & & 14 \\
1993 to 1994 & 57 & 43 & linear trend \\
1995 to 1997 & linear trend & linear trend & 5 \\
1998 and onwards & 23 & 5 & \\
\hline
\end{tabular}

A-18c-Laser Printer Equipment Power

\begin{tabular}{|c|ccc|}
\hline Year & Active $(W)$ & Standby $(W)$ & Suspend $(W)$ \\
\hline $\begin{array}{c}\text { Business-as-Usual Stock } \\
\text { 1985 and onwards }\end{array}$ & 250 & 80 & 80 \\
$\begin{array}{c}\text { Energy Star, New Equipment } \\
\text { 1993 and onwards }\end{array}$ & 250 & 80 & 25 \\
Advanced, New Equipment & & & \\
1993 to 1995 & 250 & 80 & 25 \\
1996 to 1999 & linear trend & linear trend & linear trend \\
2000 and onwards & 120 & 7 & 5 \\
\hline
\end{tabular}

A-18d-Serial Printer Equipment Power

\begin{tabular}{|c|ccc|}
\hline Year & Active $(W)$ & Standby $(W)$ & Suspend $(W)$ \\
\hline Business-as-Usual Stock & & & \\
1985 to 1990 & 45 & 15 & 15 \\
1991 to 1999 & linear trend & linear trend & linear trend \\
2000 and onwards & 20 & 8 & 8 \\
\hline
\end{tabular}


Table 18: Stock equipment power by device type (continued)

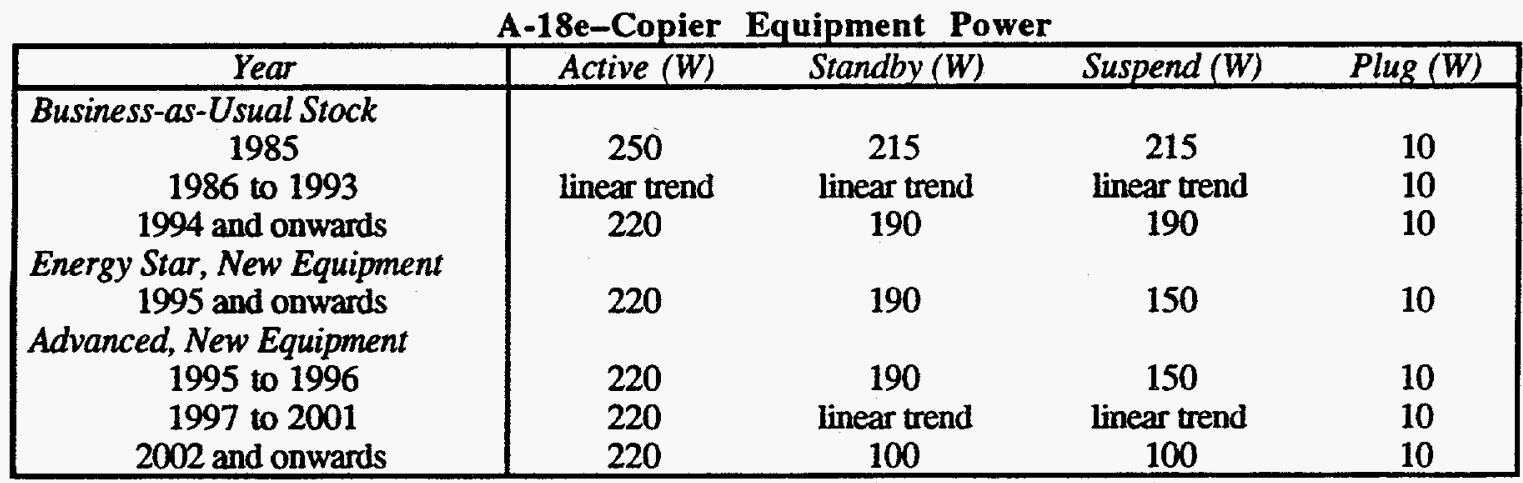

A-18f-Fax Equipment Power

\begin{tabular}{|c|cc|}
\hline Year & Active (W) & Standby (W) \\
\hline Business-as-Usual Stock & & \\
1985 & 175 & 20 \\
1986 to 1993 & 175 & linear trend \\
1994 and onwards & 175 & 35 \\
Energy Star, New Equipment & 175 & \\
1995 and onwards & & 15 \\
Advanced, New Equipment & 175 & 15 \\
1995 to 1996 & 175 & linear trend \\
1997 to 2001 & 175 & 5 \\
2002 and onwards & &
\end{tabular}

\begin{tabular}{|c|cc|}
\multicolumn{2}{c}{ A-18g-POS Terminal Equipment Power } \\
\hline Year & Active (W) & Standby (W) \\
\hline $\begin{array}{c}\text { Business-as-Usual Stock } \\
1985 \text { and onwards } \\
\text { Advanced, New Equipment } \\
\text { 1993 and onwards }\end{array}$ & 130 & 130 \\
& 70 & 10 \\
\hline
\end{tabular}

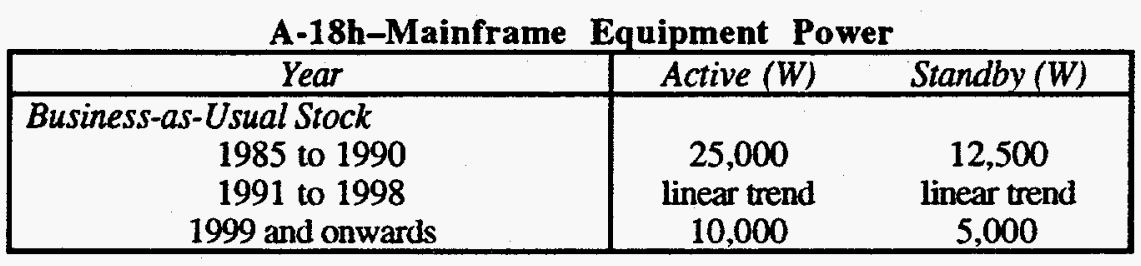

\begin{tabular}{|c|c|c|}
\hline A-18i-Mini-computer & Equipment & Power \\
\hline Year & Active (W) & Standby (W) \\
\hline $\begin{array}{c}\text { Business-as-Usual Stock } \\
1985 \text { to } 1990 \\
1991 \text { to } 1997 \\
1998 \text { and onwards }\end{array}$ & $\begin{array}{c}3,500 \\
\text { linear trend } \\
1,250\end{array}$ & $\begin{array}{c}1,750 \\
\text { linear trend } \\
625\end{array}$ \\
\hline
\end{tabular}

Table A-19 outlines annual usage for each device type, also shown in Table A-16. These are shown as the percentage of the year the devices spend in one of the three modes. We did not change these values among the scenarios except for copiers in the Energy Star and Advanced Energy Efficiency scenarios where the machines spend less time in suspend mode and more time off (using the plug load) because the newer copiers have an auto-off function. 
Table A-19: Usage by device type

\begin{tabular}{l|c|c|c|}
\hline \multirow{2}{*}{ Device type } & \multicolumn{3}{|c|}{ Percentage of year in: } \\
\cline { 2 - 4 } & Active & Standby & Suspend \\
\hline PC & $9 \%$ & $13 \%$ & $13 \%$ \\
Monitor & $9 \%$ & $13 \%$ & $13 \%$ \\
Page Printer & $1 \%$ & $4 \%$ & $30 \%$ \\
Serial Printer & $1 \%$ & $3 \%$ & $27 \%$ \\
Copier & $3.7 \%$ & $14 \%$ & $29 \%(16 \%)$ \\
Fax & $3.7 \%$ & $96 \%$ & $0 \%$ \\
POS Terminal & $30 \%$ & $20 \%$ & $0 \%$ \\
Mainframe & $44 \%$ & $45 \%$ & $0 \%$ \\
Mini-computer & $44 \%$ & $45 \%$ & $0 \%$
\end{tabular}

\section{Power Changes}

The power levels of PC CPUs, monitors, and copiers have been updated to reflect new information. Initially the standard PC CPU power was $75 \mathrm{~W}$ from 1991 onwards. However the most recent information indicates that the power for PC CPUs is probably decreasing as manufacturers have taken advantage of the improved performance and lifetime of the cooler chips, so we have decreased the power of standard machines to $65 \mathrm{~W}$ by 1999 . In addition, the Energy Star PC CPUs seem to be increasing in power. Manufacturers first redesigned their low-end models to comply with the Energy Star program, since the power of those machines is the easiest to reduce. As the manufacturers have gained more experience and developed better technology, they have started redesigning their high-end machines, which we expect will increase the average power of energy star PC CPUs. We have reflected this in OFEEM by increasing the power of these machines from $40 \mathrm{~W}$ to $55 \mathrm{~W}$ by 2005 .

Initially we assumed that the standby power for energy star monitors is about $5 \mathrm{~W}$, based on the Nanao Flexscan monitors. However, on looking at the list of Energy-Starcompliant monitors, we discovered a range of suspend power levels. The suspend power for monitors is now $14.3 \mathrm{~W}$, the average from the EPA list.

Most copiers have a plug load, power the copier uses to remember operation settings even when it is off (it also may include anti-humidity devices or other miscellaneous loads). The plug load is about $10 \mathrm{~W}$ (although it can be up to $100 \mathrm{~W}$ ) and is a significant fraction of the energy used by these machines. OFEEM includes this energy by adding a $10 \mathrm{~W}$ load anytime the copiers are not in one of the other operation states.

One final note is that the Energy Star copiers will include an auto-off after two hours, reducing the fraction of the year spent in suspend mode and increasing that in plug mode. This will reduce the power used by the copiers left on overnight and on weekends.

\section{Main Scenarios}

There are three scenario workbooks: Business-As-Usual, Energy Star (Most-Likely), and Advanced Energy Efficiency. They take the density information from the Density workbook, the power information from the Power workbook, as well as the Floor Space and Set-Up information, to forecast the energy use by each type of office equipment according to the flow chart in Figure A-2. In addition, power forecasts are developed to check how the low-power equipment affects peak power requirements. 
At the top of the energy page is a small matrix (an example is shown as Table A-20a) of when the machines are in different modes; this is used to calculate peak load. The three periods we are concerned with are shown in the first row: morning (8:00 am to $12: 00 \mathrm{pm}$ ), afternoon (12:00 pm to $6: 00 \mathrm{pm})$, and evening (6:00 pm to $10: 00 \mathrm{pm})$. The hours available in each period are shown next. Following that the annual modal information is disaggregated to a daily number of hours and then split among the three periods.

Table A-20a: Division of the day into different modes for PC CPUs

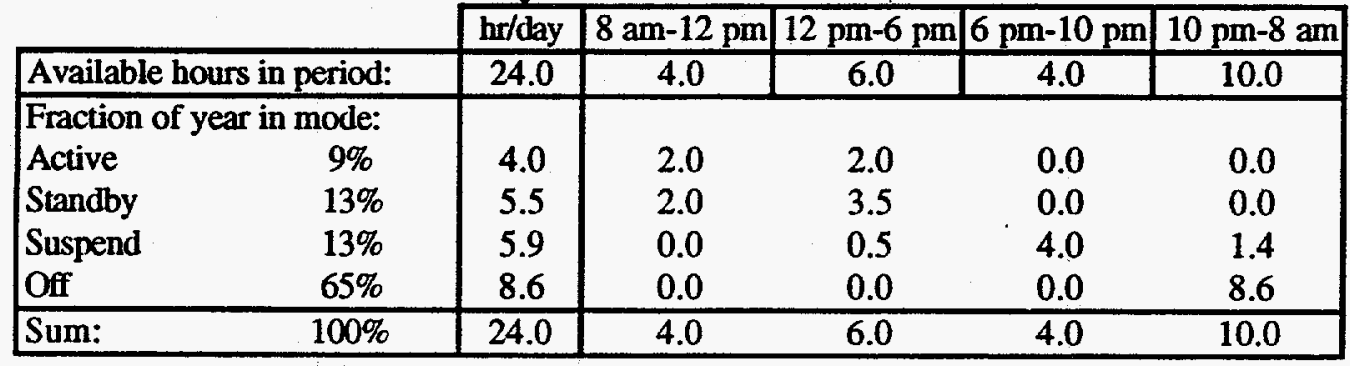

These hours are split using the following logic. Half of the active hours are spent in the morning and half in the afternoon. If there is not enough time in the morning period for half of the active hours, then the morning is filled with them and the rest are saved for later (mainframes and mini-computers are examples of this). The standby hours are then distributed using the same logic. Finally, the three periods are filled with suspend hours to the fullest extent. In this case there are some extra suspend hours available (15.4 hours available to be spread over a 14 hour day), but these are discarded for the power calculation.

This table is used in estimating the summer and winter peak power of each equipment type. The summer peak includes just the afternoon, while the winter peak includes the morning and evening. The peak power is estimated by multiplying the weighted average power by the stock. The stock was developed in the Density workbook, and the average power is weighted by the number of hours spent in each mode over the period of interest.

Table A-20b shows the first part of the PC CPU page from the Energy Star scenario. These columns take in information from other spreadsheets to have it available as the forecast progresses. Column 25 shows the percentage of equipment that is low-power, while the rest of the columns show the power for each mode for the standard and lowpower equipment. In the Business-As-Usual scenario, the low-power columns are blank, while in the Advanced Energy Efficiency scenario, the low-power columns have the power levels for the advanced equipment. 
Table A-20b: Inputs for PC CPUs in the Energy Star Most-Likely Scenario

\begin{tabular}{|c|c|c|c|c|c|c|c|}
\hline \multirow{3}{*}{$\frac{\mathrm{C} 12}{\text { Year }}$} & \multirow{3}{*}{$\begin{array}{c}\text { C25 } \\
\text { Percentage } \\
\text { Low-Power } \\
\text { \& Enabled }\end{array}$} & \multirow{2}{*}{\multicolumn{3}{|c|}{$\frac{\mathrm{C27}}{\text { Standard }}$}} & \multicolumn{3}{|c|}{$\mathrm{C} 30$} \\
\hline & & & & & & Low-Power & \\
\hline & & $\begin{array}{l}\text { Active Power } \\
\text { (W) }\end{array}$ & $\begin{array}{l}\text { Standby Power } \\
\text { (W) }\end{array}$ & $\begin{array}{l}\text { Suspend Power } \\
\text { (W) }\end{array}$ & $\begin{array}{l}\text { Active Power } \\
\text { (W) }\end{array}$ & $\begin{array}{l}\text { Standby Power } \\
\text { (W) }\end{array}$ & $\begin{array}{l}\text { Suspend Power } \\
\text { (W) }\end{array}$ \\
\hline 1985 & $0 \%$ & 97 & 97 & 97 & $\overline{0}$ & $\overline{0}$ & $\overline{0}$ \\
\hline 1986 & $0 \%$ & 93 & 93 & 93 & 0 & 0 & 0 \\
\hline 1987 & $0 \%$ & 90 & 90 & 90 & 0 & 0 & 0 \\
\hline 1988 & $0 \%$ & 86 & 86 & 86 & 0 & 0 & 0 \\
\hline 1989 & $0 \%$ & 82 & 82 & 82 & 0 & 0 & 0 \\
\hline 1990 & $0 \%$ & 79 & 79 & 79 & 0 & 0 & 0 \\
\hline 1991 & $0 \%$ & 75 & 75 & 75 & 0 & 0 & 0 \\
\hline 1992 & $0 \%$ & 75 & 75 & 75 & 0 & 0 & 0 \\
\hline 1993 & $2 \%$ & 75 & 75 & 75 & 40 & 25 & 25 \\
\hline 1994 & $6 \%$ & 75. & 75 & 75 & 40 & 25 & 25 \\
\hline 1995 & $11 \%$ & 70 & 70 & 70 & 40 & 25 & 25 \\
\hline 1996 & $17 \%$ & 65 & 65 & 65 & 40 & 25 & 25 \\
\hline 1997 & $22 \%$ & 60 & 60 & 60 & 40 & 25 & 25 \\
\hline 1998 & $28 \%$ & 55 & 55 & 55 & 40 & 25 & 25 \\
\hline 1999 & $33 \%$ & 55 & 55 & 55 & 40 & 25 & 25 \\
\hline 2000 & $39 \%$ & 55 & 55 & 55 & 44 & 25 & 25 \\
\hline 2001 & $44 \%$ & 55 & 55 & 55 & 48 & 25 & 25 \\
\hline 2002 & $47 \%$ & 55 & 55 & 55 & 51 & 25 & 25 \\
\hline 2003 & $49 \%$ & 55 & 55 & 55 & 55 & 25 & 25 \\
\hline 2004 & $50 \%$ & 55 & 55 & 55 & 55 & 25 & 25 \\
\hline 2005 & $50 \%$ & 55 & 55 & 55 & 55 & 25 & 25 \\
\hline 2006 & $50 \%$ & 55 & 55 & 55 & 55 & 25 & 25 \\
\hline 2007 & $50 \%$ & 55 & 55 & 55 & 55 & 25 & 25 \\
\hline 2008 & $50 \%$ & 55 & 55 & 55 & 55 & 25 & 25 \\
\hline 2009 & $50 \%$ & 55 & 55 & 55 & 55 & 25 & 25 \\
\hline 2010 & $50 \%$ & 55 & 55 & 55 & 55 & 25 & 25 \\
\hline 2011 & $50 \%$ & 55 & 55 & 55 & 55 & 25 & 25 \\
\hline 2012 & $50 \%$ & 55 & 55 & 55 & 55 & 25 & 25 \\
\hline
\end{tabular}

The rest of this page of the spreadsheet is filled with developing the UEC and other energy information for all the building types. Table A-20c shows an example. The average UEC is calculated using Equation A-5 and the inputs in Table A-20b. First the energy information is developed for offices, and then the rest of the building types are considered. Density is taken from the Density workbook and multiplied by the UEC to get the EUI according to Equation A-6. The EUI is multiplied by the floor space to get the energy according to Equation A-8. The summer and winter peak power are the average power multiplied by the stock for that year. 


\begin{tabular}{|c|c|c|c|c|c|c|c|c|c|c|c|}
\hline \multirow[t]{2}{*}{ Table } & \multirow{2}{*}{$\begin{array}{c}\text { A-20c: } \\
\text { C32 }\end{array}$} & \multicolumn{5}{|c|}{ Energy calculations for office } & \multicolumn{5}{|c|}{ and other building types } \\
\hline & & C33 & C34 & C35 & C36 & C37 & C38 & C39 & $\mathrm{C} 40$ & C41 & $\mathrm{C} 42$ \\
\hline & \multirow{2}{*}{$\begin{array}{c}\text { Average } \\
\text { UEC }\end{array}$} & \multicolumn{5}{|c|}{ Offices } & \multicolumn{5}{|c|}{ Retail } \\
\hline & & $\begin{array}{l}\text { Floor } \\
\text { space } \\
\text { (Msqft) }\end{array}$ & $\begin{array}{c}\text { EUI } \\
\text { (kWh/ } \\
\text { sqft-yr) }\end{array}$ & \begin{tabular}{|c|} 
Energy \\
(TWh/yr)
\end{tabular} & \begin{tabular}{|c|} 
Summer \\
Peak \\
(GW)
\end{tabular} & $\begin{array}{l}\text { Winter } \\
\text { Peak } \\
\text { (GW) }\end{array}$ & \begin{tabular}{|c|} 
Floor \\
space \\
(Msqft)
\end{tabular} & $\begin{array}{c}\text { EUI } \\
(\mathrm{kWh} / \\
\mathrm{sgft}-\mathrm{yr})\end{array}$ & $\begin{array}{l}\text { Energy } \\
(\mathrm{TWh} / \mathrm{yr})\end{array}$ & \begin{tabular}{|c|} 
Summer \\
Peak \\
(GW)
\end{tabular} & $\begin{array}{l}\text { Winter } \\
\text { Peak } \\
\text { (GW) }\end{array}$ \\
\hline 1985 & 299 & 8,794 & 0.28 & 2.48 & 0.61 & 0.48 & 12,952 & 0.03 & 0.40 & 0.10 & 0.08 \\
\hline 1986 & 287 & 9,546 & 0.32 & 3.03 & 0.75 & 0.58 & 12,805 & 0.03 & 0.44 & 0.11 & 0.09 \\
\hline 1987 & 276 & 10,298 & 0.33 & 3.42 & 0.84 & 0.66 & 12,658 & 0.04 & 0.46 & 0.11 & 0.09 \\
\hline 1988 & 265 & 11,050 & 0.32 & 3.56 & 0.88 & 0.69 & 12,512 & 0.04 & 0.44 & 0.11 & 0.08 \\
\hline 1989 & 254 & 11,802 & 0.33 & 3.84 & 0.95 & 0.74 & 12,365 & 0.04 & 0.44 & 0.11 & 0.08 \\
\hline 1990 & 242 & 12,040 & 0.33 & 4.00 & 0.99 & 0.77 & 12,650 & 0.04 & 0.46 & 0.11 & 0.09 \\
\hline 1991 & 231 & 12,230 & 0.34 & 4.13 & 1.02 & 0.80 & 12,920 & 0.04 & 0.48 & 0.12 & 0.09 \\
\hline 1992 & 231 & 12,420 & 0.37 & 4.56 & 1.13 & 0.88 & 13,170 & 0.04 & 0.53 & 0.13 & 0.10 \\
\hline 1993 & 231 & 12,650 & 0.41 & 5.15 & 1.27 & 0.99 & 13,470 & 0.04 & 0.60 & 0.15 & 0.12 \\
\hline 1994 & 231 & 12,880 & 0.45 & 5.83 & 1.44 & 1.13 & 13,770 & 0.05 & 0.68 & 0.17 & 0.13 \\
\hline 1995 & 216 & 13,120 & 0.47 & 6.14 & 1.52 & 1.19 & 14,080 & 0.05 & 0.72 & 0.18 & 0.14 \\
\hline 1996 & 200 & 13,350 & 0.47 & 6.30 & 1.56 & 1.22 & 14,380 & 0.05 & 0.74 & 0.18 & 0.14 \\
\hline 1997 & 185 & 13,570 & 0.46 & 6.23 & 1.54 & 1.20 & 14,690 & 0.05 & 0.74 & 0.18 & 0.14 \\
\hline 1998 & 169 & 13,770 & 0.44 & 6.01 & 1.48 & 1.16 & 15,010 & 0.05 & 0.71 & 0.18 & 0.14 \\
\hline 1999 & 169 & 13,980 & 0.45 & 6.23 & 1.54 & 1.20 & 15,330 & 0.05 & 0.74 & 0.18 & 0.14 \\
\hline 2000 & 169 & 14,170 & 0.45 & 6.40 & 1.58 & 1.24 & 15,650 & 0.05 & 0.77 & 0.19 & 0.15 \\
\hline 2001 & 169 & 14,350 & 0.46 & 6.56 & 1.62 & 1.26 & 15,990 & 0.05 & 0.80 & 0.20 & 0.15 \\
\hline 2002 & 169 & 14,540 & 0.46 & 6.72 & 1.66 & 1.30 & 16,320 & 0.05 & 0.82 & 0.20 & 0.16 \\
\hline 2003 & 169 & 14,710 & 0.47 & 6.88 & 1.70 & 1.33 & 16,670 & 0.05 & 0.85 & 0.21 & 0.16 \\
\hline 2004 & 169 & 14,890 & 0.47 & 7.05 & 1.74 & 1.36 & 17,030 & 0.05 & 0.88 & 0.22 & 0.17 \\
\hline 2005 & 169 & 15,060 & 0.48 & 7.21 & 1.78 & 1.39 & 17,390 & 0.05 & 0.91 & 0.22 & 0.18 \\
\hline 2006 & 169 & 15,230 & 0.48 & 7.38 & 1.82 & 1.42 & 17,770 & 0.05 & 0.94 & 0.23 & 0.18 \\
\hline 2007 & 169 & 15,400 & 0.49 & 7.56 & 1.86 & 1.46 & 18,160 & 0.05 & 0.97 & 0.24 & 0.19 \\
\hline 2008 & 169 & 15,570 & 0.50 & 7.73 & 1.91 & 1.49 & 18,570 & 0.05 & 1.00 & 0.25 & 0.19 \\
\hline 2009 & 169 & 15,740 & 0.50 & 7.91 & 1.95 & 1.53 & 18,990 & 0.05 & 1.04 & 0.26 & 0.20 \\
\hline 2010 & 169 & 15,900 & 0.51 & 8.08 & 1.99 & 1.56 & 19,420 & 0.06 & 1.08 & 0.27 & 0.21 \\
\hline 2011 & 169 & 16,120 & 0.51 & 8.27 & 2.04 & 1.60 & 19,844 & 0.06 & 1.11 & 0.27 & 0.21 \\
\hline 2012 & 169 & 16,342 & 0.52 & 8.46 & 2.09 & 1.63 & 20,276 & 0.06 & 1.14 & 0.28 & 0.22 \\
\hline
\end{tabular}

EUIs are generated for each building and equipment type by multiplying the equipment EUI in offices by the ratio of the equipment density in other buildings to that in offices. This is then multiplied by the floor space to generate the energy usage. The peak powers use the same weighted average power with the stock from each building type. Finally, the commercial sector total is the sum of the building totals.

At the end of each scenario workbook, the output spreadsheet takes information from the previous spreadsheets and puts it into a convenient format. No examples are shown here. The first matrix is of the total energy by machine type and includes the total sectoral energy. Next come the UEC from 1990 and 2005, when in the Energy Star and Advanced scenarios there are no standard machines left in the stock. The office EUIs are next, and then the EUIs for each building type. There is a spreadsheet for paper usage and one for peak power. Finally, the equipment densities in office buildings are summarized. 
APPENDIX B: COMMEND INPUT DATA FILE

A COMMEND data file that embodies the main scenarios described in this report is currently being revised, but was not available in time for publication. Please Fax a request to 510/486-6996 if you would like to receive the file, or send email to JGKoomey@lbl.gov. 
This section contains a complete set of briefing charts and tables related to office equipment energy use in the US commercial sector. We did not include all of them in the main body of the report for the sake of readibility, but we include them here because they represent a convenient summary of all the important information.

Please note that the graphs that involve floor area (Figures C-1, C-2, C-3, and C-6) use square feet (English units) because that is the way the calculations were originally done. The counterpart to $\mathrm{C}-1$ in the main text has been converted to metric units for the international audience. 
Figure C-1a: Equipment Densities in Offices Using ITI Growth

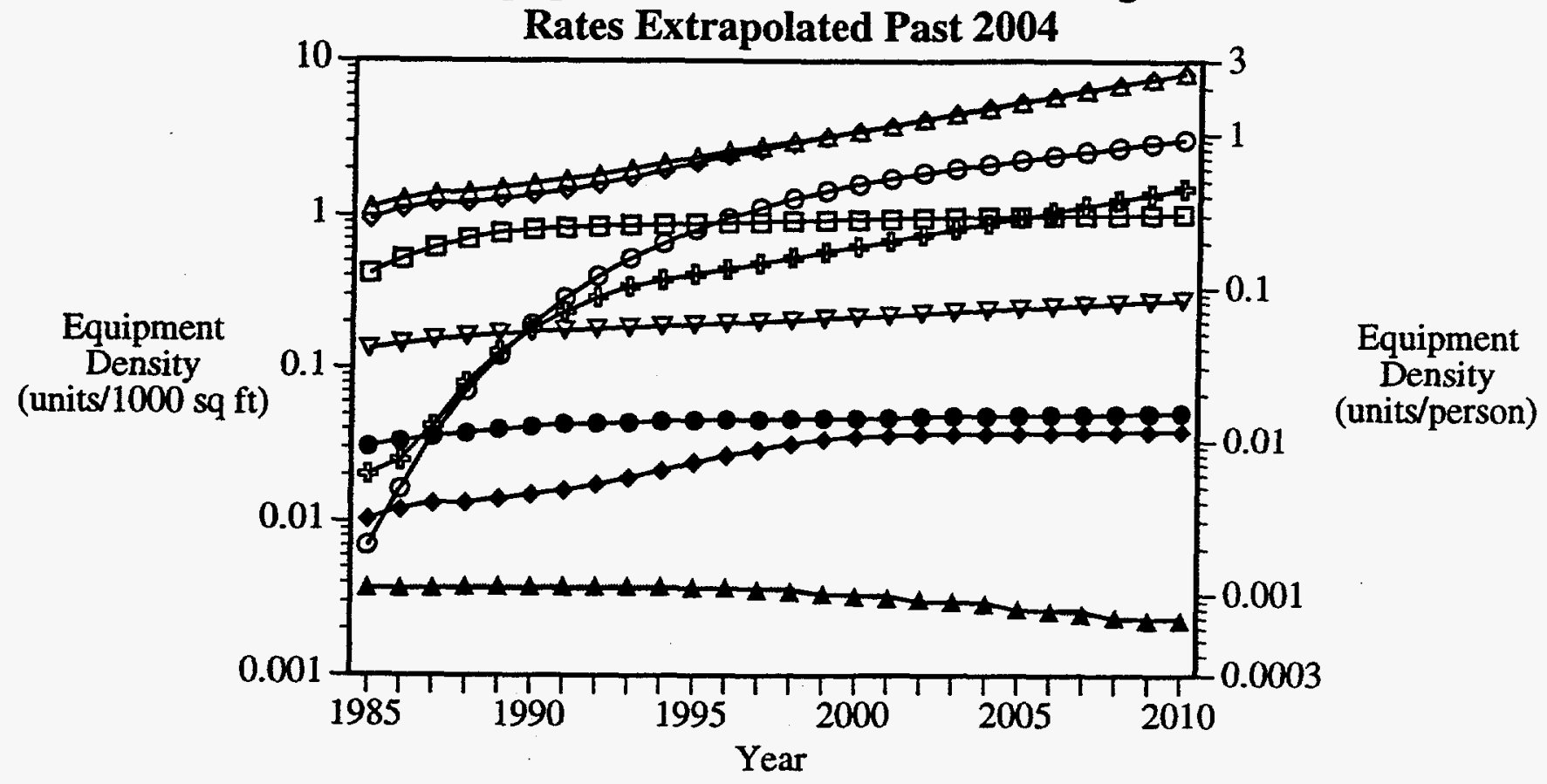

Figure C-1b: Equipment Densities in Offices in This Study

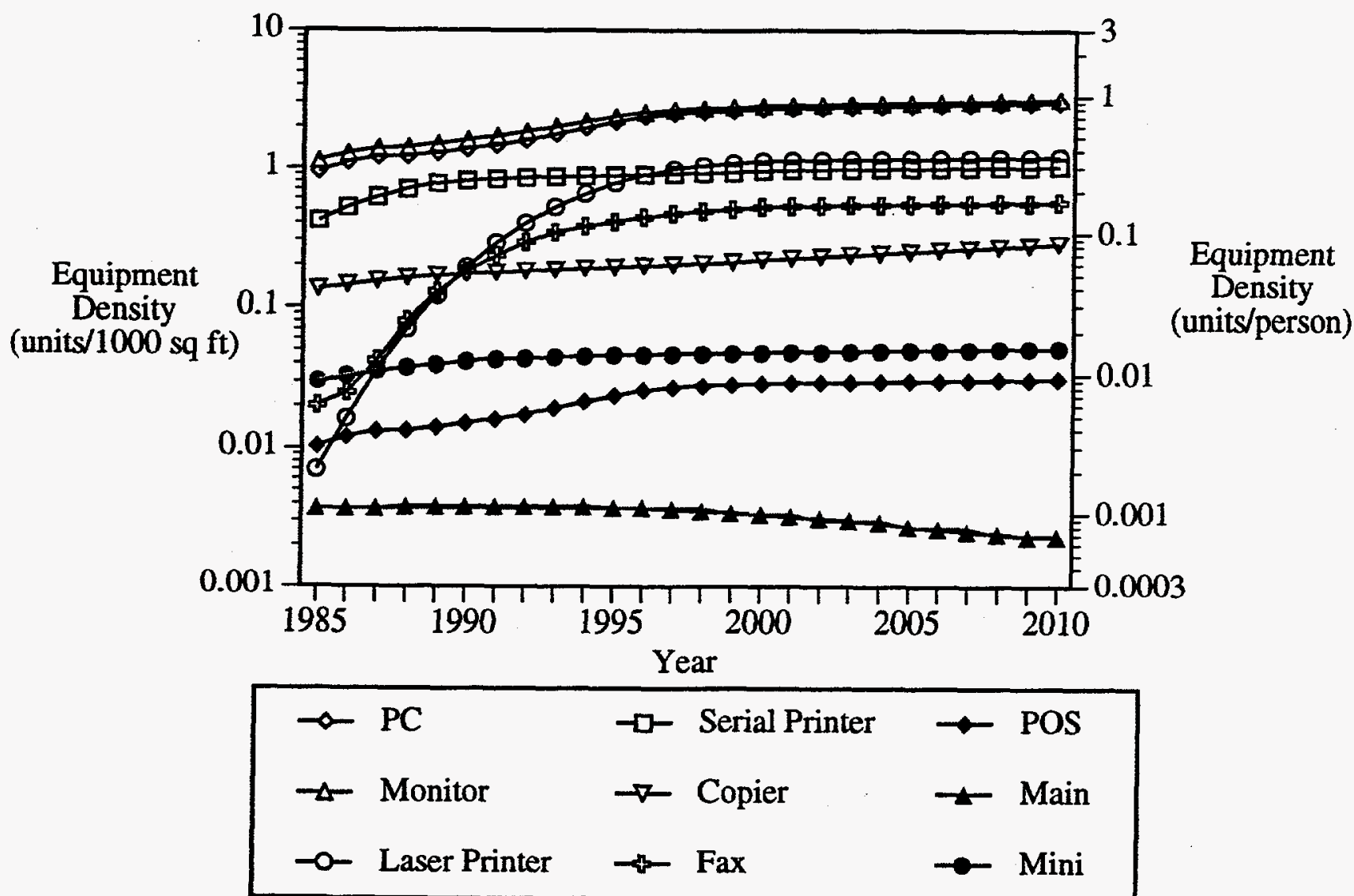

Units per person density assumes 300 square feet ( 27.88 sq. meters) per person. In our forecast, $P C$ CPU and monitor sales are assumed to grow at $2 \%$ /year after 1998, while serial printer, laser printer, and fax sales are assumed to grow at the same rate that floor stock grows (about 1.5\%/yr) starting in 1998. ITI has no forecast for POS terminals, so we assume that they grow at the same rate as PC CPUs until 1998 and then grow at $1.5 \%$ /year thereafter. 1 square meter $=10.76$ square feet. 


\section{Figure C-2: Equipment Densities by Building Type}
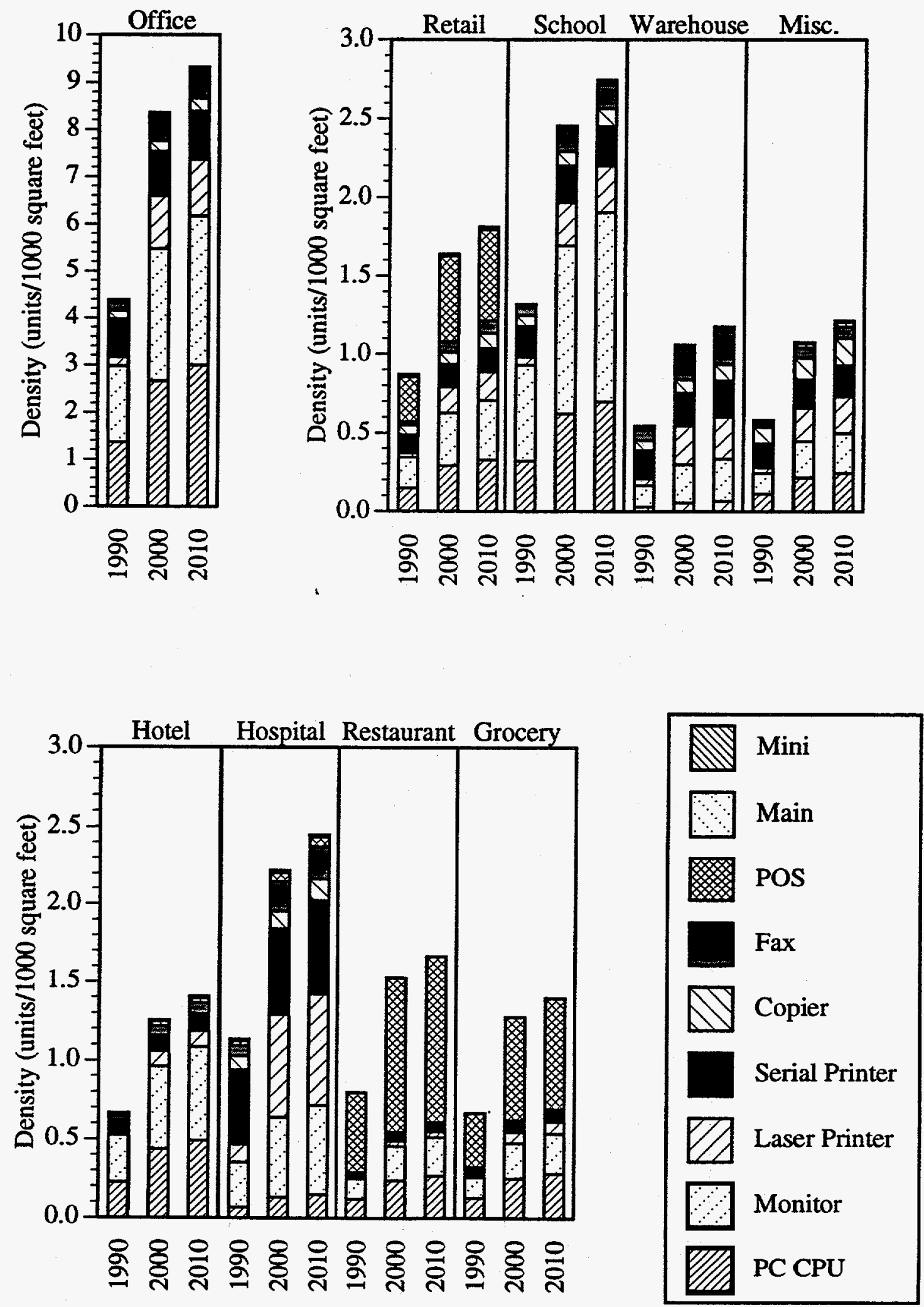
Figure C-3: Projected Commercial Sector Floorspace by Building Type

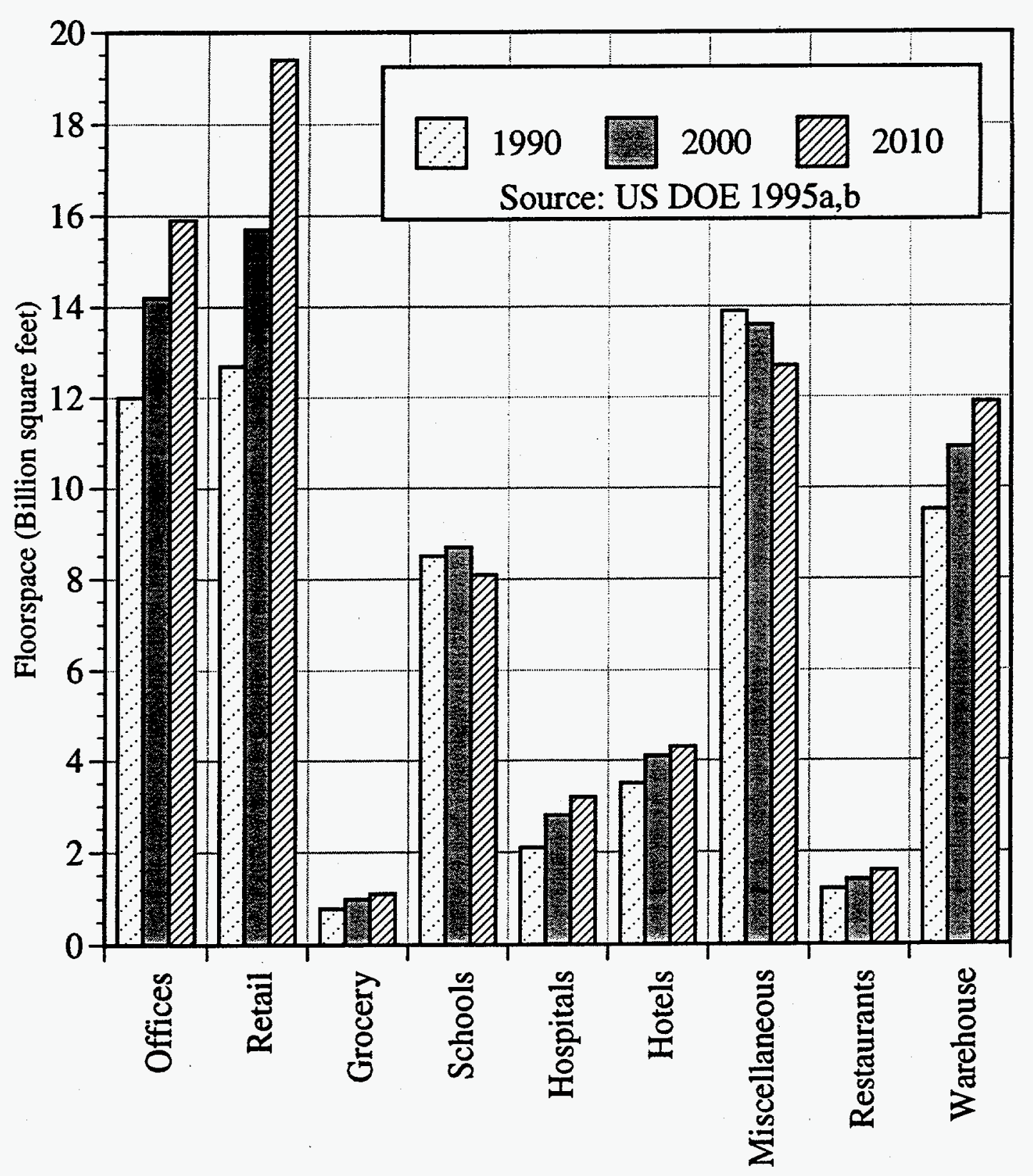




\section{Figure C-4: Summary of Stock by Building Type}
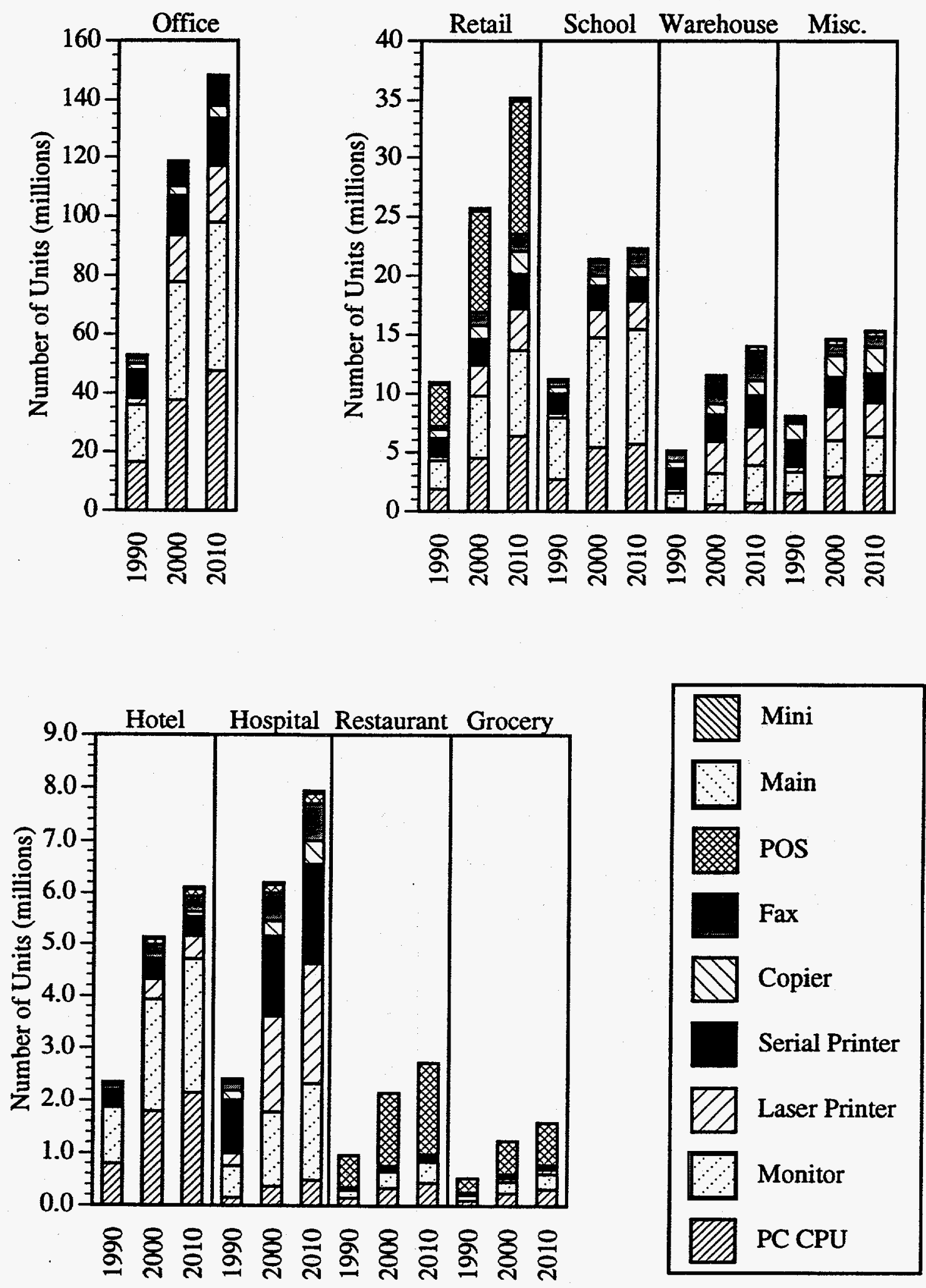

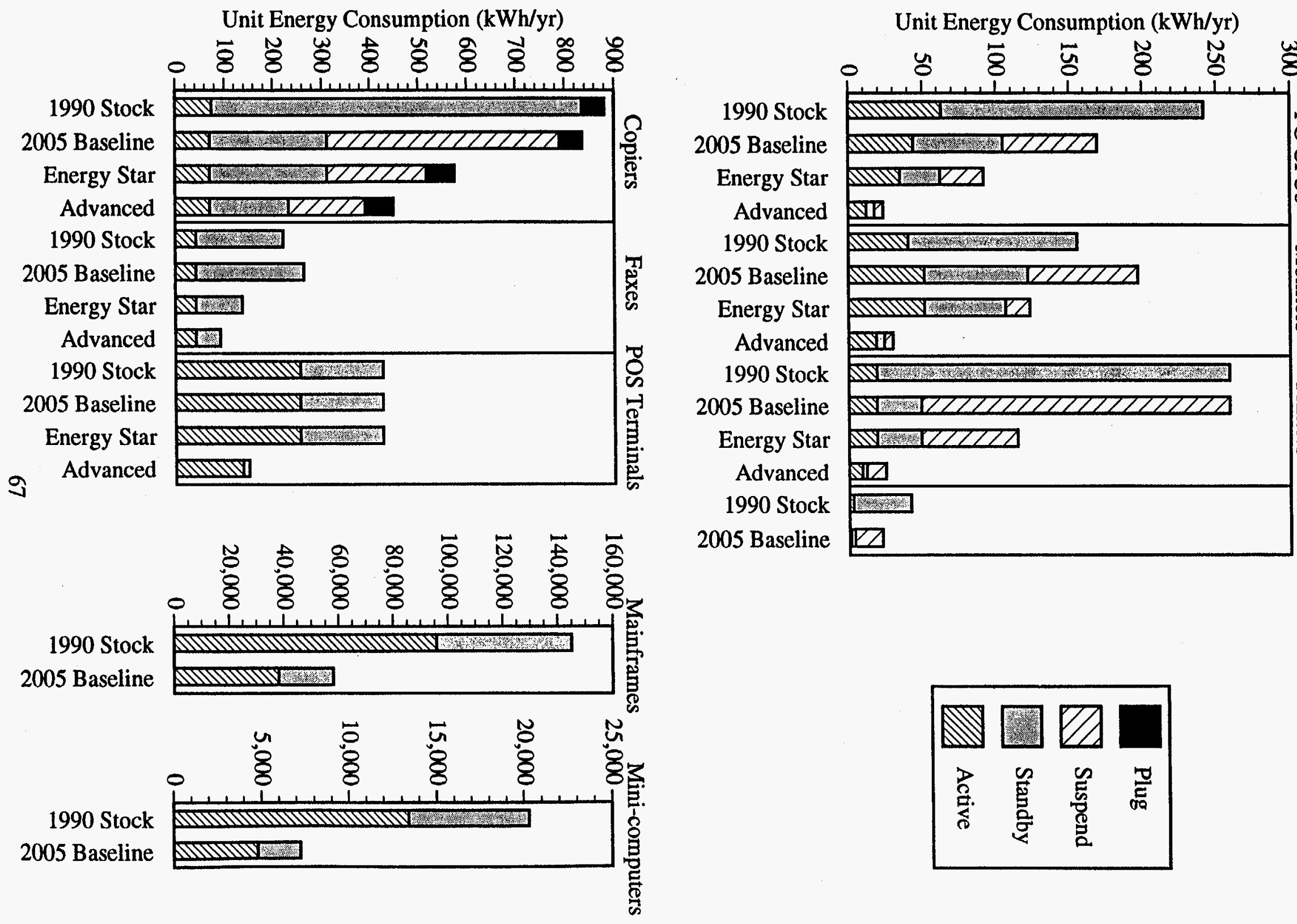

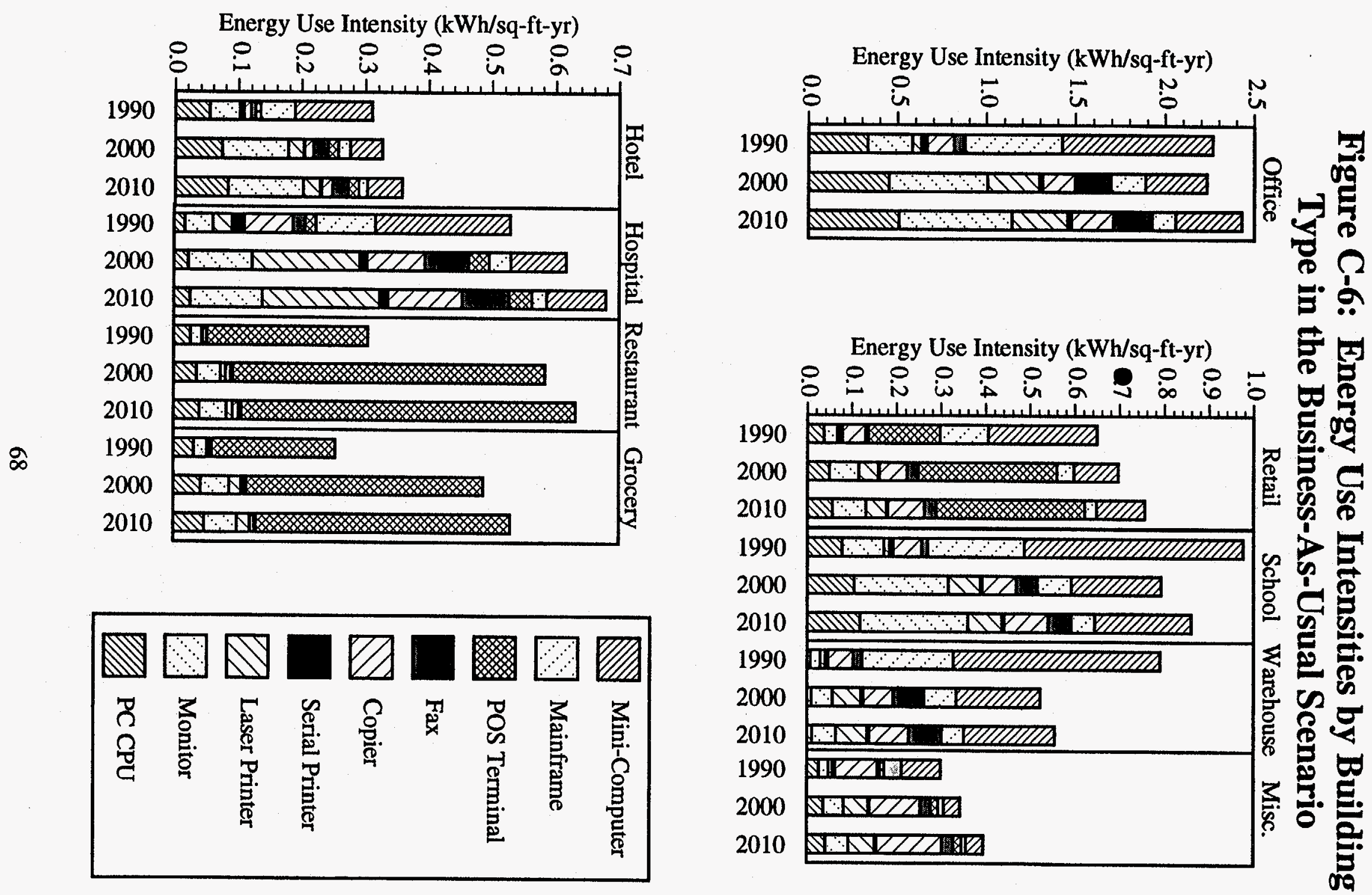
Figure C-7a: Normalized Trends in Floorspace, EUI, and Annual Energy Use

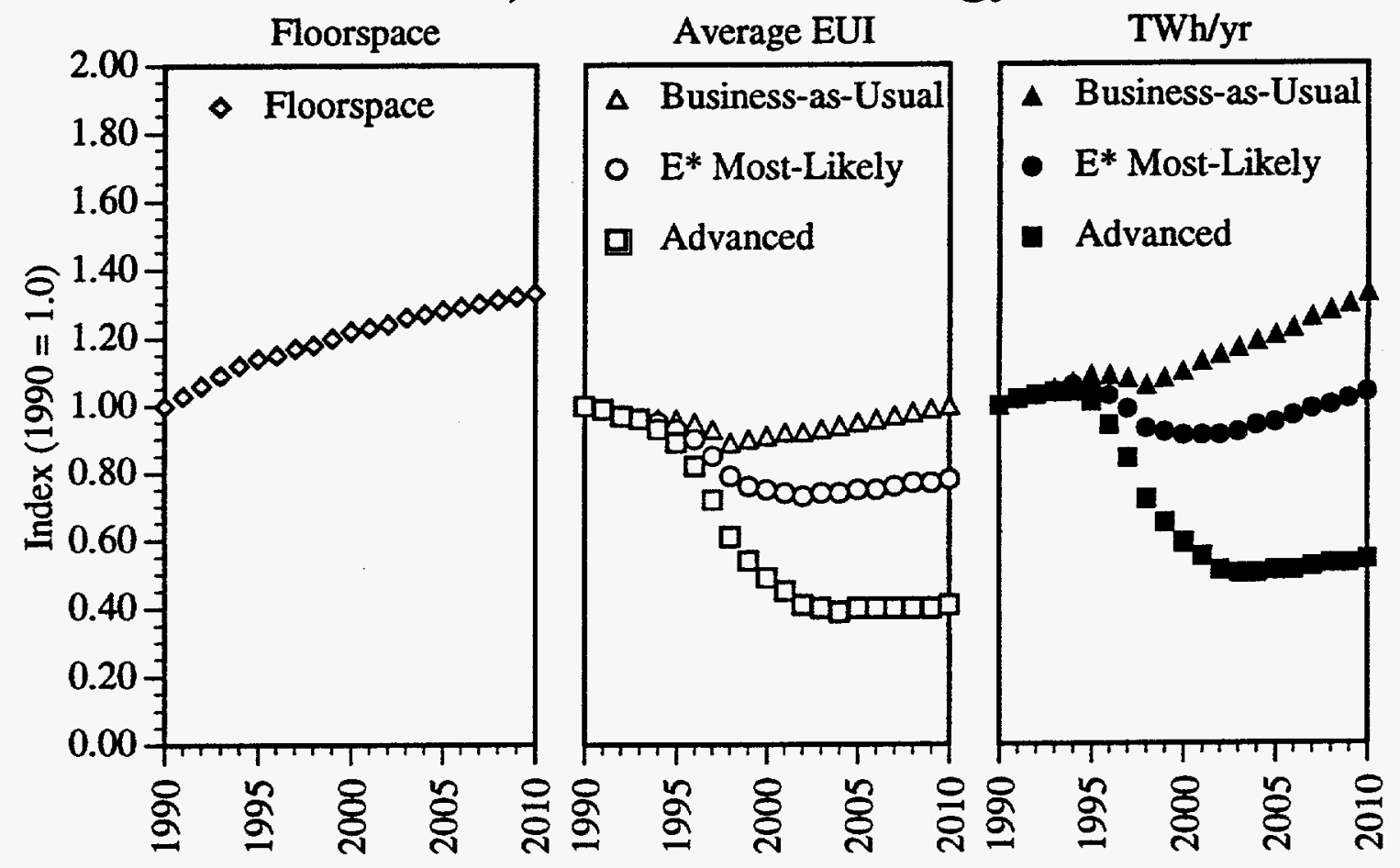

Figure C-7b: Normalized Trends in Floorspace, EUI, and Annual Energy Use Without Mainframes or Mini-Computers

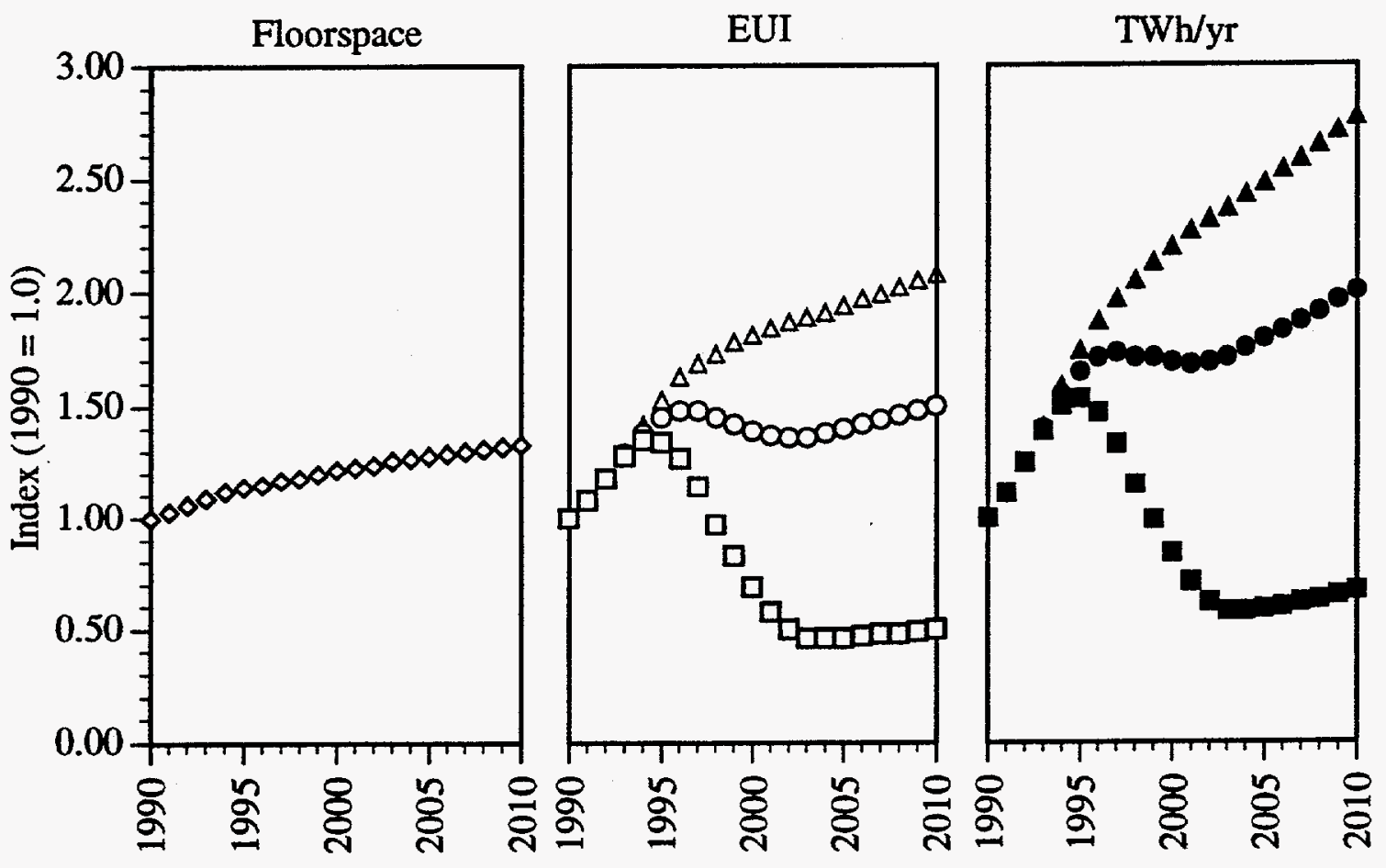

Average EUI equals TWh/yr divided by total floorspace. 


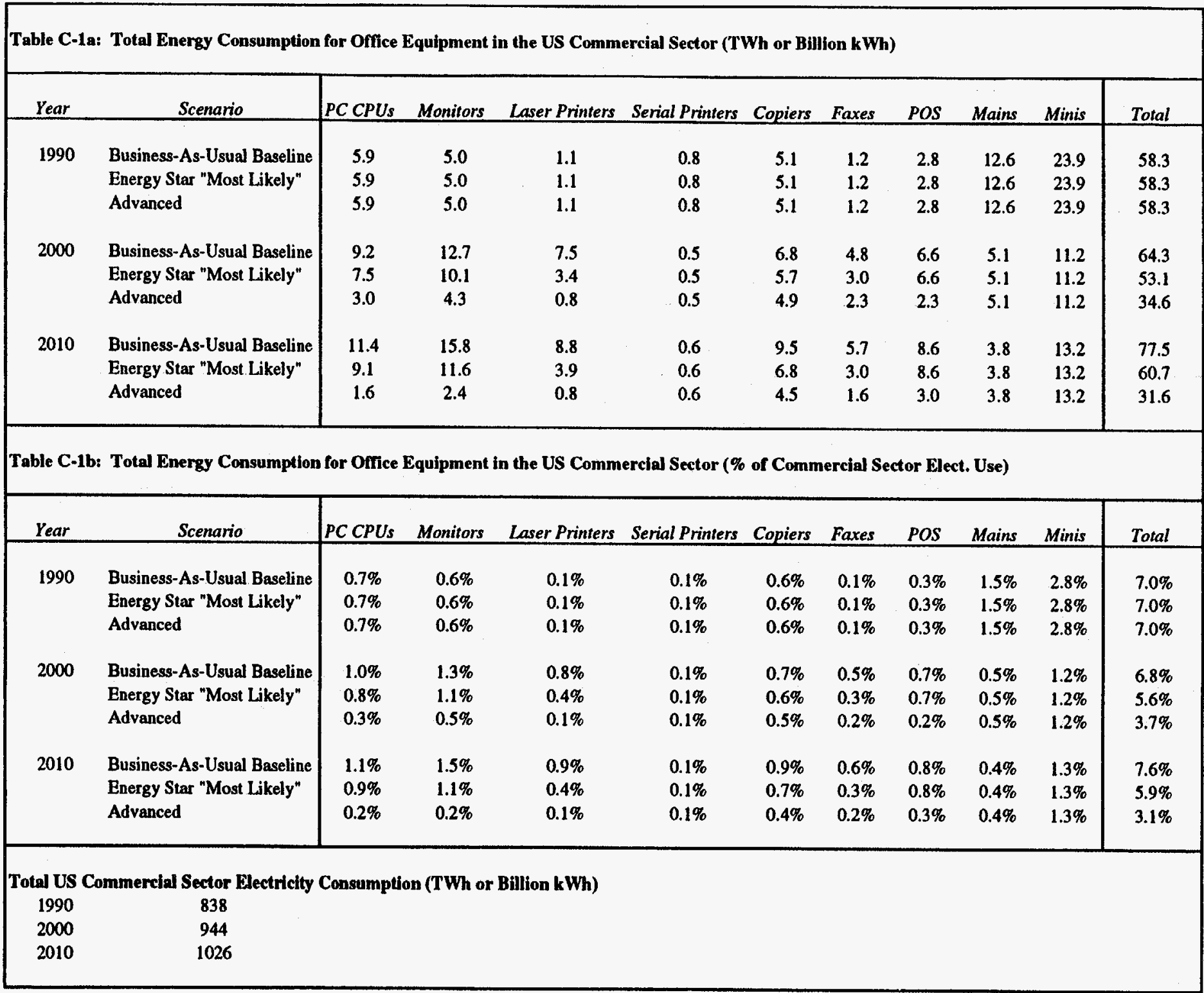

(1) Source of office equipment energy use: Jonathan Koomey and MaryAnn Piette, LBNL 510/486-5974.

(2) Source of total commercial electricity use: US Department of Energy, Annual Energy Outlook 1994 and 1995 


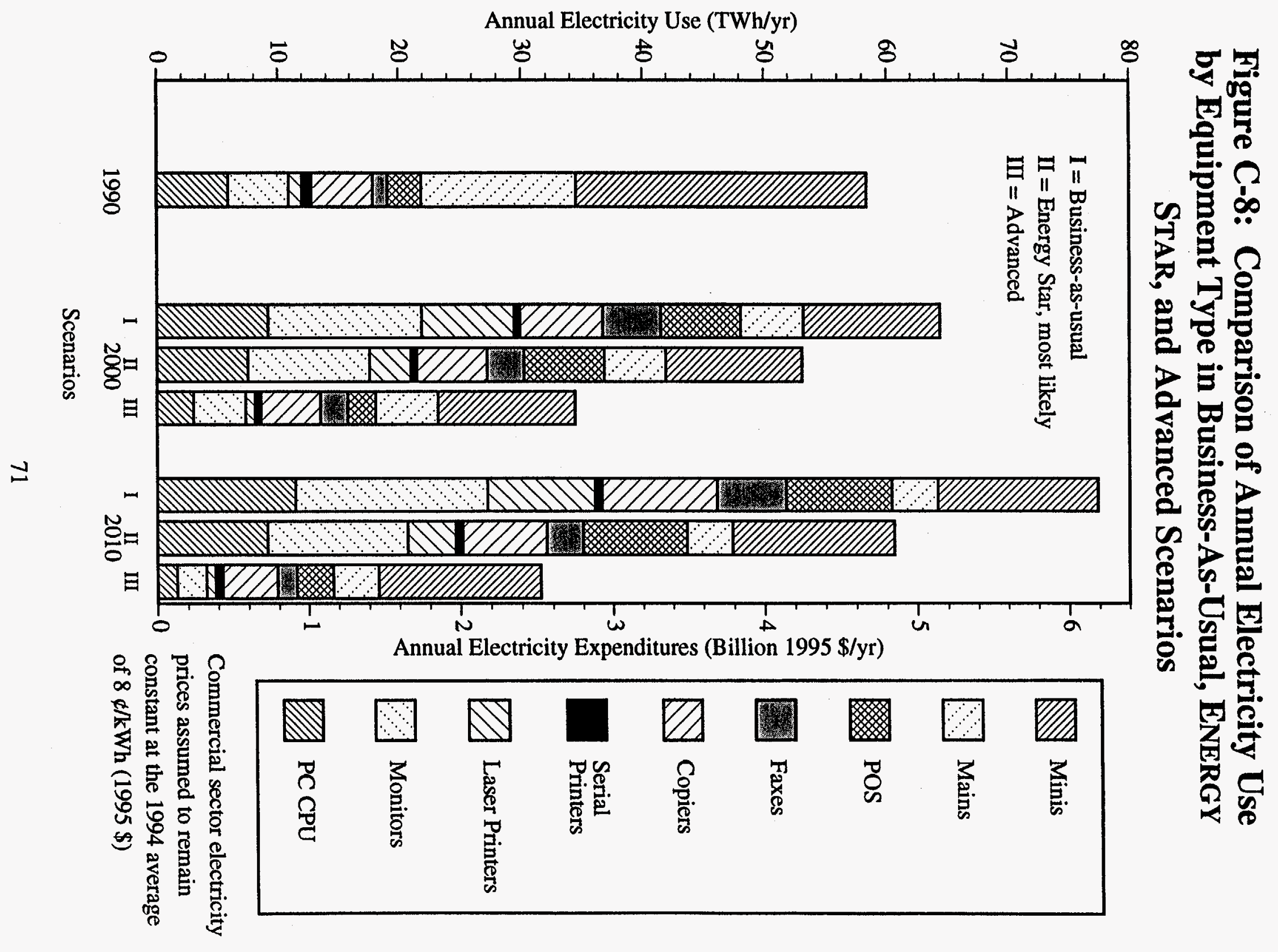




\section{Figure C-9: Percentage of Total Electricity Savings by Equipment Type in 2010}

ENERGY STAR Most Likely case compared to business-as-usual case

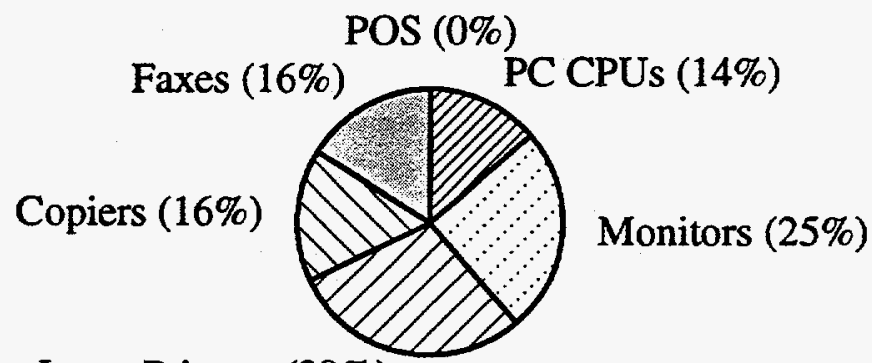

Laser Printers (29\%)

Total savings $=17 \mathrm{TWh}$

Advanced case compared to ENERGY STAR Most Likely case

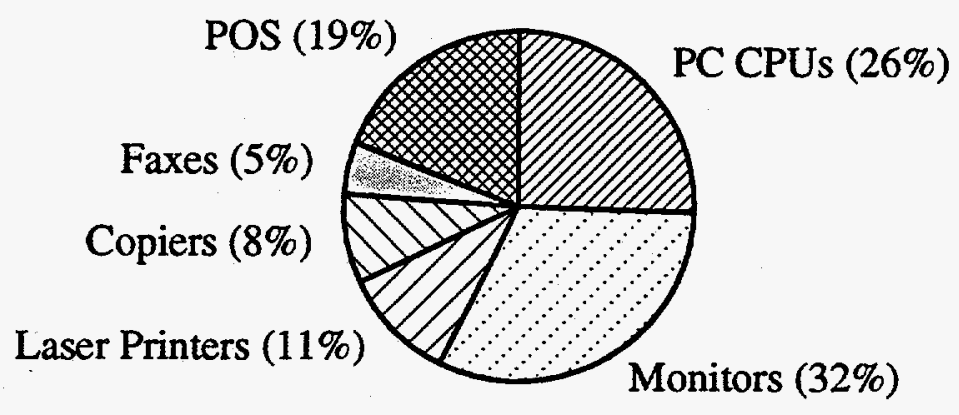

Total savings $=29 \mathrm{TWh}$ 

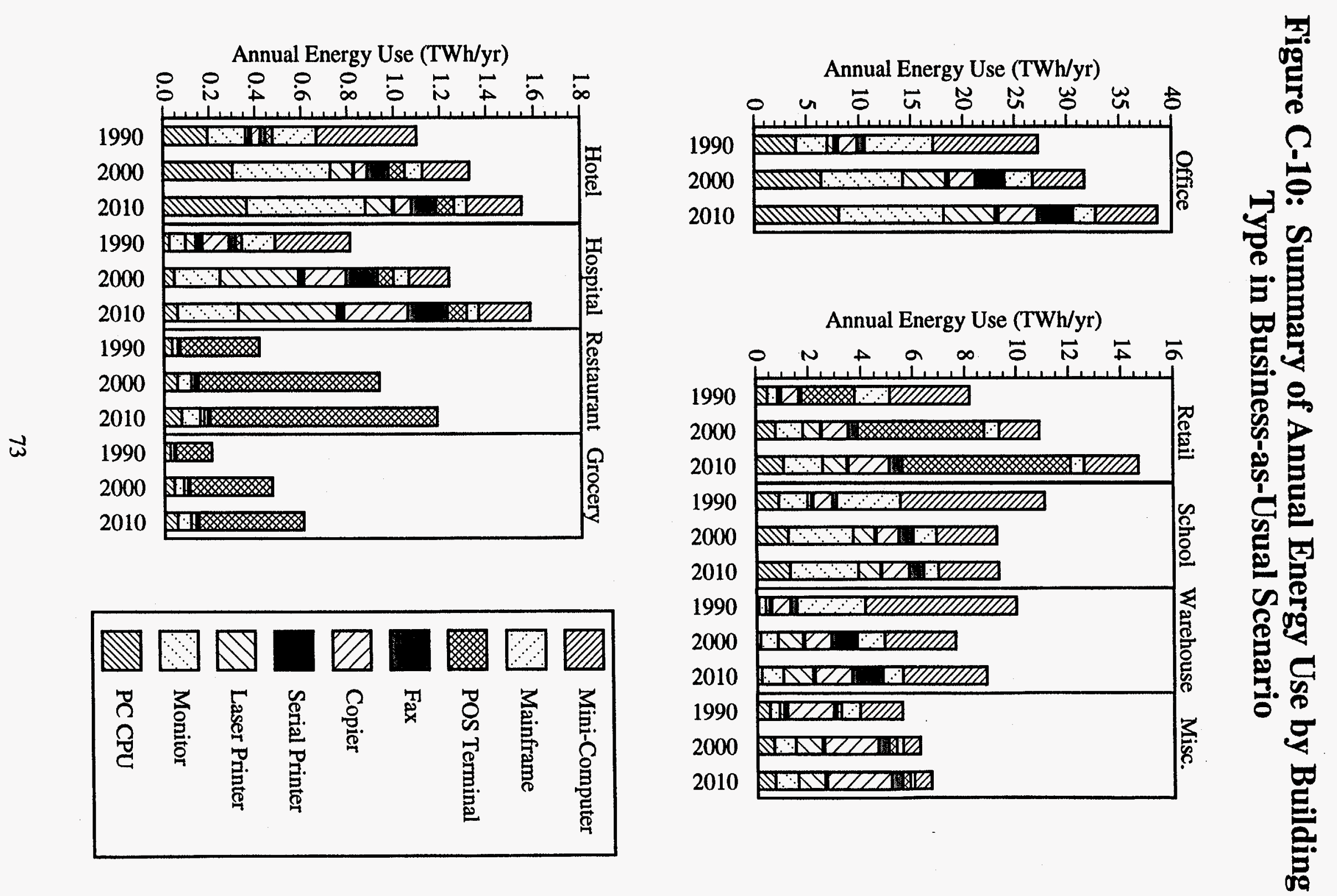


\section{Figure C-11: Summary of Annual Energy Use by Building Type in ENERgY STAR Most Likely Scenario}
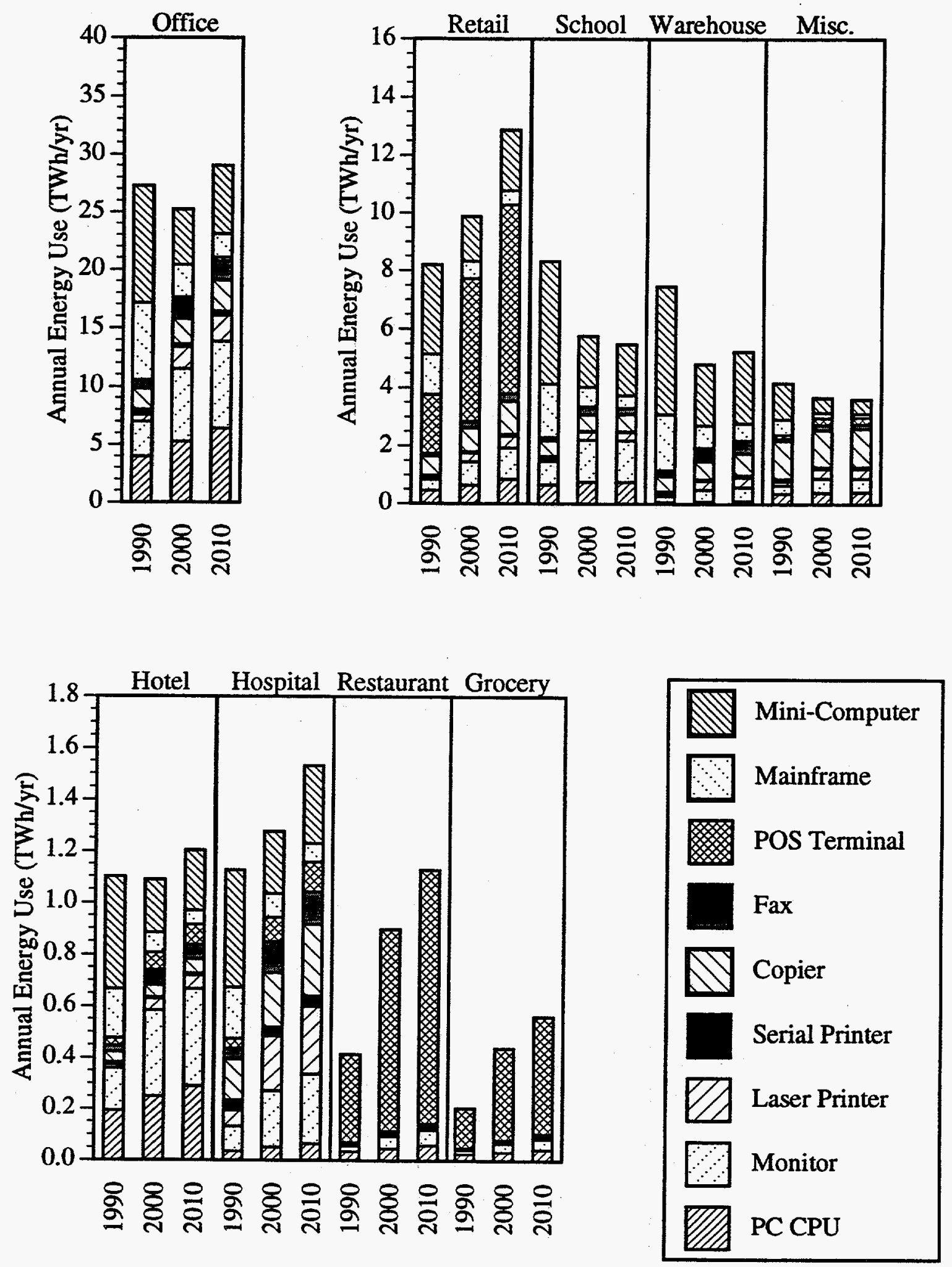